\title{
Workshop on Calorimetry for the Superconducting Super Collider
}

\author{
The University of Alabama \\ Tuscaloosa, Alabama, USA \\ March 13-17, 1989
}

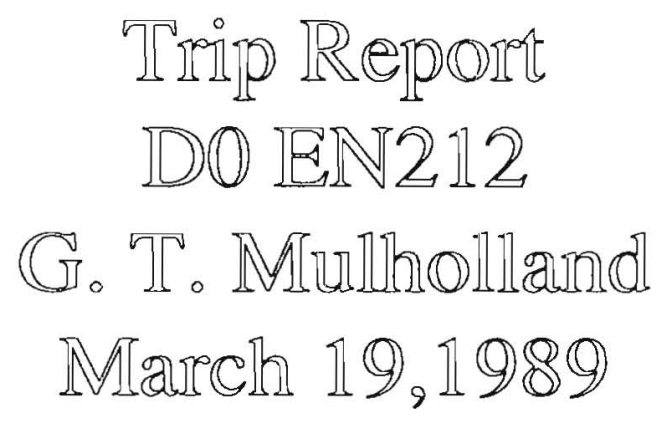




\section{Workshop on Calorimetry University of Alabama March 13-17,1989}

\section{Summary}

The international workshop brought together 170 participants to further develop the SSC design and performance specifications of the LAr, Gas, Scintillation, Silicon, and Warm Liquid calorimeter technologies, and to develop the general topics of Requirements, Simulation, and Electronics. Progress was made across a broad front in all areas; at the feasibility level for some and in the fine structure for others.

The meeting established areas of agreement, provided some general direction, and helped to quantify some differences at widely varying levels of detector technology development. The workshop helped to level the different understandings of the participants; increased the depth of the generalists and the breadth of the specialists. A high degree of group partitioning limited access to the detailed discussion within some detector groups. The communication was clearly necessary and rewarding, and seemed to meet or exceed the expectations of most participants.

This the report will deal with: the Liquid Argon detector and, to a lesser extent, the Requirements working groups, an update on uranium material logistics, and a view of LAr calorimetry by others. 


\section{General}

The workshop brought together those interested in contributing to the design of SSC calorimeters from among five detector technologies: Liquid Argon, Gas, Scintillation, Silicon, and Warm Liquids. The updated agenda is attached. The 170 conference participants, see list attached, divided themselves into these five major groups, and in some cases were further subdivided, after the plenary talks of Monday. The working groups and subgroups met in the mornings of Tuesday, Wednesday, and Thursday, and regrouped in the afternoons for the more general detector considerations: Requirements, Simulation, Electronics, and the added Test Beams subject. Plenary Summary talks were presented all day Friday according to the attached agenda. The workshop summary of Gilchriese is attached.

The opening plenary talks of, especially, Gilchriese, Radeka, and Groom set the stage for the general and LAr discussions to follow. Gilchriese introduced seven requirements against which he suggests the proposed detectors be measured: Survival, Depth, Granularity (segmentation) in rapidity and phi, Energy resolution, speed and hermeticity ( copies attached). Radeka made an especially clear and organized presentation to set the electronics requirement (copies attached), and Groom set the radiation damage parameters that would challenge the survival of one or more aspects of all the detector proposals (copies attached).

Special invited talks pertaining to calorimeter plate material options were given during the week by Dennis Floyd, President of Manufacturing Sciences Corporation, on the fabrication of Uranium plate for detectors from alloy and unalloyed source billets, and by Earle Fowler, Chief, Fac. Op. Div. HEP, DOE Washington, on the availability and cost of the uranium materials to supply the billet fabrication, and the availability of the equipment to do the actual billet fabrication. Earle Fowler was accompanied by Chuck Bieber of Y12, ORNL, and Phil McGee, DOE Washington.

\section{Liquid Argon Workshop Group}

The Liquid Argon group plenary session opened with a general summary of the Boulder meeting by Howard Gordon and the introduction of a LAr calorimeter design geometry by the H. Gordon, M. Marx, Martin Marietta effort (the Martin Marietta group, MMG) presented by Nick DiGiacomo (MM). The LAr group was then divided into four subgroups; 


\section{Liquid Argon Workshop Group (cont'd)}

I. Structural, Mechanical, and Cryogenic design

II. Hermeticity considerations

III. Electronics considerations

IV. Details (Nitty-gritty group)

The Howard Gordon summary of the Boulder Workshop is adequately described in D0 EN202. The LAr calorimeter design geometry of the MMG is shown in the appendix as the "Stayed Head Argon Vessel. As proposed by the MMG, the calorimeter has the following characteristics,

$\begin{array}{ll}\text { CC Module Parameter } & \underline{\text { Value }} \\ \text { Average module density } & 7.5 \mathrm{~g} / \mathrm{cm}^{* * 2} \\ \text { Central Cal. Inner radii } & 1.7 \mathrm{~m}, 2.81 \mathrm{~m} \\ \text { Central Cal. Outer radii } & 2.66 \mathrm{~m}, 3.71 \mathrm{~m} \\ \text { Central Cal. length } & 10 \mathrm{~m} \\ \text { FH/CH wiring gap } & 15 \mathrm{~cm} \\ \text { CH/OD wiring wall gap } & 15 \mathrm{~cm} \\ \text { Est. Wt. } & 2691 \text { Tons } \\ \text { Calorimeter packing fraction } & 86 \% \\ & \\ \text { CC Cryostat Parameter } & \text { Value } \\ \text { Material } & \text { Al } \\ \text { VT Inner wall t } & 2.54 \mathrm{~cm} \\ \text { LAr inner wall t } & 3.5 \mathrm{~cm} \\ \text { VT End wall t } & 7.62 \\ \text { LAr End wall t } & 5.08 \mathrm{~cm} \\ \text { LAr outer wall t } & 10.16 \mathrm{~cm} \\ \text { Inner disc t } & 5.0 \mathrm{~cm}(?) \\ \text { Stay reinforcing cyl. t } & 2.54 \mathrm{~cm} \\ \text { Cryostat wt. } & 141 \text { tons } \\ \text { Argon volume } & 41,056 \text { gls. } \\ \text { Wt. Argon } & 239 \text { tons }\end{array}$

\section{End Cap}

The nose design of the End cap by the MMG was studied by Forden, Strovink, and Wombersley. They showed energy loss was significantly reduced by removing the walls introduced by the nose. 
SSC Calorimeter Workshop, University of Alabama

\section{End Cap (cont'd)}

$\begin{array}{ll}\text { EC Module Parameter } & \underline{\text { Value }} \\ \text { Average module density } & 7.5 \mathrm{~g} / \mathrm{cm}^{* * 2} \\ \text { Central Cal. Inner radii } & 5 \text { degrees } \\ \text { Central Cal. Outer radii } & 2.9 \mathrm{~m} \\ \text { Central Cal. length } & 2.2 \mathrm{~m} \\ \text { Est. Wt. } & 500 \text { Tons } \\ & \\ \text { EC Cryostat Parameter } & \text { Value } \\ \text { Material } & \text { Al } \\ \text { VT Inner wall t } & 0.79 \mathrm{~cm} \\ \text { LAr inner wall t } & 1.9 \mathrm{~cm} \\ \text { VT End wall t } & 6.35 \mathrm{~m} \\ \text { LAr End wall t } & 7.62 \mathrm{~m} \\ \text { LAr outer wall t } & \text { not sized } \\ \text { Stay reinforcing cyl. t } & \text { not sized } \\ \text { Cryostat wt. } & \text { not sized } \\ \text { Argon volume } & 7,970 \text { gls. } \\ \text { Wt. Argon } & 46.5 \text { tons }\end{array}$

Although the MMG IDEA's work that provided the 3D color views of the the proposed cryostat were impressive, we are all developing an immunity to the appreciation of, even, state-of-the-art computer generated graphics. More impressive was the optimization program "Design Aid", an option in the IDEA's library. (Mark Lienninger has agreed to get a copy for "evaluation" for Fermilab people interested to learn more.) Design Aid allows general design optimization, e.g. for minimum material thickness for a given maximum stress. More importantly, it allows searches for solutions that minimize one wall thickness at the expense of all others. The latter is directly applicable to fast and efficient iteration of early design options.

\section{Cryogenics}

All dewars are to be provided complete (i. e. carrying all the necessary operating equipment: valves, operators, and LAr condenser) are to be located -82 meter below ground level. It was suggested the filling liquid head concerns ( $L N 2=87.5 \mathrm{psi}, \mathrm{LAr}=150 \mathrm{psi}$ ) be addressed in failsafe hardware, not by dewar pressure rating increase (the cost of $250 \mathrm{psi}$ is $\$ 250,000$ more). Filling was assumed to be periodic by truck in all cases. 
SSC Calorimeter Workshop, University of Alabama

Later review should consider supplying the LN2 load from an accelerator continuous source, or a dedicated LAr calorimeter refrigerator (see loads). It was proposed that uploading of the LAr or LN2 to the surface, as may be necessary, be done with a pump (LP dewars preclude pressure transfer).

4ea. 20,000 gal,65 psi, vertical*, LAr dewars@ @ $\$ 100,000$ each

1ea. 20,000 gal, 65 psi, vertical*, LN2 dewar @ \$100,000 each

*Horizontals available, checking vertical for dia. by height. Verticals may be precluded for a number of reasons: liquid head (or change) provided for a given cryostat, facility height, or tank support difficulties.

A "Venting knock-out drum" (aka: "LN2/LAr boiler") was recommended for saturated vapor venting with out regard for serious liquid carryover and attendant vent line back pressures. The insulated, low mass (or cooled) drum is vented to the surface by a suitable line and might include heaters or other vaporizers to deal with large accumulations. Until a knockout drum can be sized, it should be taken as a 20,000 gls. dewar (another $\$ 100,000)$ for planning purposes.

Similar concerns lead to a recommendation to manifold all the large reliefs together. They can be manifolded to a vent or to the "knockout drum" if relief performance isn't affected by any back pressure that may be generated. In any case a suitable line(s) to the surface must be provided.

\section{Capacities,}
L Argon dewars*
$4(20,000) \mathrm{gls}$
Central Cryostat
$41,000 \mathrm{gls}$
L Nitrogen dewar*
$20,000 \mathrm{gls}$.
End Cap A
$7,970 \mathrm{gls}$
End Cap A
$7,970 \mathrm{gls}$

*The division of the total storage requirement to more standard capacity units has a number of advantages: lower unit cost, ease of transportation, delivery and installation, individual operation (fill, empty, purify, etc.), and simple redundancy. Each LAr dewar could be equipped with about $60 \mathrm{~kW}$ LN2 condensing coil. The unit static load is $400 \mathrm{~W}$.

\section{General Cryogenic Considerations}

Bob Watt had done a lot of consulting for the MMG in terms of general layout, see attached "Calorimeter System Block Diagram, 2/17.89" and "Plant2". He made a presentation proposing that the SLD cooling loop design: aluminum tube array welded to the aluminum shell, modified from 


\section{General Cryogenic Considerations (cont'd)}

two fold, vertical, symmetry to a four fold, quadrant, symmetry, be adopted for SSC LAr calorimeter. He explained the need to modulate the valves open and closed in quick succession for the cooldown operation, the coolant overflow requirement of this proposal during normal operation, and the bottom feed, in terms of the SLD design and Mark II experience.

The cooling loop design was scaled from the operating experience of a much smaller application, accepting the design aspects with little change. No alternates were provided for comparison, and it is not clear that the problem was rethought in a general way. The move to provide upper and lower quadrants is in the right direction to provide the operational cooling at the top, but is that location optimal? Feeding a "top" loop may remove the overflow requirement. Dynamic radiation shields may be able to replace much of the function of the shell loops, allowing the cooldown refrigeration to be more loosely coupled to the shell. I am concerned that the proposed coupling of liquid cooling is so close that external "rate of cooldown" limiting equipment may be required.

Although I missed the discussion, Mike Marx said the consensus of the group favors a flooded cryostat, i.e. one with a "head" tank. The liquid head provided on the fluid in the cryostat helps to suppresses bubble formation. Pressure control and liquid subcooling must be sensed and provided separately unless the volumes are connected by a very large cross section, or more than one connection. You could ask, if subcooling must measured and provided in any case, why is the head required? The head tank seems to make relief more difficult and must, I think, vent liquid through the connection provided.

Bob Watt provided a concept drawing for the counterflow gas cooling of the horizontal signal leads. The idea is to depress the temperature gradient of the leads over the last few $\mathrm{cm}$. to reduce the heat reaching the liquid directly, just as in $\mathrm{He}$ gas cooled power leads. If $\mathrm{Ar}$ or $\mathrm{N} 2$ is the gas a means for recirculation and a cold end seal is proposed to separate the lead flows from the detector fluid. Concern was expressed for the usual power lead problem of depressed entry end temperatures and the consequent condensation. This approach will constrain the possible lead feedthrough designs to those with many small longitudinal passages, large exchange surface areas, and cold end seal compatibility. I wouldn't put all my eggs in that basket just yet. 


\section{Cryogenic Heat Loads (workshop estimates)}

The Electronics group concluded the preamps should be located very close to the modules for signal/noise reasons. The conclusion is a Central calorimeter load of $16 \mathrm{~kW}$ and a total EC calorimeter load 1.57 times that value. The cryogenic design group agreed to attempt to size a set (one per module) of thermal siphons to remove this very local heat load.

Central Leads $\quad 1.0 \mathrm{~kW}^{1}$

Radiation $1.6 \mathrm{~kW}$

Supports $3.6 \mathrm{~kW}^{1}$

Electronics

Totals $\underline{16.0 \mathrm{~kW}}$

$6.2 \mathrm{~kW}^{1} \overline{16.0 \mathrm{KW}} \quad 22.2 \mathrm{~kW}^{1}$

End Caps

Leads $\quad 1.57 \mathrm{~kW}^{1}$

Radiation $0.52 \mathrm{~kW}$

Supports $3.6 \mathrm{~kW}^{1}$

Electronics

Totals

$\frac{25.0 \mathrm{~kW}}{25.0 \mathrm{~kW}} \quad \overline{30.7 \mathrm{~kW}^{1}}$

Grand Total

$52.9 \mathrm{~kW}^{2}$

1 May be reduced by gas intercept, low thermal conduction material, or other design means.

2 Does not include the LAr dewar loads. 


\section{$\underline{\text { Uranium }}$}

I missed the formal talk by Dennis Floyd, but did hear Earle Fowler's talk and spoke to Chuck Bieber privately. I learned that the EPA has allocated money to clean up the uranium scrap situation. Some of that money is being spent to turn depleted $U$ into $U O$. The cost $(\$ 2 / \mathrm{kg})$ to turn $U$ into $U O$ is about the same as that to turn $U$ into billets for rolling plate. The advantage to keeping the $U$ in metal form is its availability, the oxide can't be economically reclaimed as metal. All the scrap that might be used by the HEP program could be put in the form of billets at no additional cost to the EPA. It is important to the HEP community that the EPA stop oxidizing and start casting billets of known chemistry, if $U$ is to be the absorber of popular choice. The only cost to HEP would be the warehousing of the materials.

There are alternate sources of material; depleted $U$ with controlled chemistry on the open market is factors more expensive than the government scrap billets, and the cost of U metal reclamation from the huge UF6 gaseous diffusion plant inventory is $\$ 16 / \mathrm{kg}$.

Current production (output of one, dual, casting station) is 2 (1800\#)billets/day, or about 423 tons/year. The proposed LAr calorimeter FH and $\mathrm{CH}$ requirement at $50 \%$ yield (by weight) is the full billet production for 3.1 years.

There is a real concern that the scrap that might be needed by the SSC and other detectors be harvested now, or at least very soon, or the supply of material, and not the casting and plate fabrication throughput, will limit the rate at which finished plate can be made available for SSC prototype and production efforts. Their is experience that the full sequence of events has an enormous lead time if it is to done conservatively, i.e. prototypes fully debugged before production quantities, high levels of intermediate quality control, the quick turn-around remanufacture of rejected materials, and etc..

\section{Other Views}

The general interest in LAr calorimeters was in the area of Hermeticity. The area between the cryostats is thought to be the Achilles' heal of the LAr approach. The notion was dispelled at some level by the proponent attention it received, the MMG strawman design, the demonstrated efforts that showed a clear method to measure the effect (Forden, et. al.), and the plans to study instrumenting the troubled areas (Strovink). 
SSC Calorimeter Workshop, University of Alabama

\section{Other Views $($ cont'd)}

Wigman took careful aim at the interaction per unit length of the current $U$ plate calorimeters and challenged the $U$ plate people (Why Uranium?) to beat his proposed $80 \%$ packing fraction $\mathrm{Pb} / \mathrm{Scintillator}$ design. I have attached Wigman's transparency copies so you may draw your own conclusion. It is interesting to note there was no immediate rebuttal.

\section{Closing Remarks}

I have attached the closing remarks of Gilchriese.

This reoprt is derived entirely from my notes and may contain minor errors. If you come upon an error I would appreciate your bringing it to my attention (FNAL::MULHOLLAND). I will address a copy to all of the working group members, as follows,

Liquid Argon Calorimeter Design Working Group

D. Be'de're'de

CEN Saclay

W. Cooper

Fermilab

P. Kroon

BNL (D0)

F. Lobkowicz

U. Rochester (Fermilab E706)

L. Mason Martin Marietta

G. T. Mulholland

Fermilab (D0)

J. Pohlen

Martin Marietta

R. Schindler

SLAC (SLD)

E. A. Scholle

U. Pittsburg

Y Watanabe

Tokyo Inst. of Technology

R. Watt SSCCDG

W. Guryn

$\mathrm{BNL}$ (D0) 


\title{
AGENDA \\ FOI the \\ WORKSHOE ON CALORIMETRY FOR THE \\ SUPERCONDUCTING SUPER COLIIDER
}

\begin{abstract}
March 12 (Sunday)
7:00 - 9:00 Reception at the Sheraton Capstone Inn
\end{abstract}

March 13 (Monday)

8:00 - 9:00 Registration at the Conference Center

9:00 - 9:15 Welcome by Dr. Douglas Jones, Acting Vice President for Academic Affairs

9:15 - 9:30 SAHEP-the Southern Association for High Energy Physics J. Gumnick (ORAU)

9:30 - 10:00 Preliminary Report of the Requirements Working GroupM. Gilchriese (SSC)

10:00 - 10:35 Electronics Considerations for SSC Calorimetry-

V. Radeka (BNL)

$10: 35-11: 05$ Break

11:05 - 11:40 Triggering and Data Acquisition for SSC CalorimetryA. Lankford (SLAC)

$13 \cdot 40$ - 12:10 Radiation Levels in SSC Calorimetry-D. Groom (SSC)

$1: 0-2: 00$ Lunch

2:00 - 2:40 Performance Predictions and Simulation for Ssc CalorimetryT. Gabriel (ORNL)

2:40 - 3:40 Plans for working groups. Each group will have 5 minutes maximum to have one member get up and explain their plans. 3:40 - 4:15 Break

4:15 - 6:00 Working group parallel sessions for the five calorimeter typesthat islscint., LA, warm liquid, gas and silicon. I would like each group to schedule talks for this time and would suggest that they might wish to start with a review talk to bring the working group members up to speed and then to discuss goals and plans. The working groups on requirements, electronics/DAQ and performance/simulation will not meet during this time.

7:00 P.M. Buffet Dinner at the Battle-Friedman Home

March 14 (Tuesday)

8:30 - 12:30 Parallel working groups on the five calorimeter types $12: 30$ - 2:00 Lunch

2:00 - 6:00 Parallel working groups on requirements, elecs/DAQ and simulation 8:00 P.M. Concert by the Cadek Trio at the Moody Music Building 
March 15 (Wednesday)

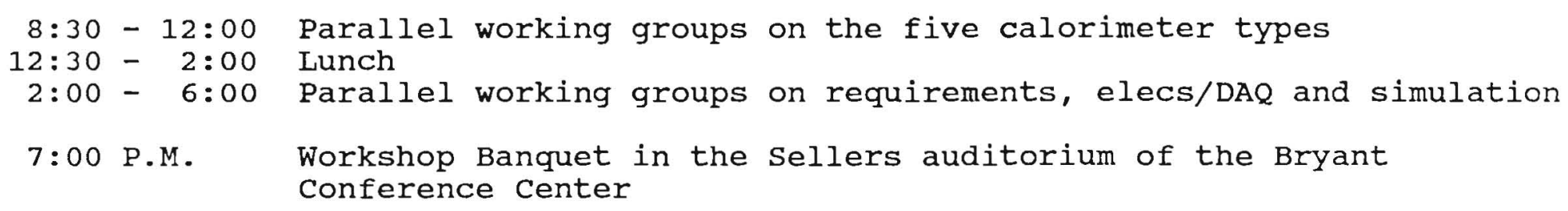




\section{Requirements for Calorimetry \\ at the \\ Superconducting Supercollider}

- This talk will be introduction to some requirements for large, $4 \pi$ experiments

- Survival

- Depth

- Granulartty in rapidity and phis

- Energy resolution

- Relative electron/hadron reaponse

- Speod

- Hormeticity

- Based on general physics considerations not detailed examination of new physics signatures and backgrounds

- Results so far are not definitive - more work needed - but you should get reasonable feeling for key issues.

- Travelogue - details in working group talks. 


\section{Survival}

- At design luminosity, significant radiation levels - see talk later today by Don Groom. Also see summary plot.

- Survival, including acceptable deterioration, is critical requirement - no compromise allowed.

Depth

- Possible criteria

- TeV jet energy measurements - containment. Specific physics benchmark is quark compositeness signature. See talk in working group by $\mathrm{D}$. Bintinger and plots.

- Punchthrough? Important but iron is cheaper than calorimetry. Punchthrough not important in setting depth. See talk by Bintinger

- Single particles? I don't think so. Seo plot.

- Uncertainties

- Cannot predict longltudinal hadronic shower profiles precisely. See Bintinger talk and plot.

- Answers

- In central rapidity region $|y| \leq 2,7-10$ lambda are required. See words on uncertainties.

- More at larger rapidity - slow change with jet energy. 
Also Neutrents?

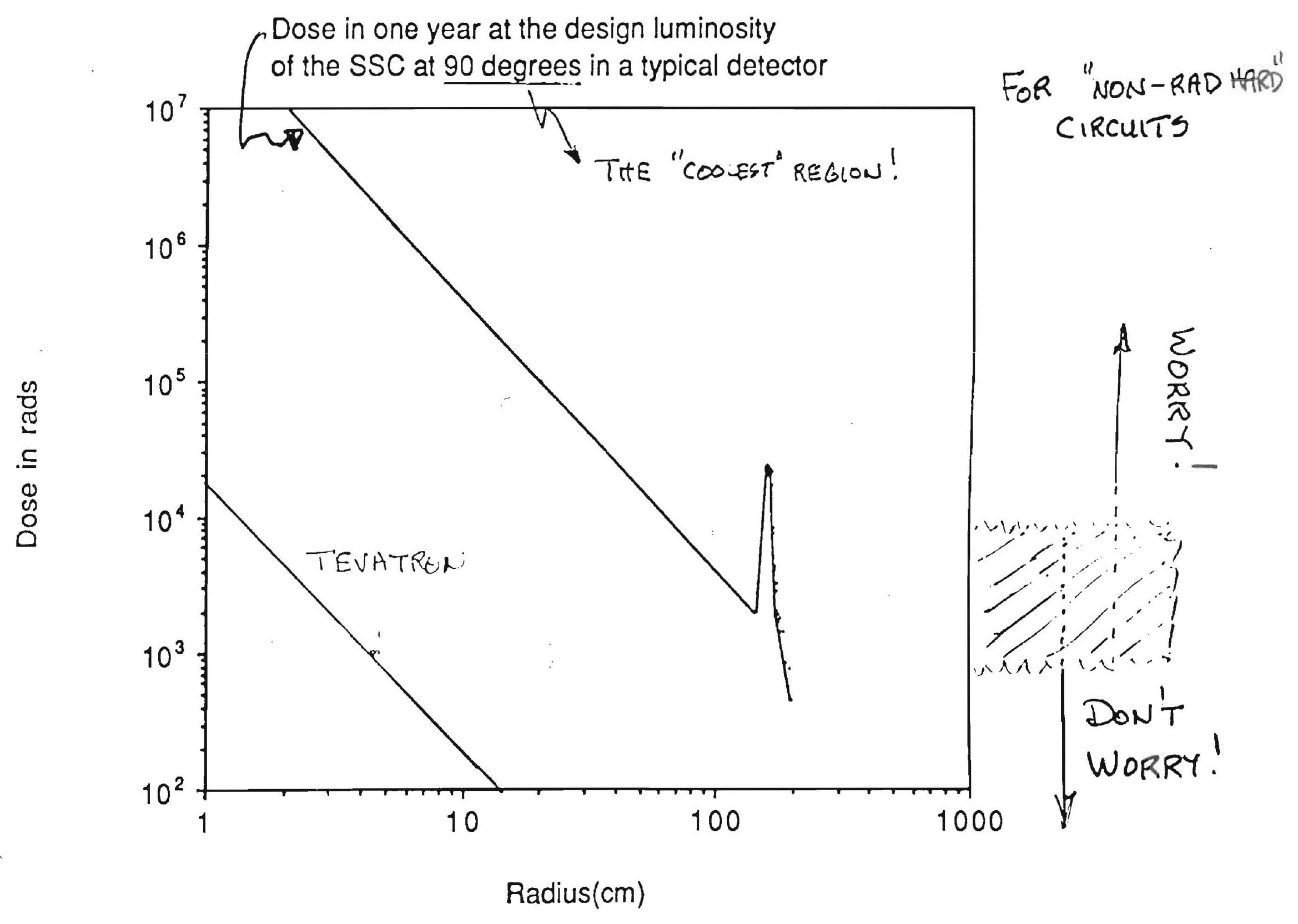


Compositeness Signal $\Lambda=15 \mathrm{TeV}$ const.

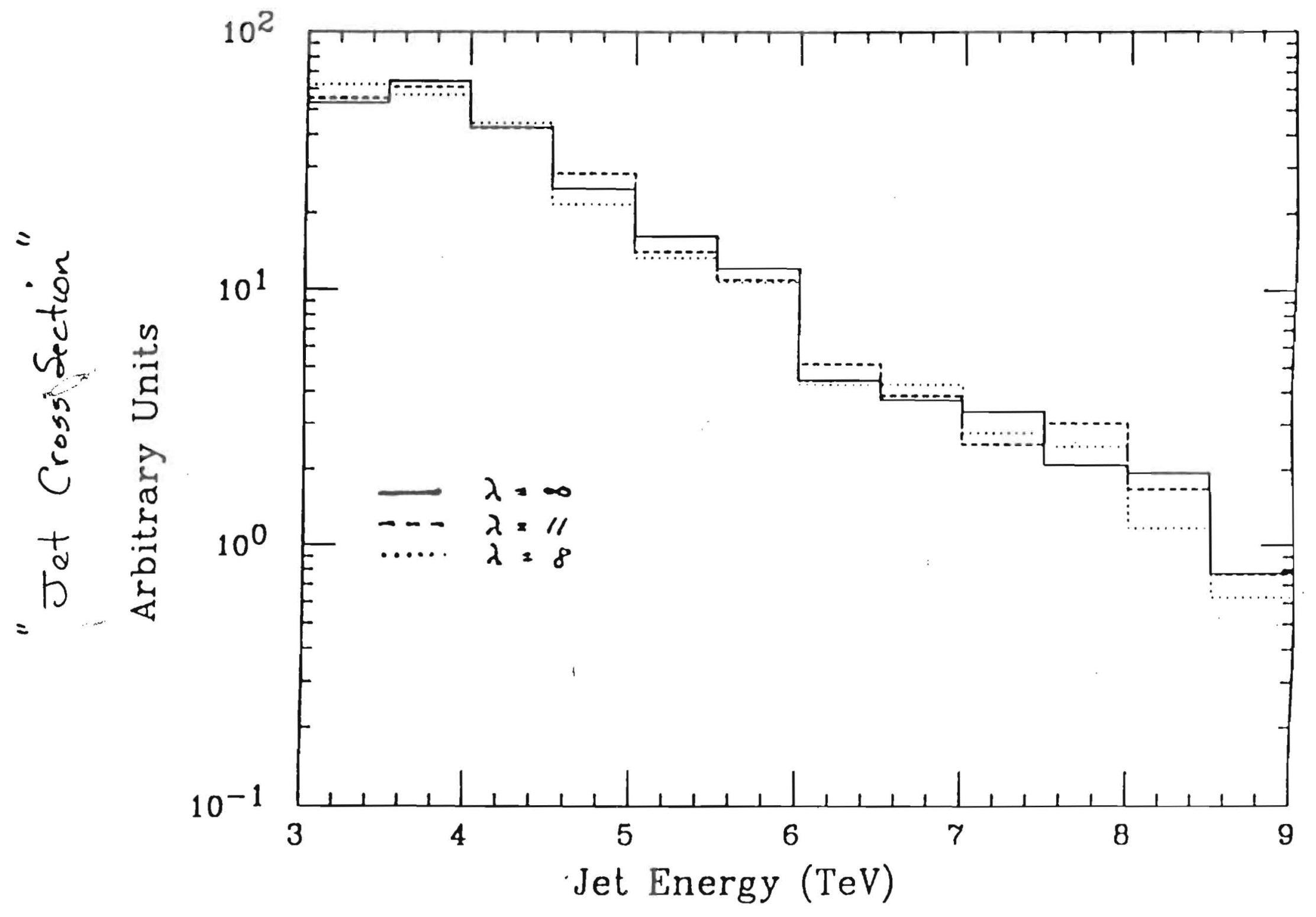


Energy vs Depth for 95\%/99\% Containment

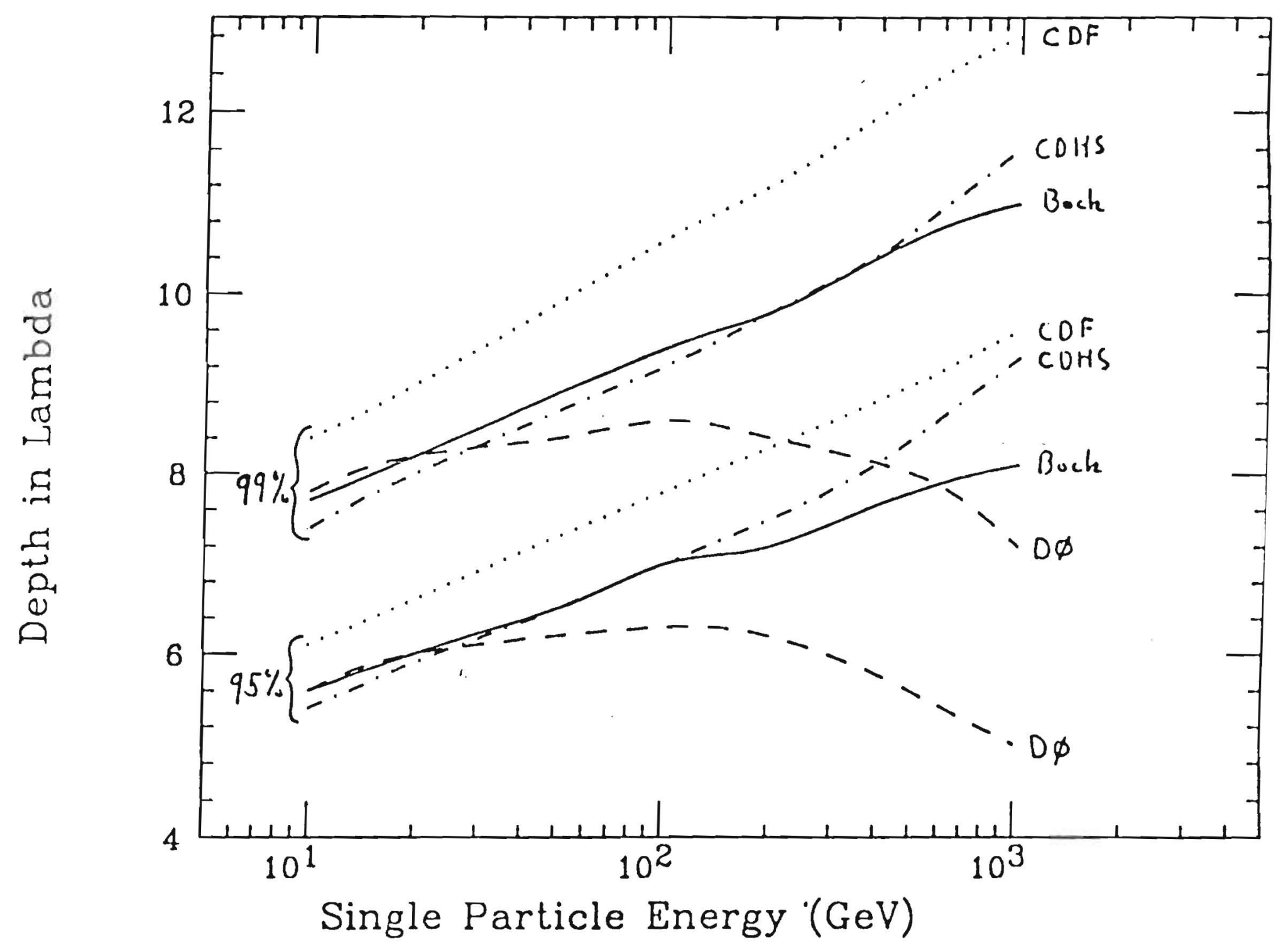


Shower Parameterization, Lead $50 \mathrm{GeV}$

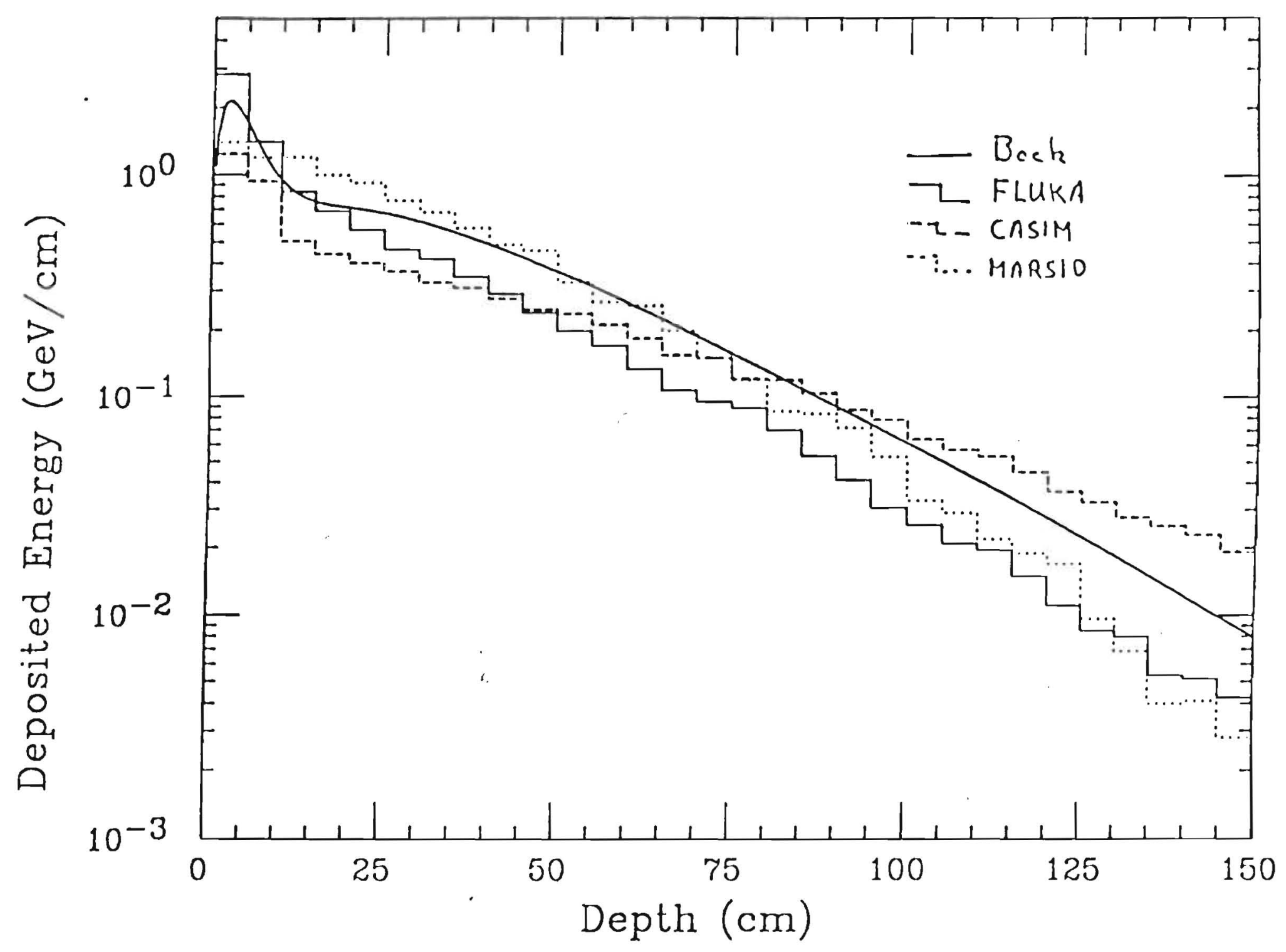




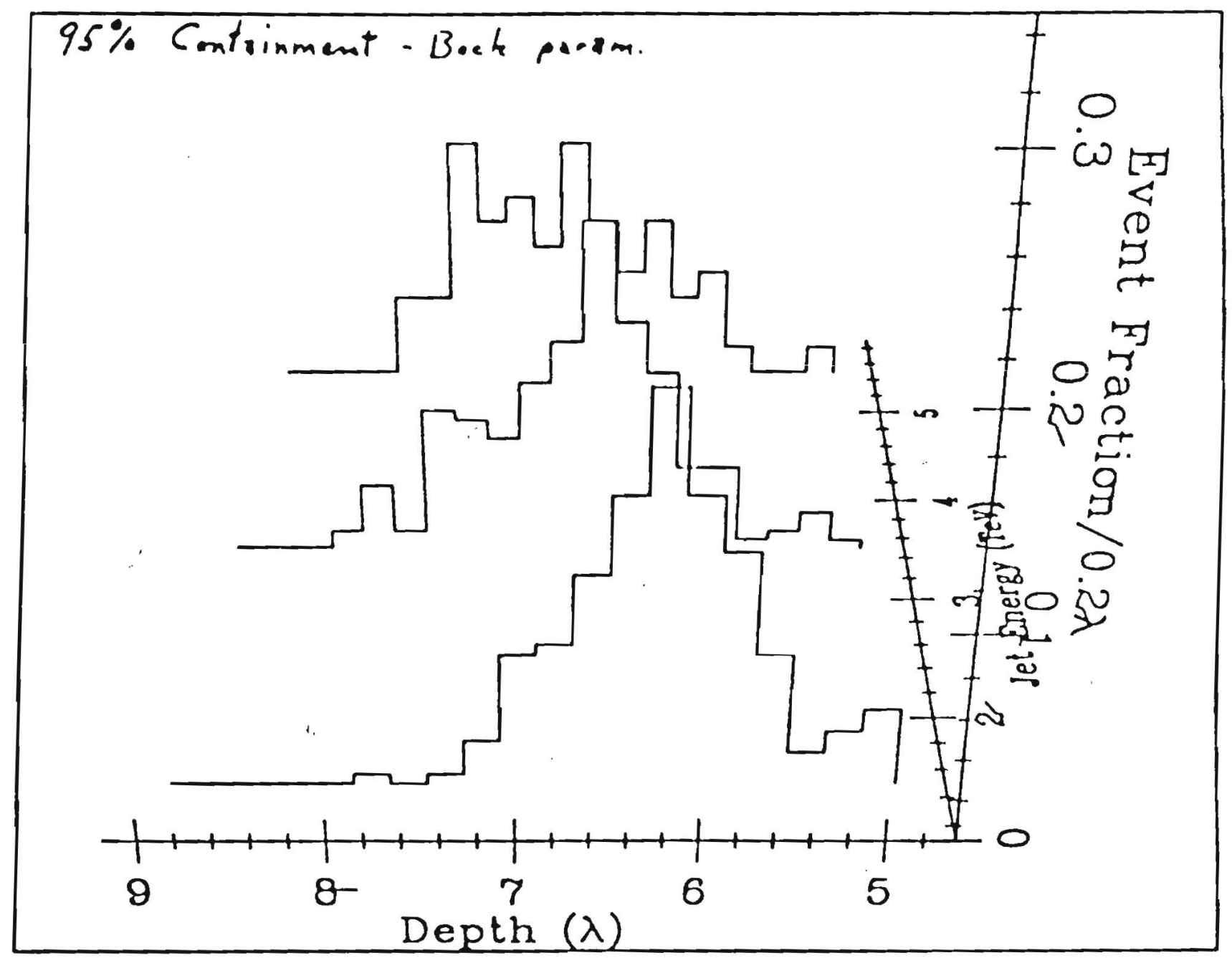




\section{Transverse Granularity}

- Possible criteria for granularity in $y$ and phi are

- Reconstruction of high PT W $>$ jets. See talk by E. Wang.

- Shower spreading is important

- Relevant varlables are granularity and (radius of calorimeter)/lambda

- See plots.

- Conclusions

- $B \lg R=$ "radius"/lambda is useful - big is beautiful

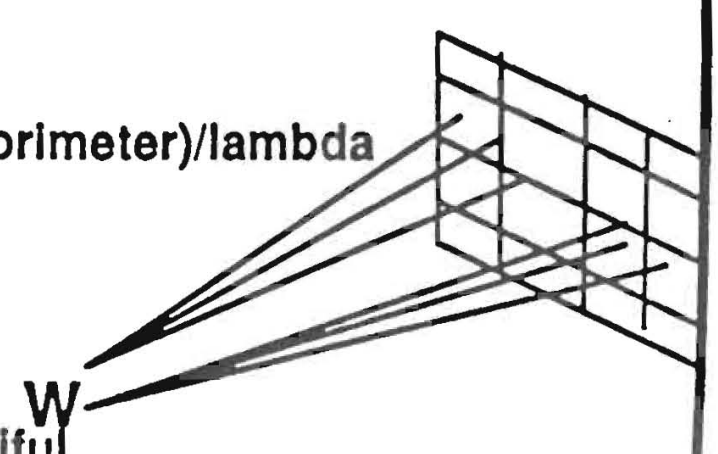

- For reasonable R, $0.05 \times 0.05$ is fine. Don't lose much in mass resolution for $0.1 \times 0.1$ in hadronic. 2 -jet separation?

- Electron identification

- This is complicated and do not have complete results. Can have some sampling with fine granularity. Isolation criteria important. See talk by E. Stern.

- $Z \rightarrow$ ee mass resolutlon $=>$ electromagnetic granularity but can get directions from tracking very precisely. No problem to separate energies for realistic PT of $Z$ and radius.

- Pileup - see speed section 
Figure 13 ideal detector (lb1118:[deg.wang]fig13.top) $5006 \mathrm{CW} P T$

4-vectors only

$W \rightarrow j e t-j e t$
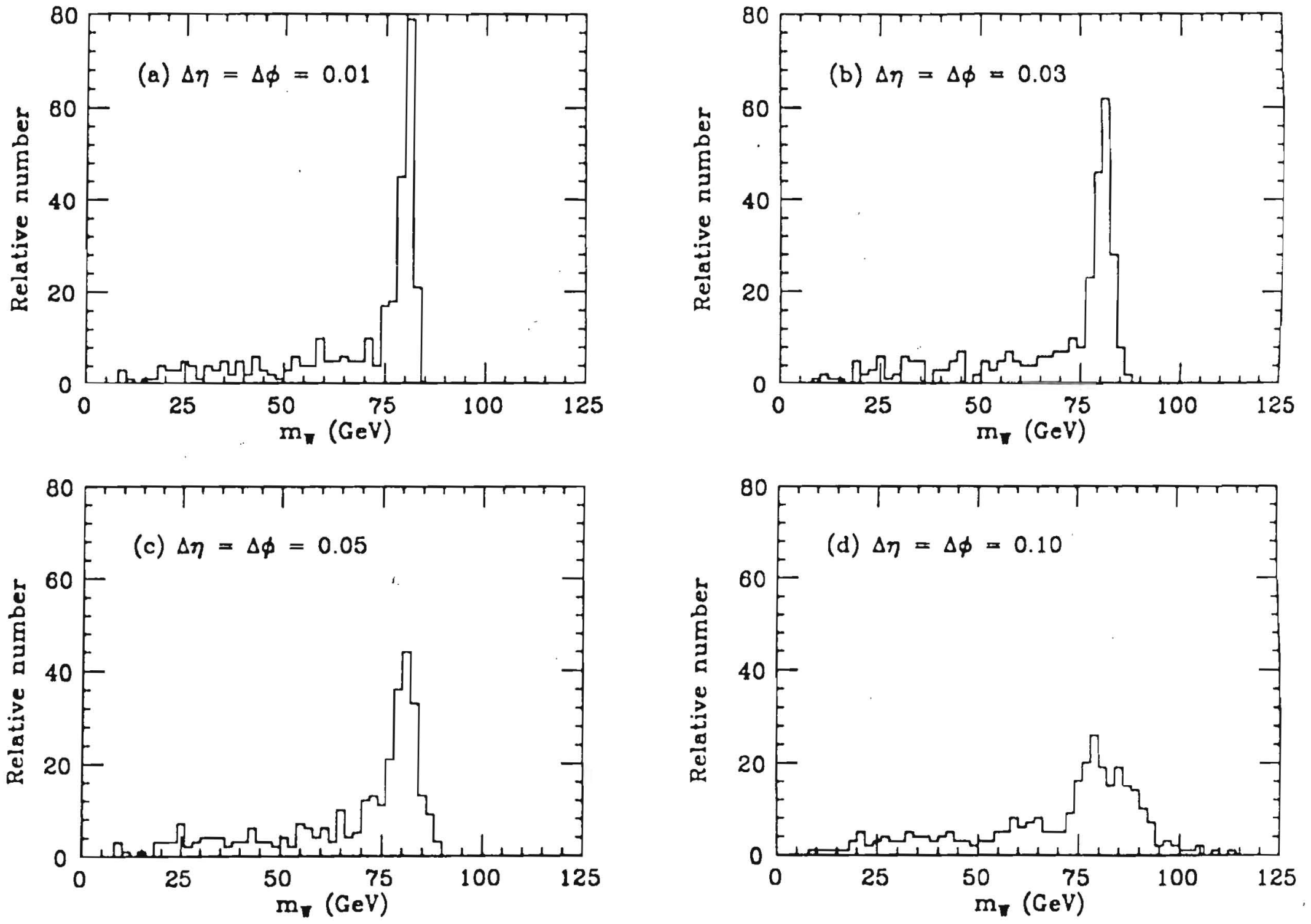

9 
500 GeV P $P_{T} W \rightarrow$ get -get

Figure 14 LSD no pileup (lbl118:[deg.wang]fig 14.top)

$$
\begin{aligned}
& R=1.6 \mathrm{~m} \\
& \lambda=22 \mathrm{~cm}
\end{aligned}
$$$$
\text { With shower spreading }
$$
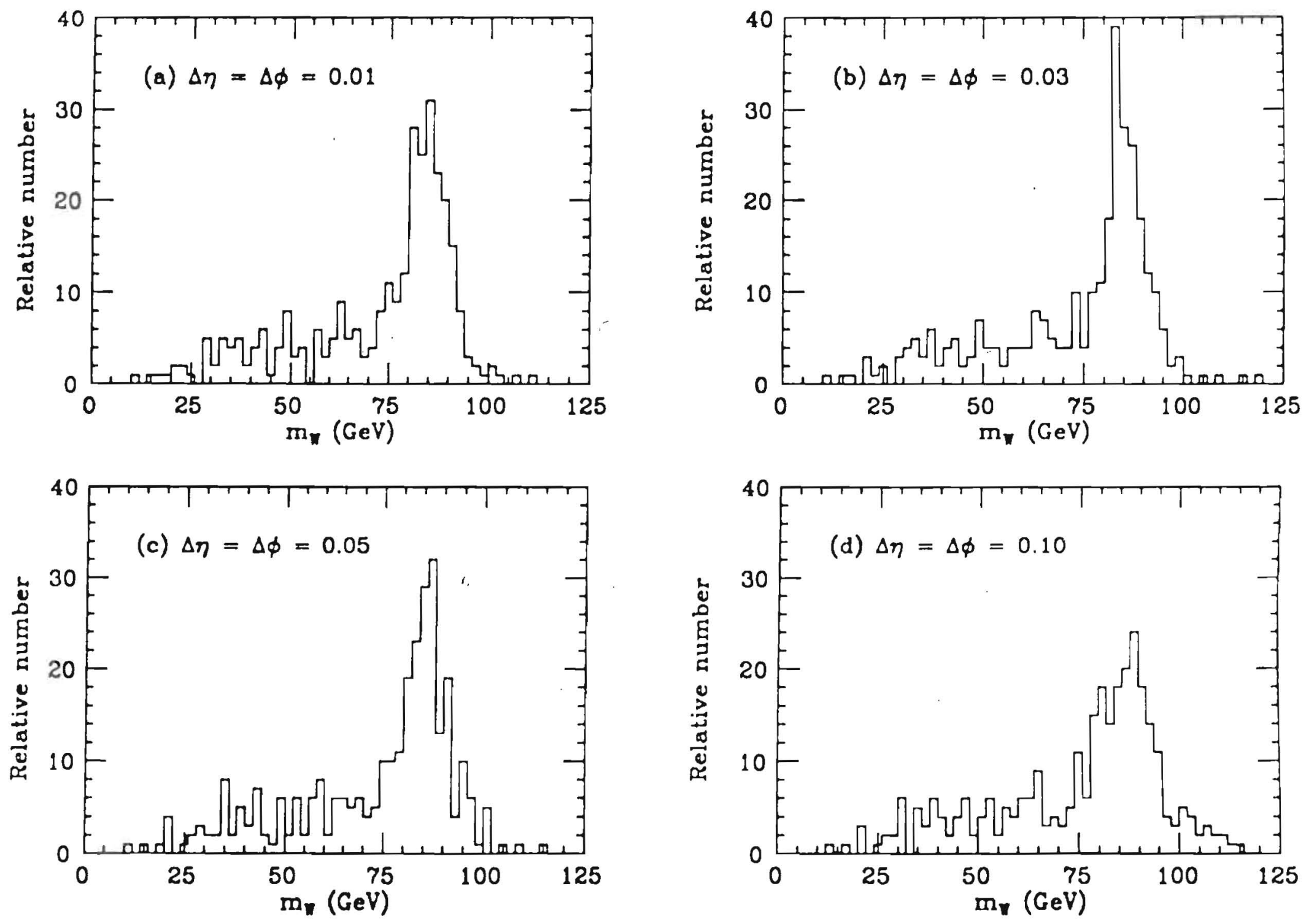


\section{Energy Resolution}

- Electromagnetic

- See simple plot - systematics will be Important even for lousy calorimeter by standards of crystal devices.

- Need for resolution better than (0.10-0.15)/VE? Given systematic floor of $1-2 \%$, hard to see reason. Need quantitative example, presumably low PT electrons.

- Hadronic

- Very high PT jets eg. compositeness signature - don't need super resolution - see plot In e/ $\pi$ section. Super means $\leq 0.5 / \sqrt{ } E$. Belleve that $1.0 / \sqrt{ } E$ is good enough for hlgh PT jet measurements, even if systematic effects are small - slow change in PT spectrum.

- Missing ET - some effect - see plots. Prudent to have $0.50 / \sqrt{E}$ but not big degradation for 1.0/ $\mathrm{VE}$

- $W$ - $>$ jets mass resolution or modest PT jet-jet resolution in general?

- Systematics and Calibration

- How important at SSC? Talks by Huth and Hahn on present experience. Many contributions to resolution - how do they extrapolate with energy(of jets)?

- Do we need to go all out to have $1-2 \%$ calibration? Perhaps can come to a conclusion at this meeting. 


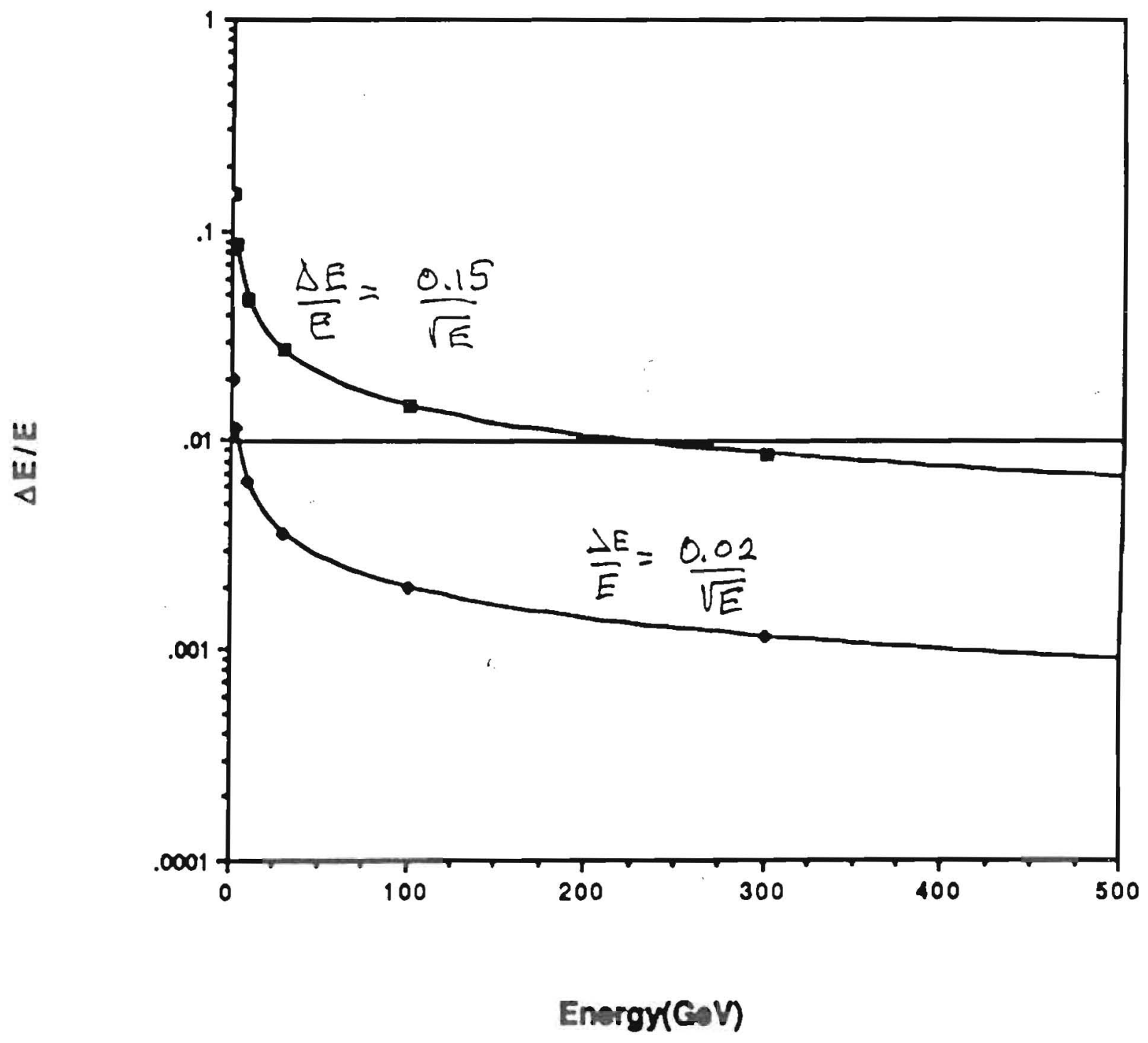




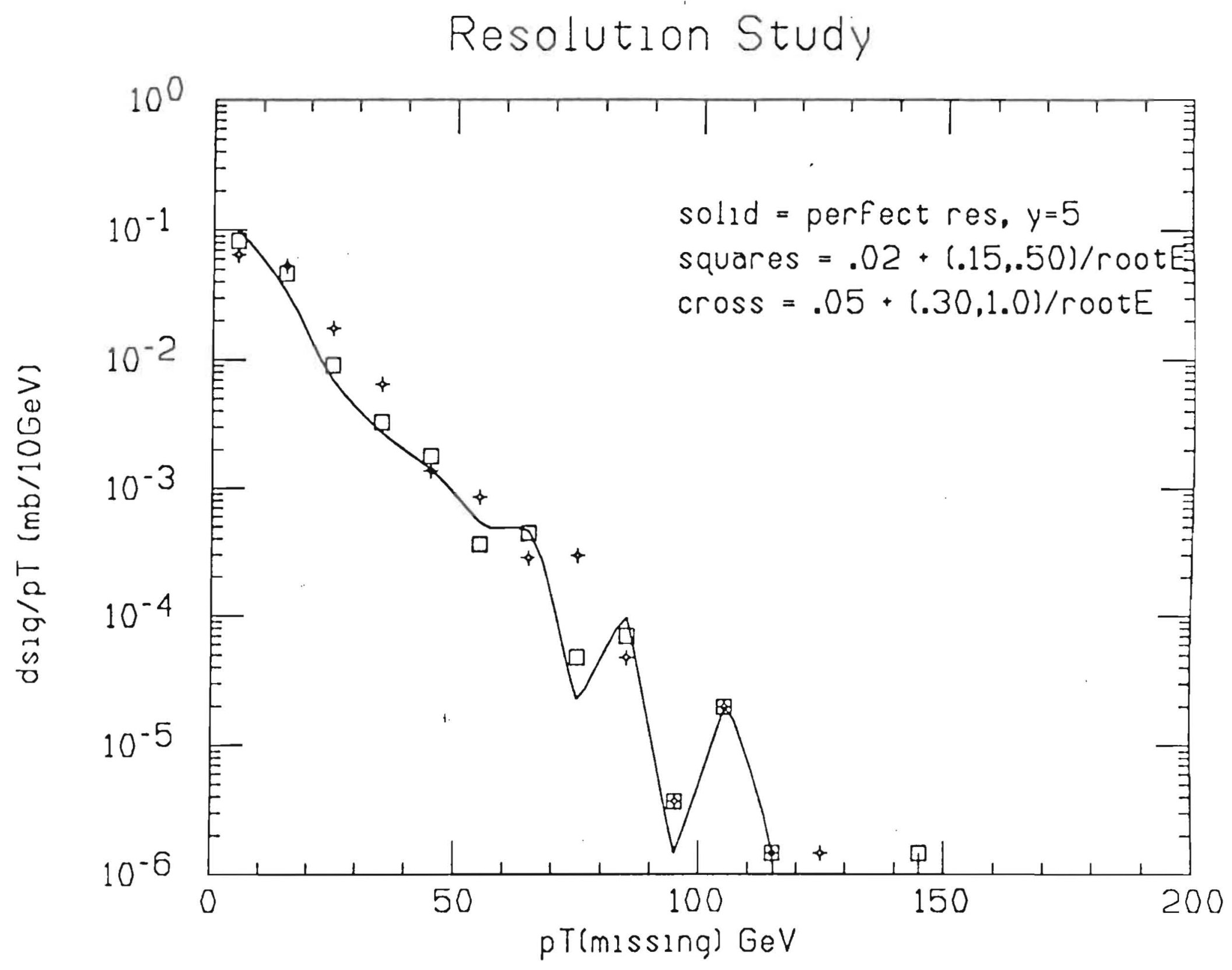




\section{Electron/hadron Response}

- All other things being equal, clearly better to have calorimeter with $\mathrm{e} / \pi=1$ or very close to 1 . But not all other things are equal, so how much non-compensation is allowed before impacting physics?

- This is related to energy resolution question via connection with "constant" term.

- Can weighting techniques be used to effectively obtain compensation? See H1 plots and talk by Oberlack.

- Impact on physics?

- Only quantitative study of which I am aware is effect on quark compositeness signal. See talk by J. Huston and plot. Substantlal effect and, if correct, implies to me that $e / \pi \leq 1.1$ is required. But can this be mostly taken out in calibration?

- Other studies? Tell me if you know. 
QCD only

Compared to $e_{i h}^{\prime}=1.0$

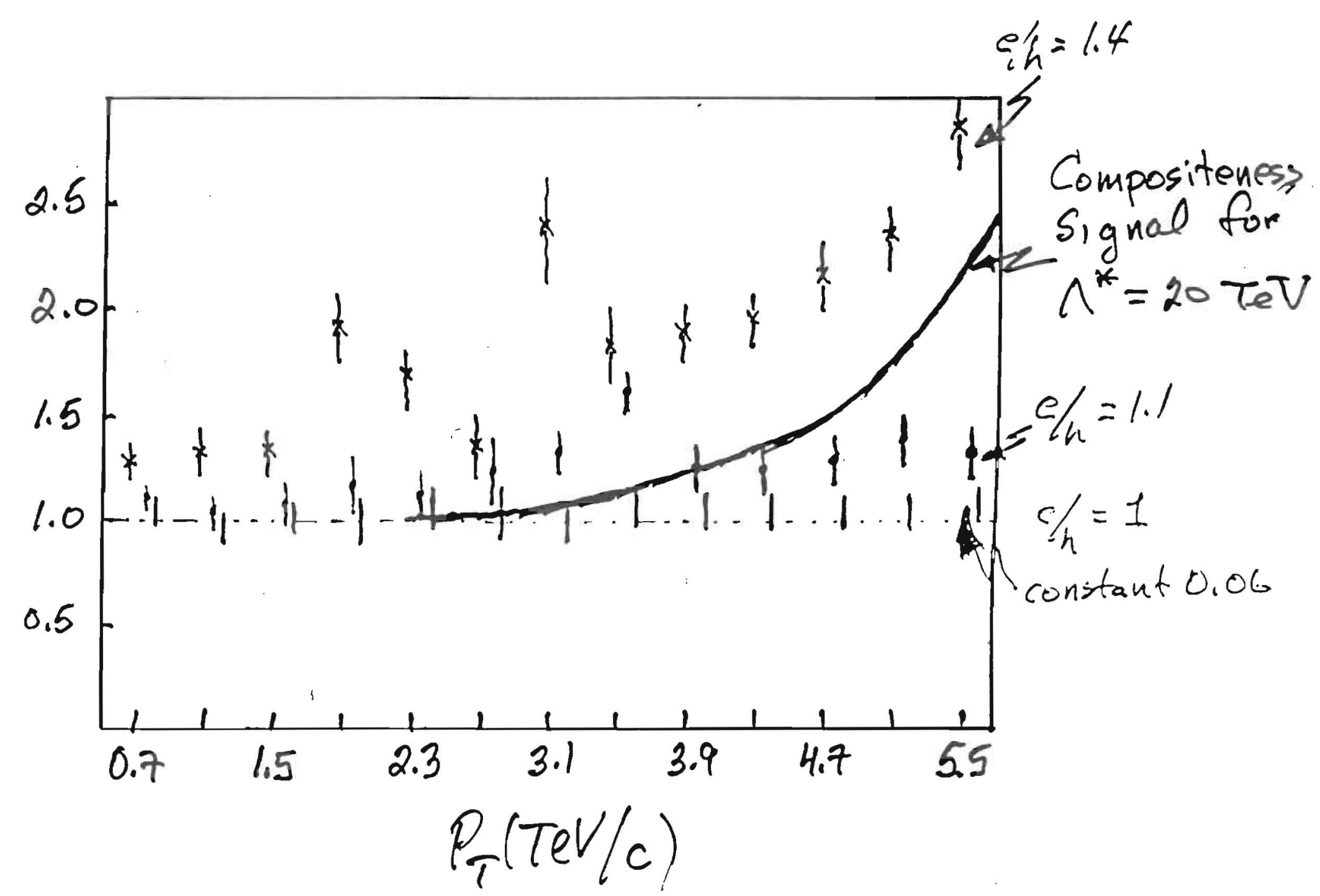

J. Hustonetal. Borkeloy ' $87{ }_{16}$ 


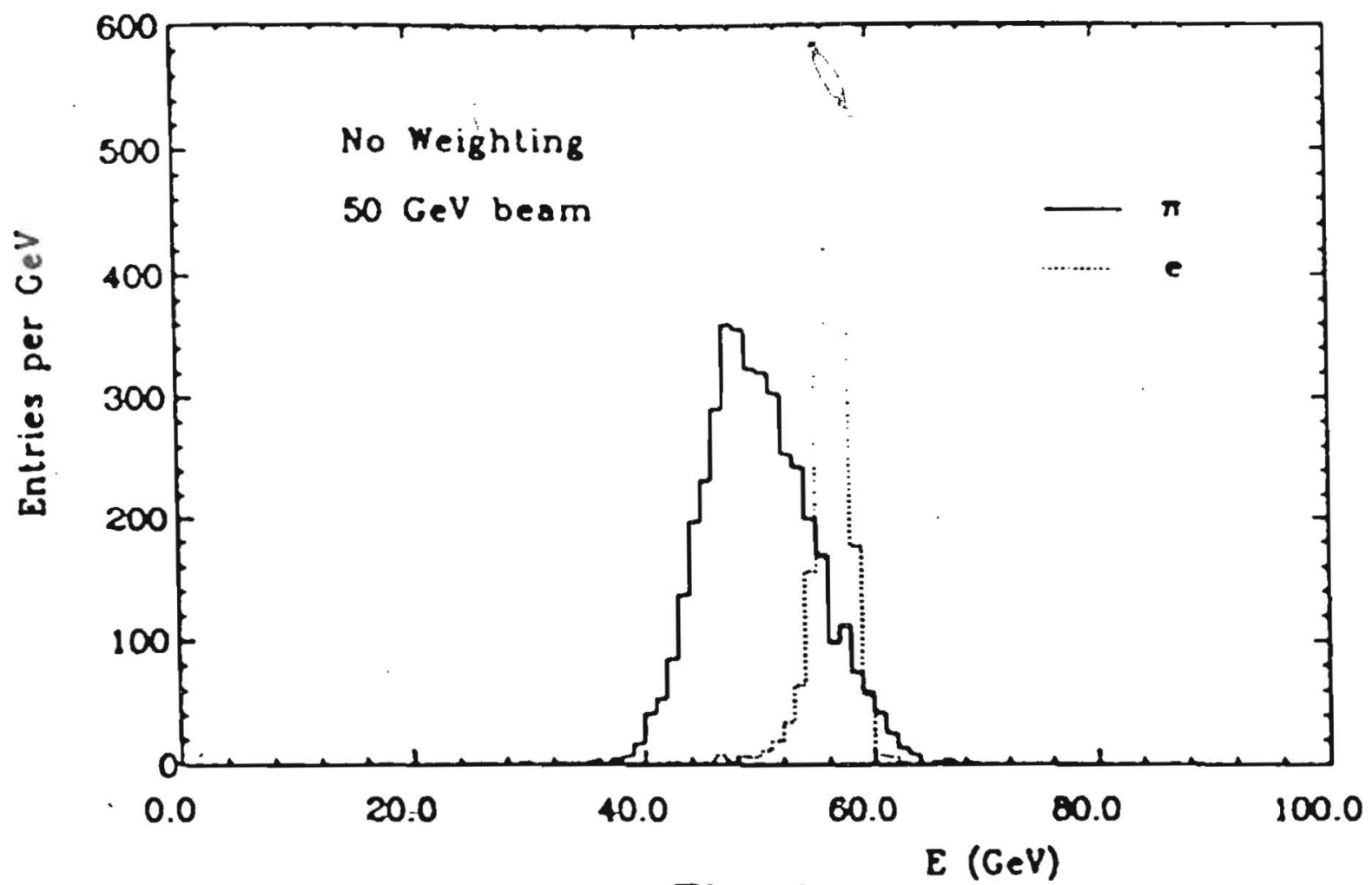

Fig. 18a

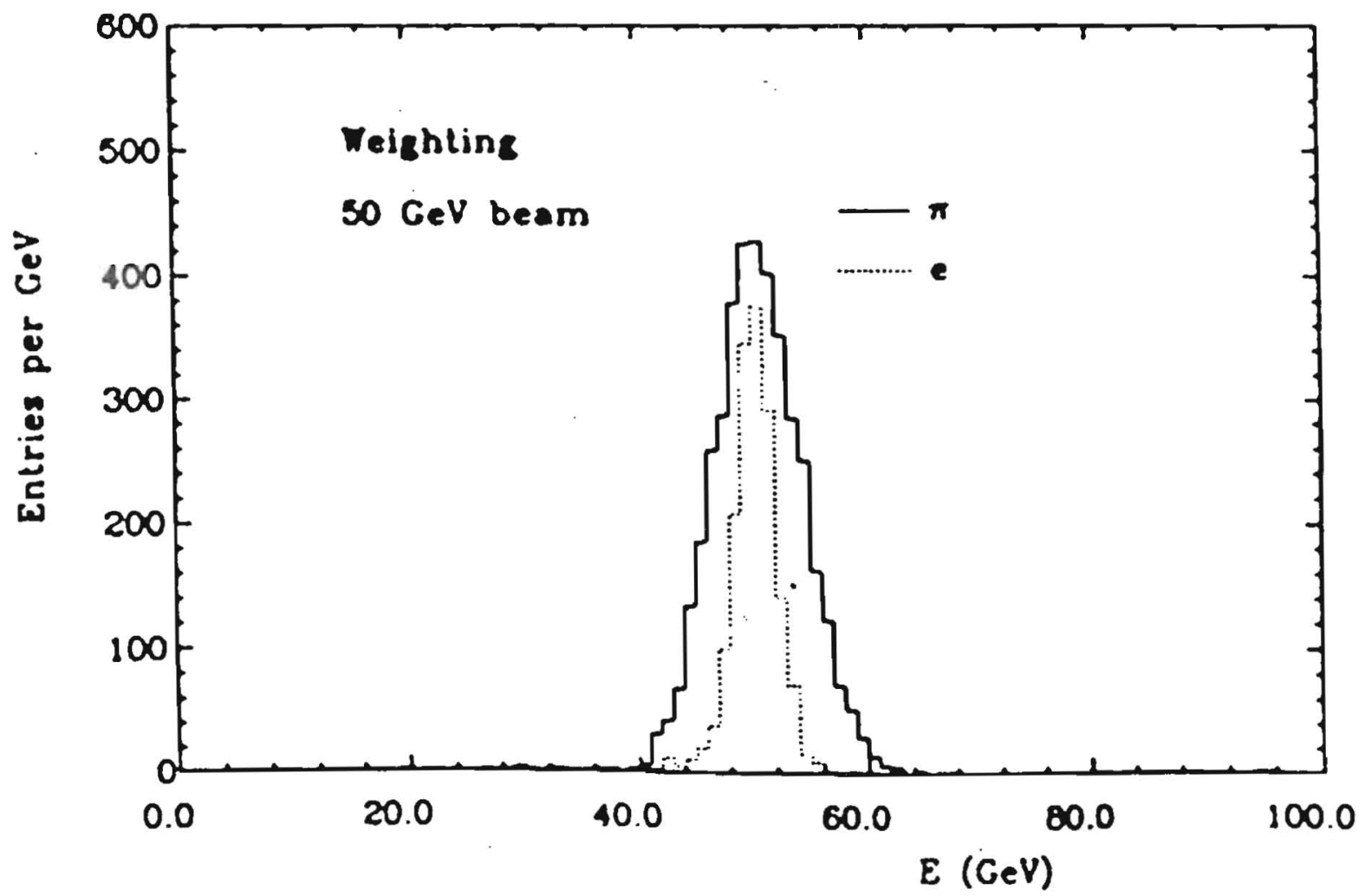

Fig. $18 b$

HI Group

DESY 87-098

₹ 


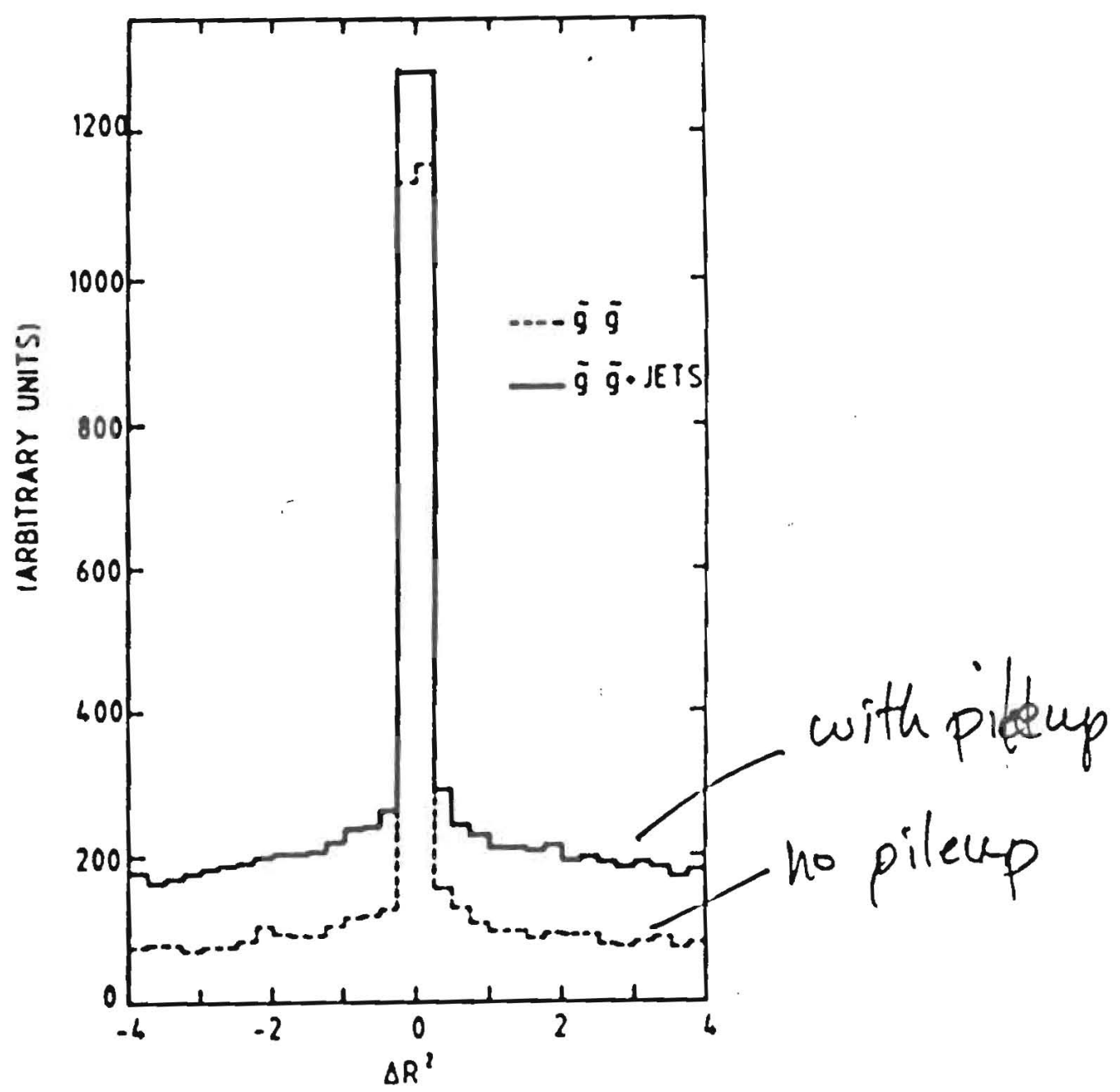

Figure 4: Jet energy profile for gluing even ls, both with (full histogram) and without (dashed histogram) pile-wp. The gluing mass is I GeV $/ c^{2} . \Delta R^{2}$ bs $>0(<0)$ for cells with $\Delta y>0(<0)$.

$$
\text { CERN 88-02 pg } 85
$$

18 


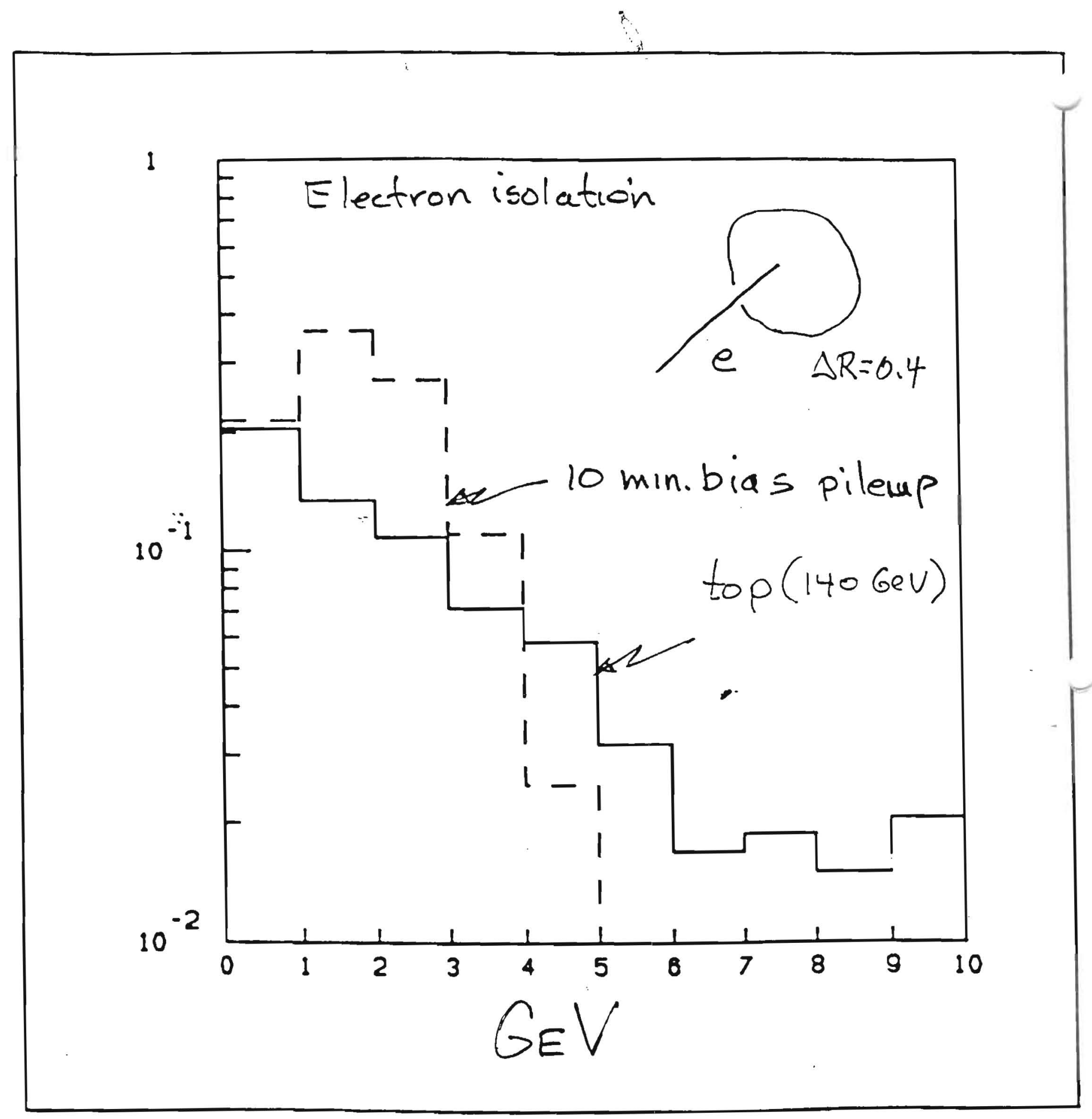

Figure 3: Solid curve: Transverse esergy in a cose $\Delta R=0.4$ for top events with $m_{l}=1+0 \mathrm{GeV}$. Dashed curre: Pileup in the same cone from 10 minimum bis events. 


\section{Speed and Pileup}

- Speed refers to both leading edge timing and integration time

- Time tag energy deposition by cell and reject out of time background leading edge timing. Limited by noise/energy threshold of interest. Is this a requirement? Clearly desirable but not aware of example showing need. My guess is yes, try to do it.

- Integration time also relevant to compensation - for practical calorimeters seem to need $\approx 100-150$ nsec to obtain best compensation (if anyone knows differently, please show me).

- Pileup is obviously luminosity dependent. Inasmuch as there is a gradual approach to the design luminosity coupled with increased PT thresholds, pileup is less of an issue.

- Impact of overlap of $\approx 10$ bunch crossings

- On high PT processes eg. $500 \mathrm{GeV}$ PT W -> jets reconstruction. No problem - see talk by Wang. See also plot for high PT jets from gluino production with and without pileup. There have been many other studies(Yamashita \& Kondo, Snowmass 1986, Fabjan in CERN 88-02 and Cox in CERN 88-02).

- On moderate PT jet reconstruction. Minimize cone size. Probably not an issue. See comments by Paige in working group sessions.

- On missing ET - see Yamashita and Kondo. Not much effect for interesting region of missing ET.

- On isolation criteria for electrons. This may be a problem but depends in detail on how much isolation is required and hence on PT of electron. See plots from Paige and Wang. 


\section{Hermeticity}

- How hermetic is good enough? Complicated!

- What is the minimum interest missing ET scale as a primary signature? See comments by Paige. Between $50-100 \mathrm{GeV}$ for new physlcs? How about single $W$ production as old physics?

- A straightforward approximate measure is to try to make detector effects small compared to real missing ET from neutrinos (plus to some extent muons, at least at the trigger level). See plots for different beam hole sizes compared to neutrino + muon missing ET. Must cover well to at least $y=5$ (which means $y=5.5-6$ including edges) in reasonable geometry to approach real missing ET at about $100 \mathrm{GeV}$.

- Effects of cracks, coils, marginal regions - a long and complicated subject.

- Requires detailed modeling for precise estimates.

- Some approximations see plots

- Compare at Workshop

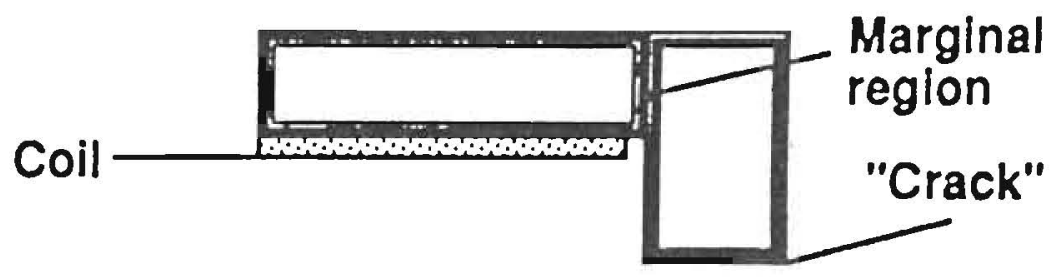
with other calculations

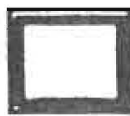

- Conclusions??

- Thin coil has negligible effect

- "Cracks" are known to be significant - need crack fillers.?See plot. 


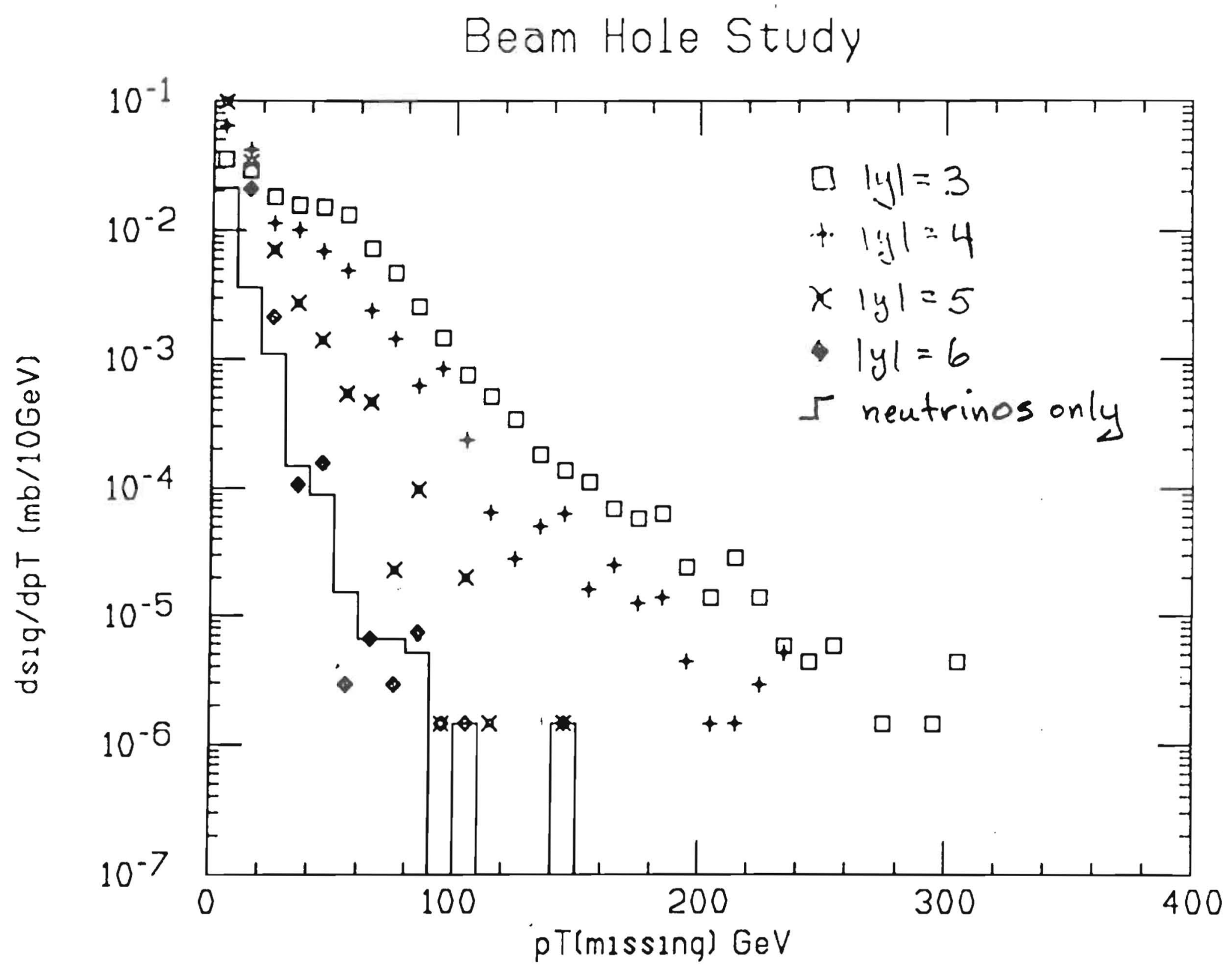


Solenoid in front of EM Study

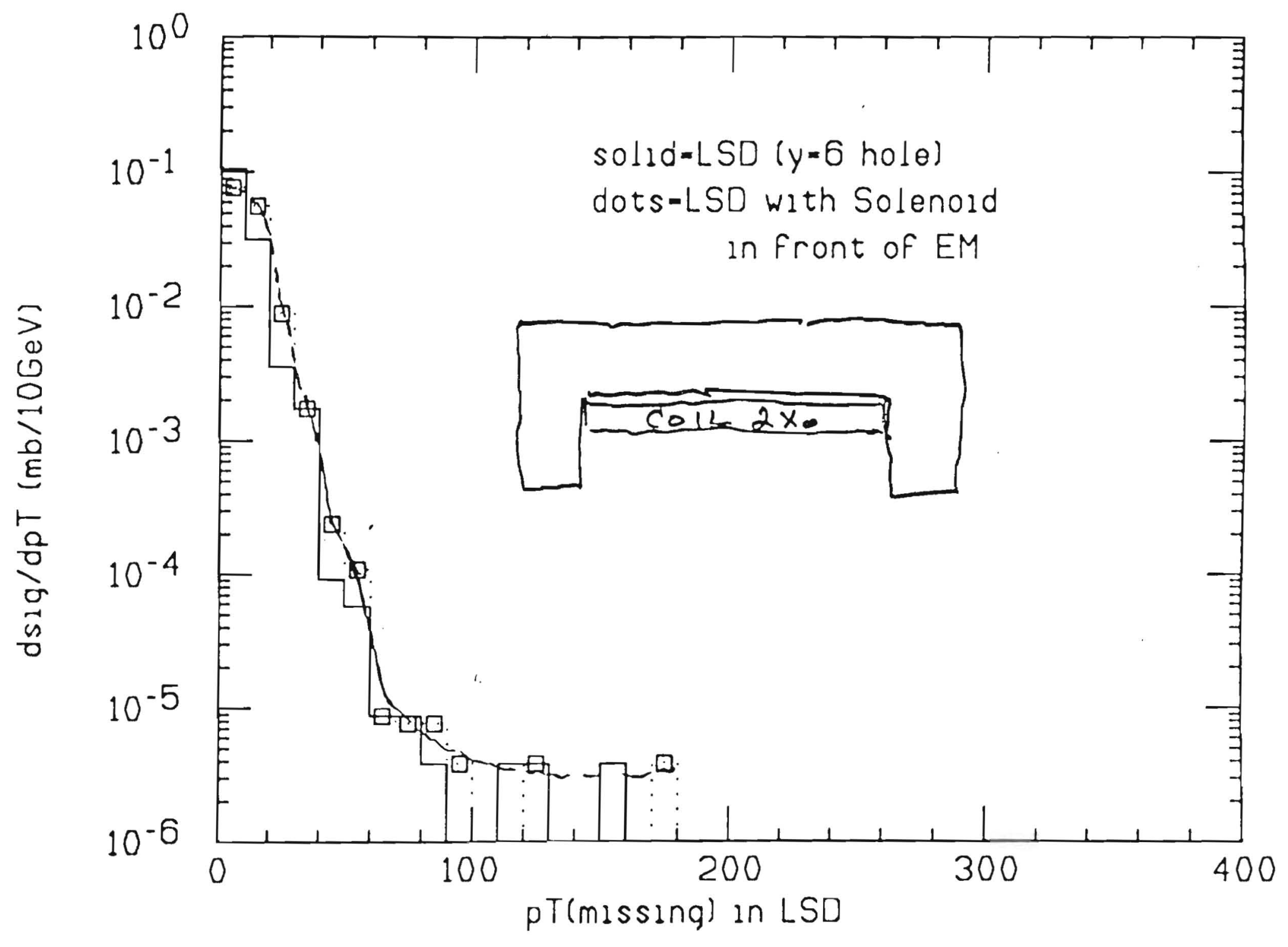




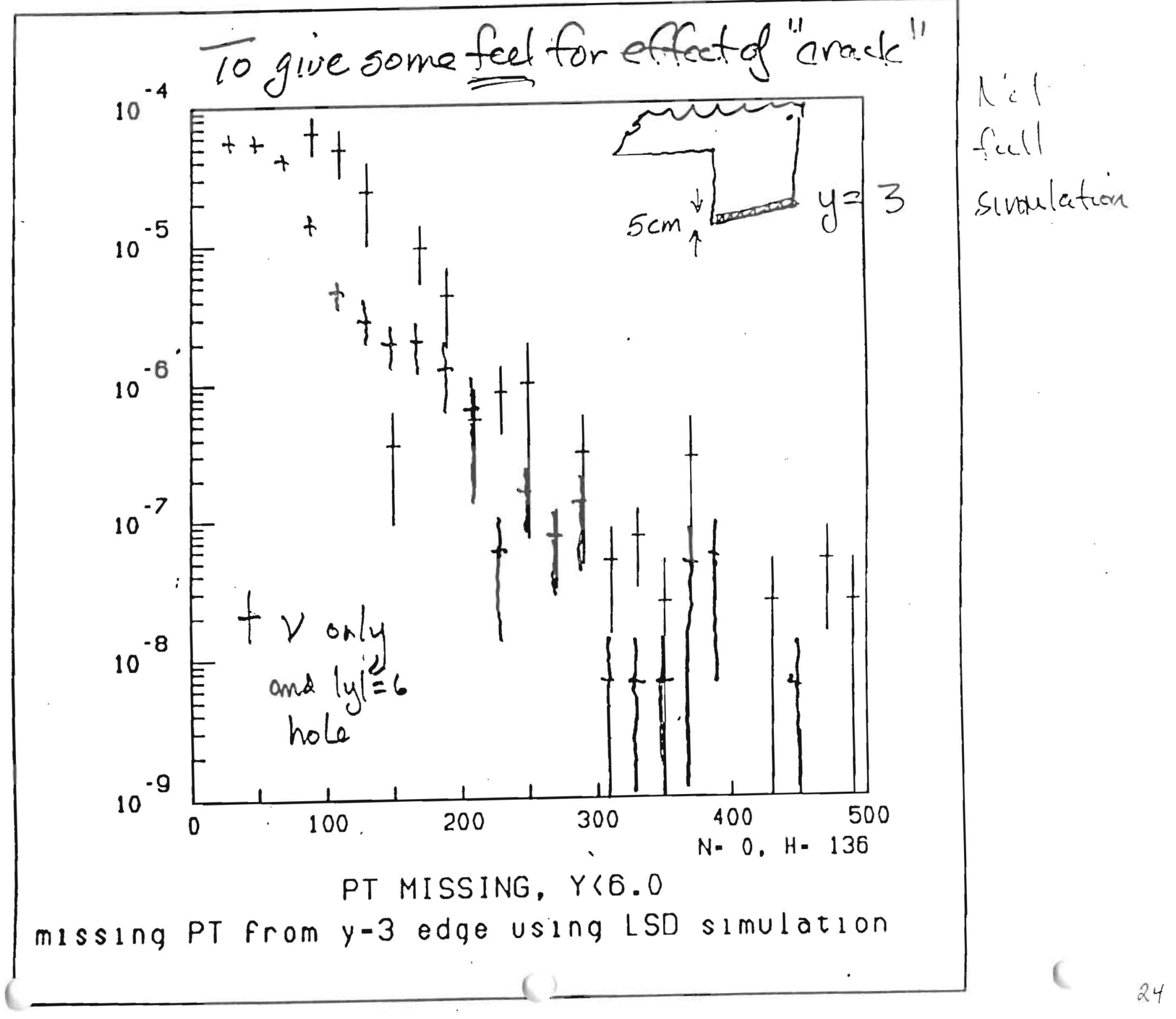




\section{Summary}

- Survival - of course!

- Depth - some uncertainty but about 8 lambda at 90 degrees and somewhat more at forward angles.

- Transverse granularity(mainly hadronic) - depends on radius/interaction length but shower spreading has significant effect on jet-jet mass resolution at high PT. From this alone $\Rightarrow$ make radius/interaction length large as feasible

- Energy resolution - super EM resolution? No convincing case. Hadronic resolution? Better is better if jet-jet masses at modest PT are important.

- Electron/hadron - seems prudent to have $0.9<e / \mathrm{h}<1.1$ (or better) either by true compensation or by weighting techniques (if they can be applied).

- Speed - no convincing evidence that overlap of $\approx 10$ minimum bias events is disaster except possibly for electron isolation criteria at low PT, which may be important even for high mass objects via many cascade decays.

- Hermeticity - try to cover to $|y|=6$ to match natural missing ET from neutrinos. Effect of coil in front of calorimetry is negligible. Modest cracks can have significant negative impact on missing ET. Either have minimal cracks or fill them with separate calorimetry. Needs more study. 
Electronics Considerations

for

Muraturanos

SSC Calorimetry

V. Radeka, BNL

Acknowledgements:

S. Rescia

HELIOS ULAC team: BNL, CERN, Heidelberg,

Do collaboration Pittsburgh, Tel Avis

Calorimetry with:

- Liquid Argon

- Warm Liquids

- Silicon

- Gas

- Scintillators
Problems:

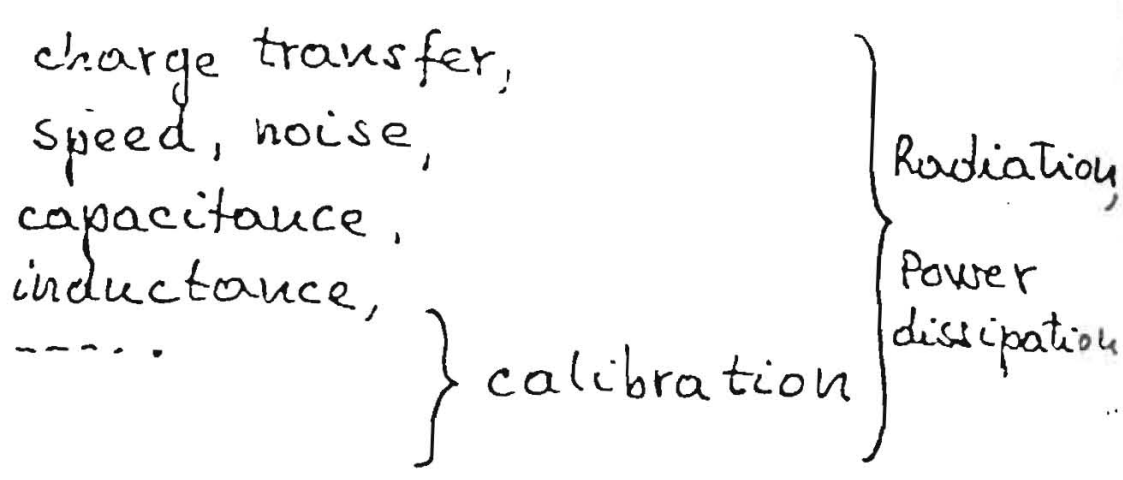

Outline:

- Charge collection, transfer and speed of response

- Noise and speed

- Electrode topology

- Electronics "inside"?

- Power dissipation

- Radiation Effects - Survival 
Ionization Chamber Calorimetry

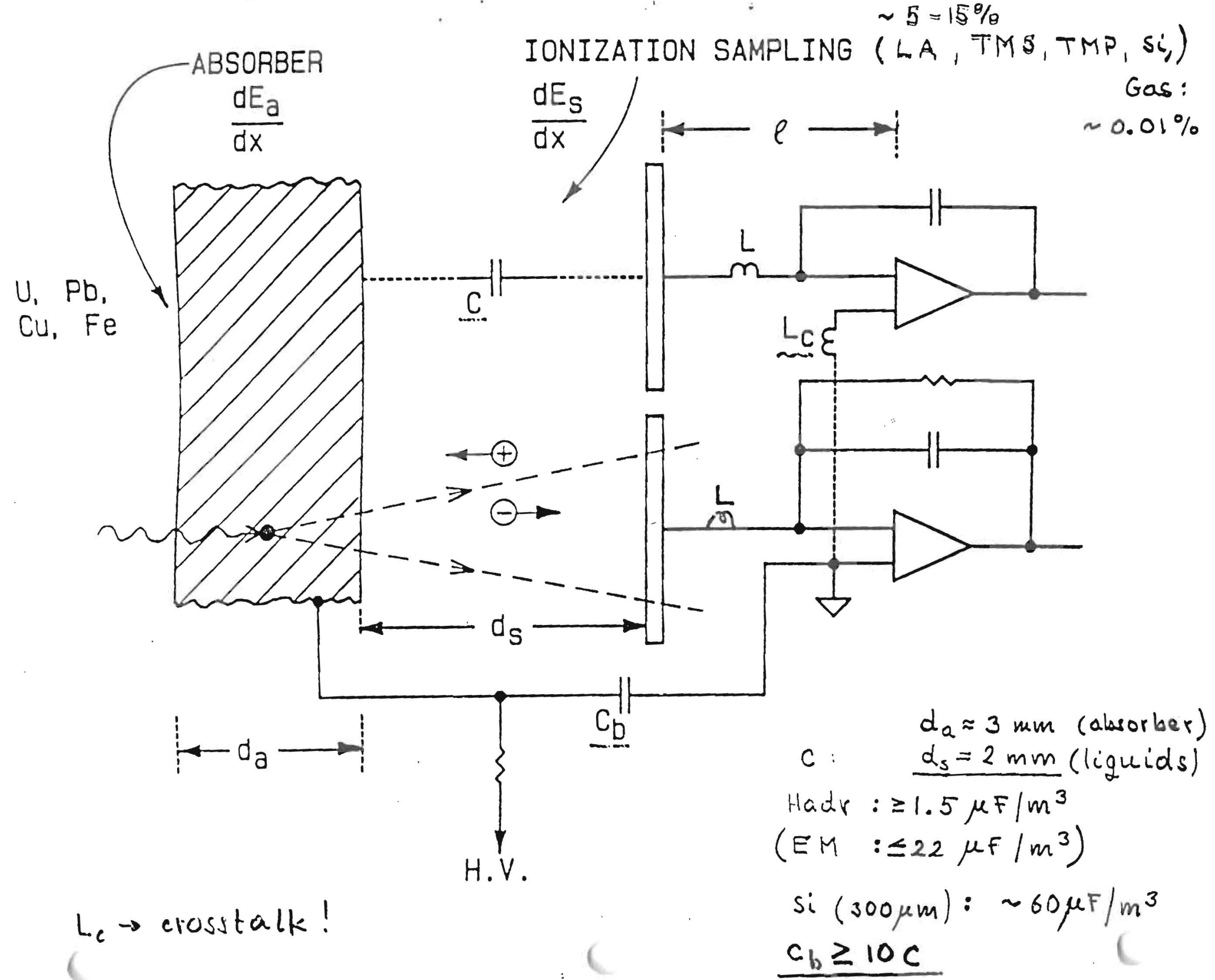


Ionization Chamber - Amplifier Circuit

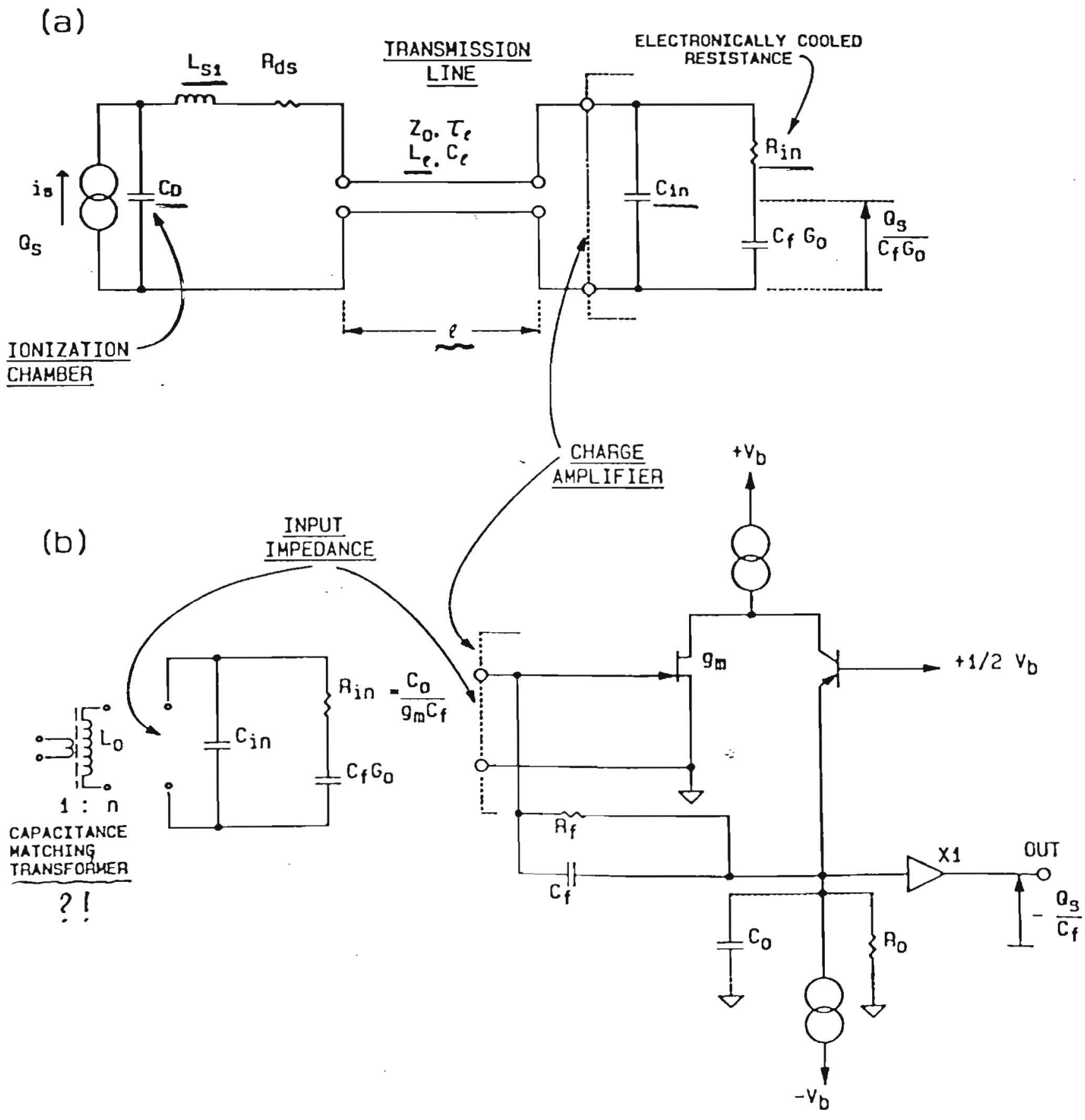


Charge transfer us time

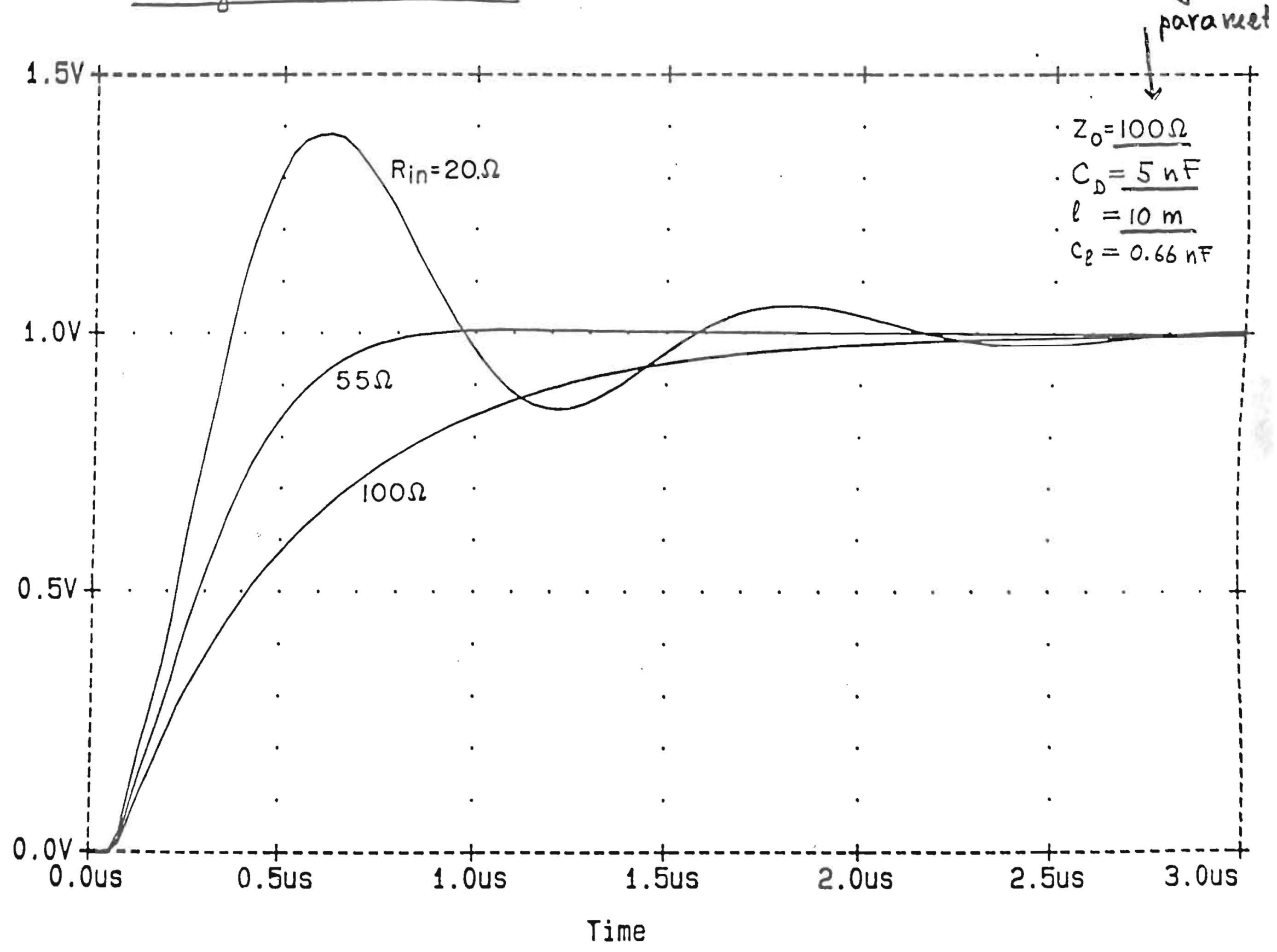


Charge transfer us time

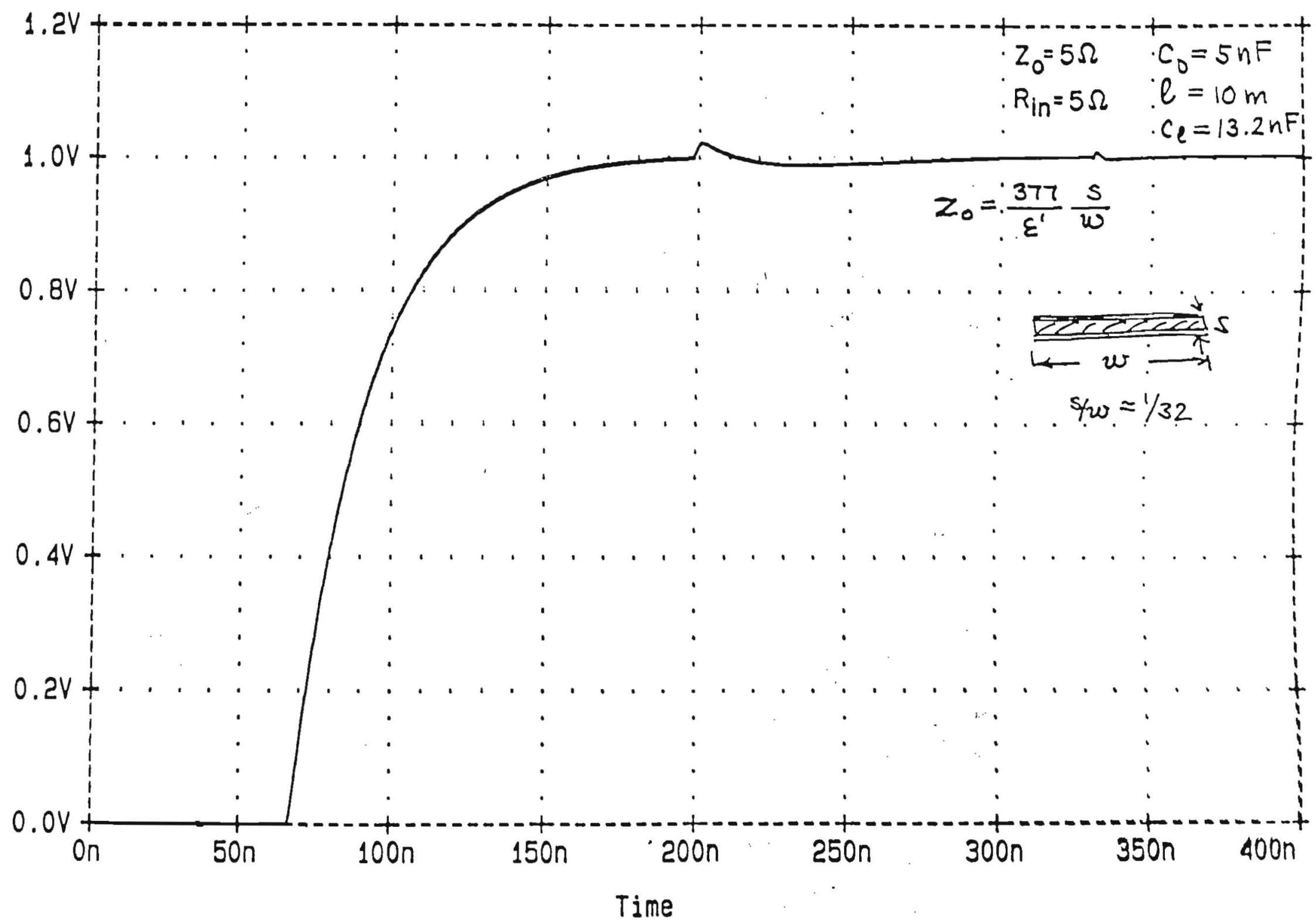




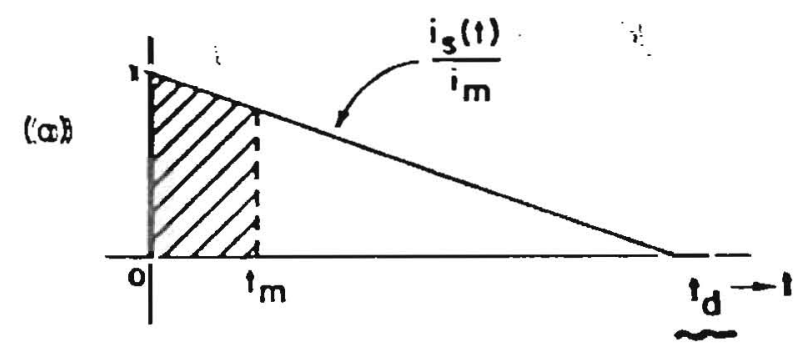

(b)

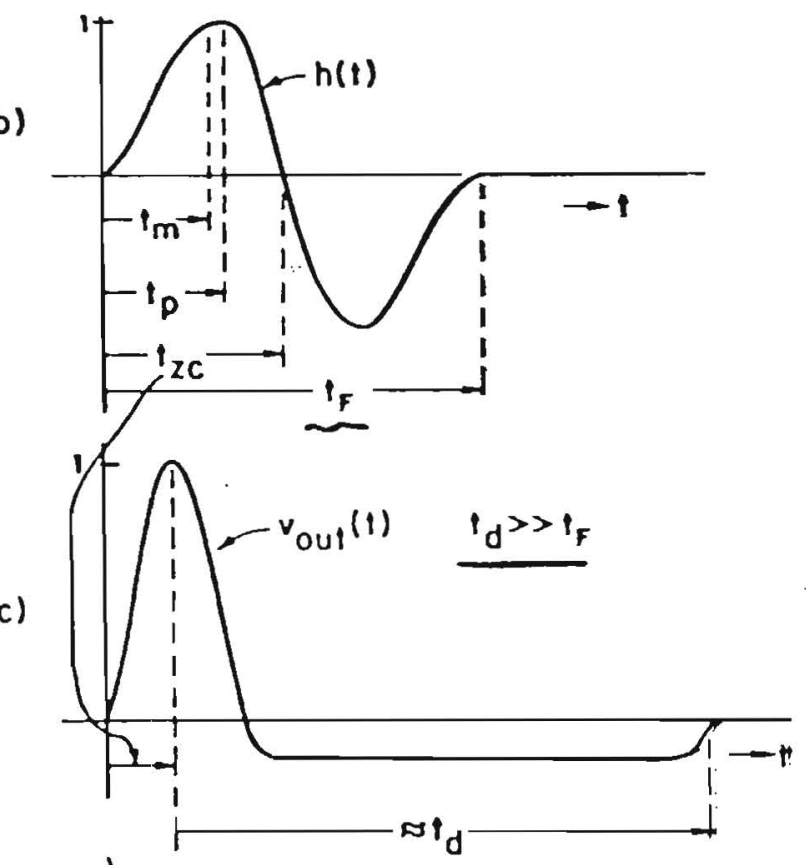

(d)

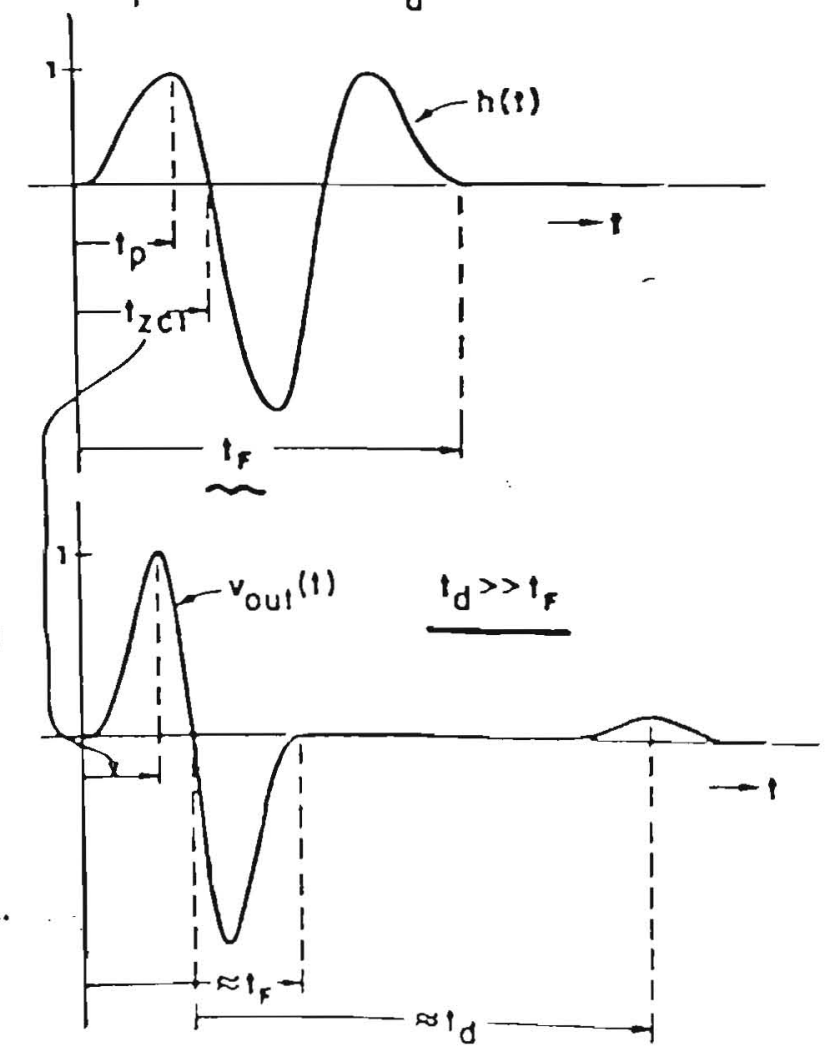

Processing of liquid ionization chamber signals 


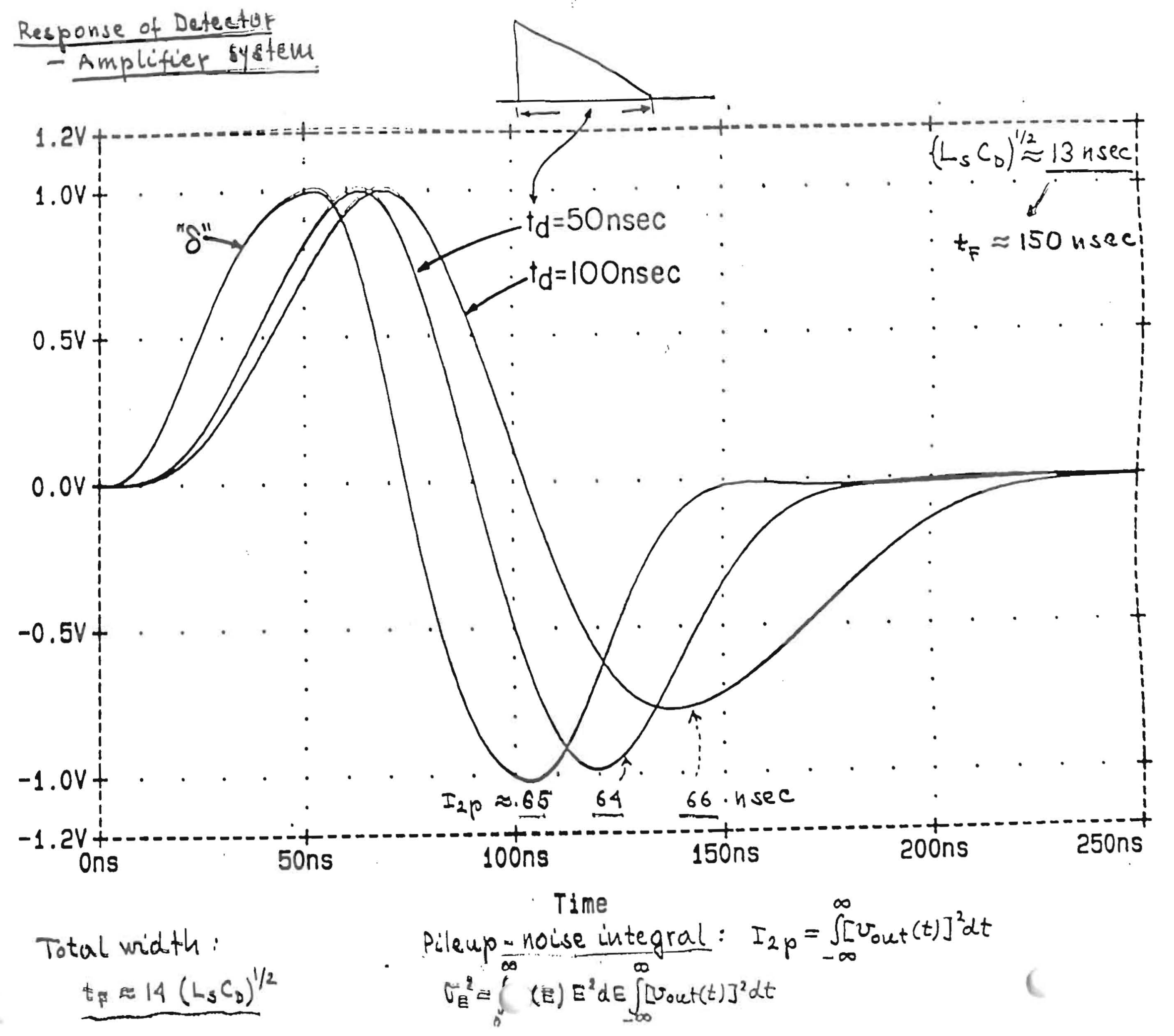


HELIOS, Uramium - Liguid Argon Latorimeter.

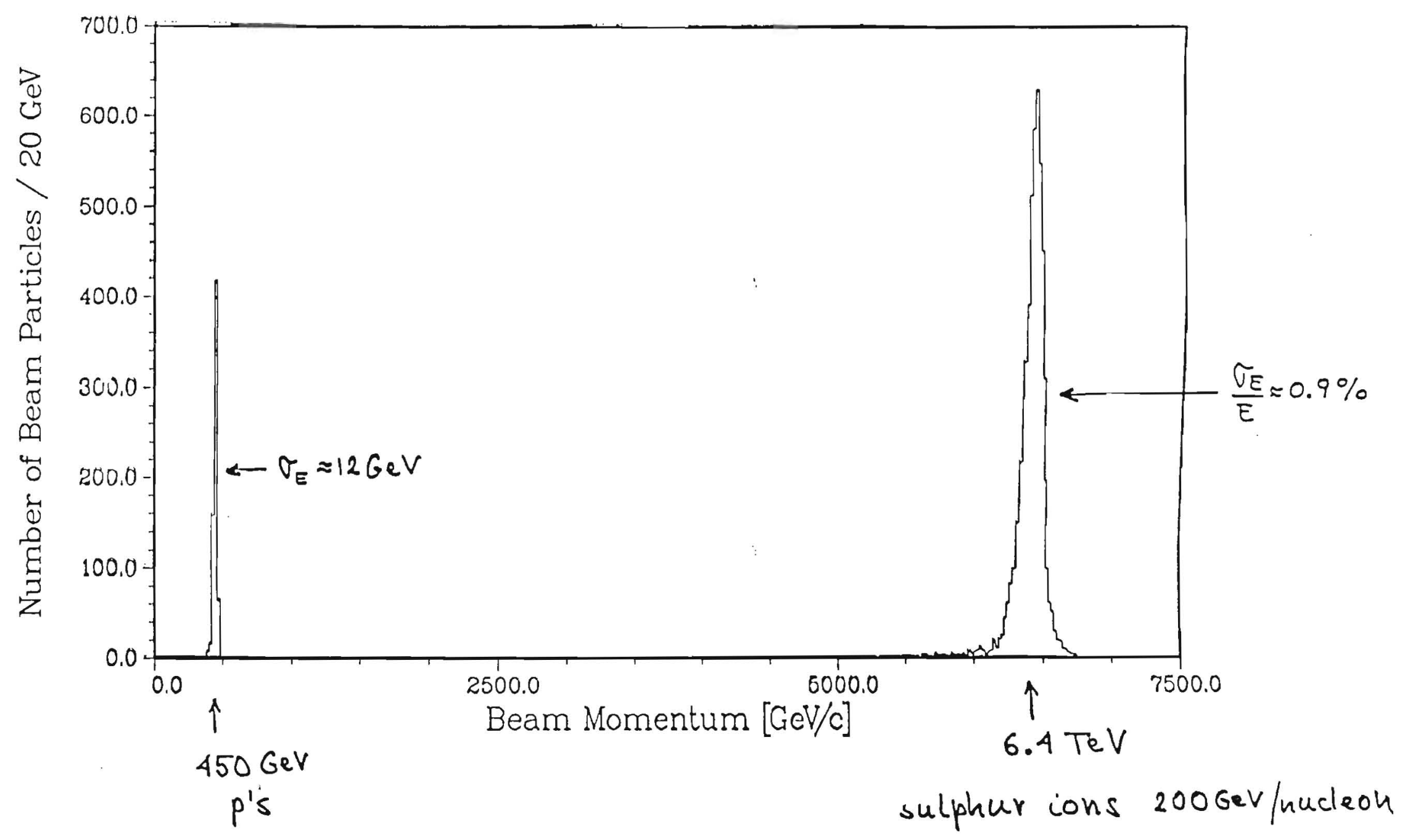




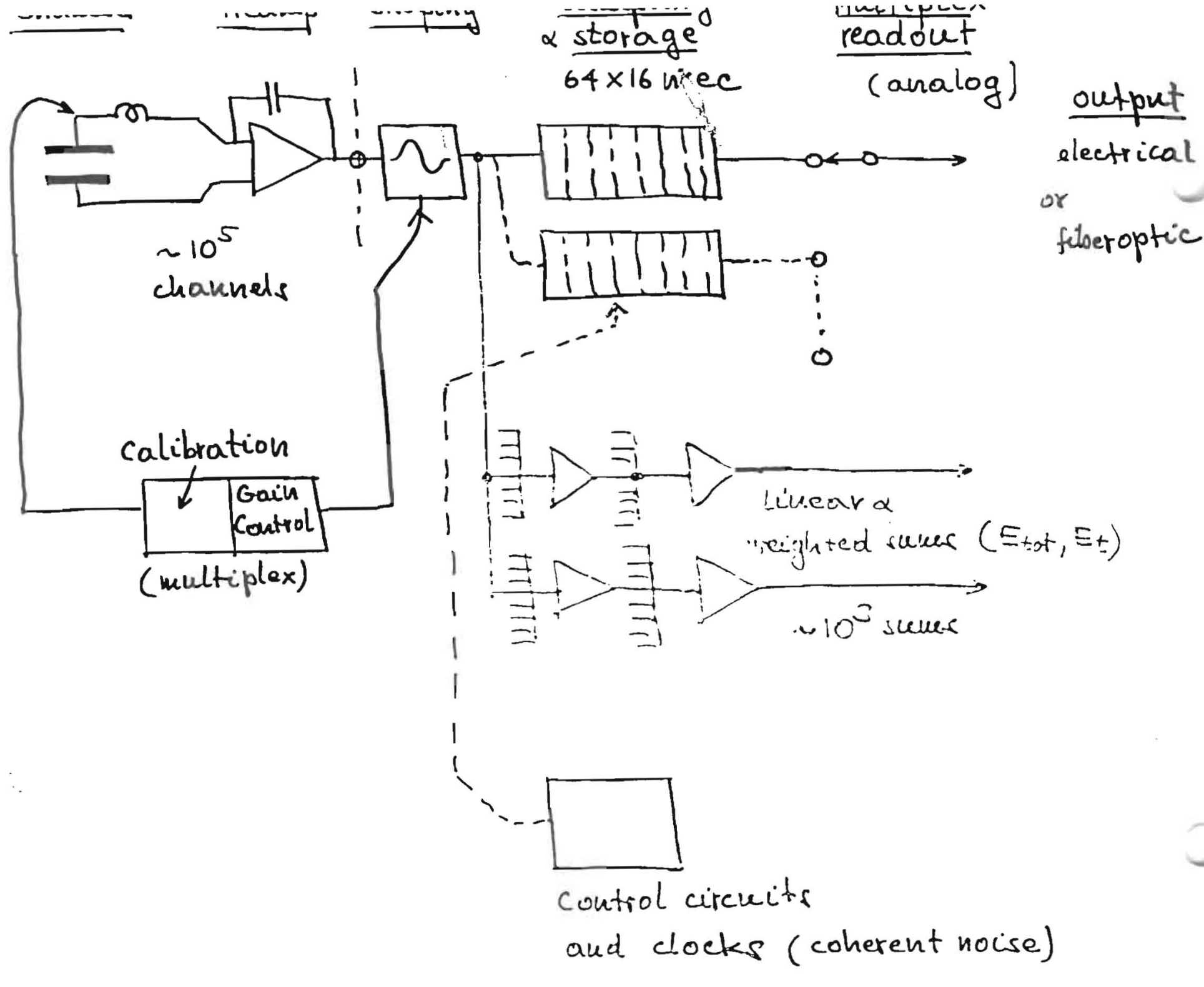

Calorimeter electronics (nursery school drawing)

What inside the vessel?

Preamp. only has to be near the electrodes. " "will be in high radiation fields. 


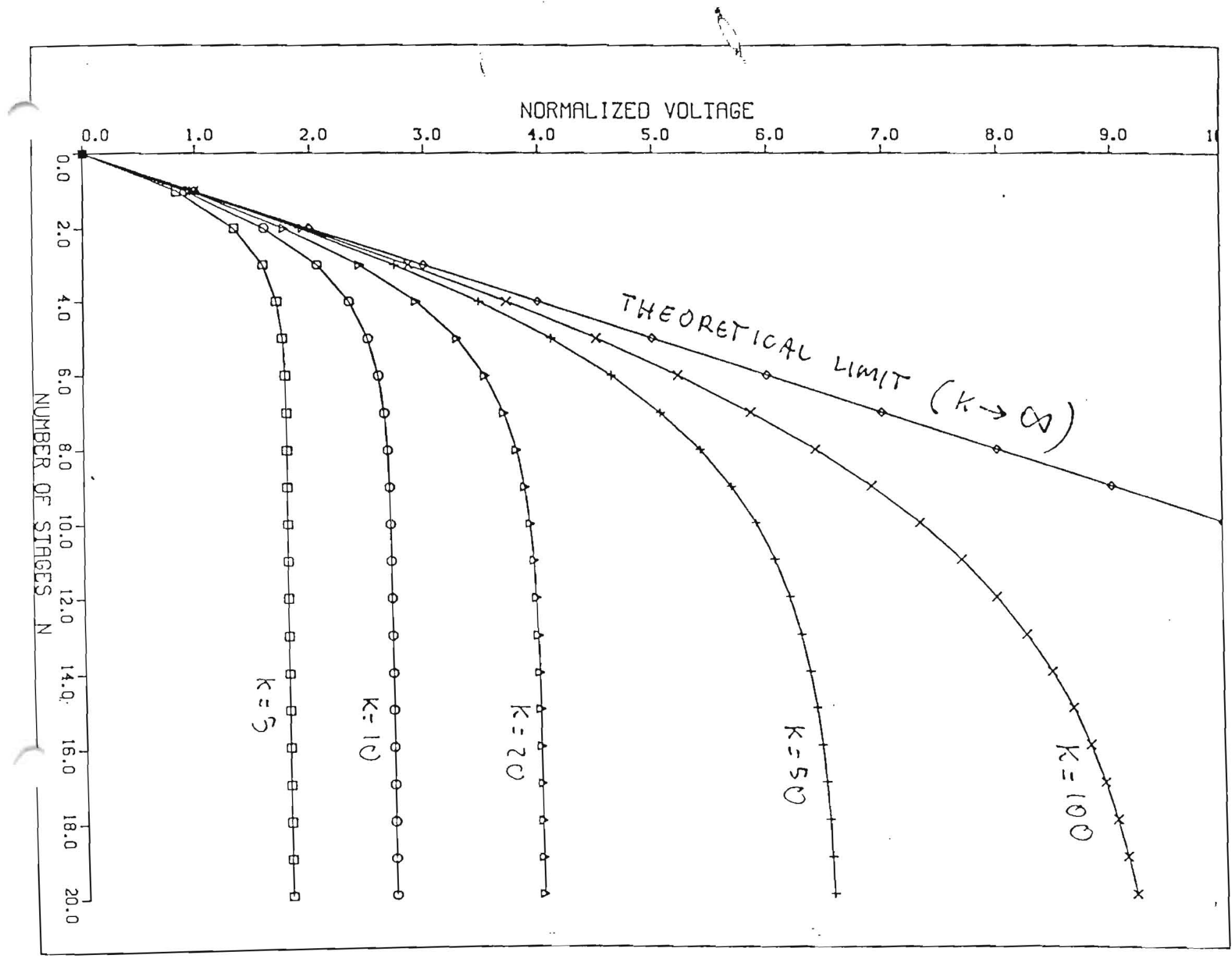




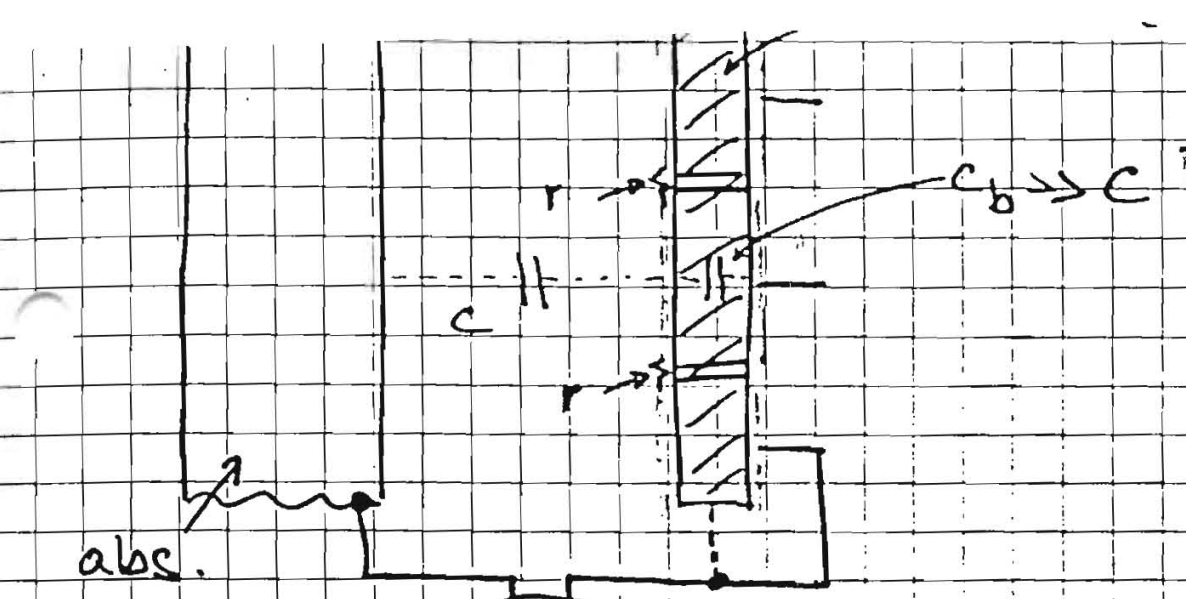

Decoupling compactor

$$
c_{b}
$$

SIGNAL

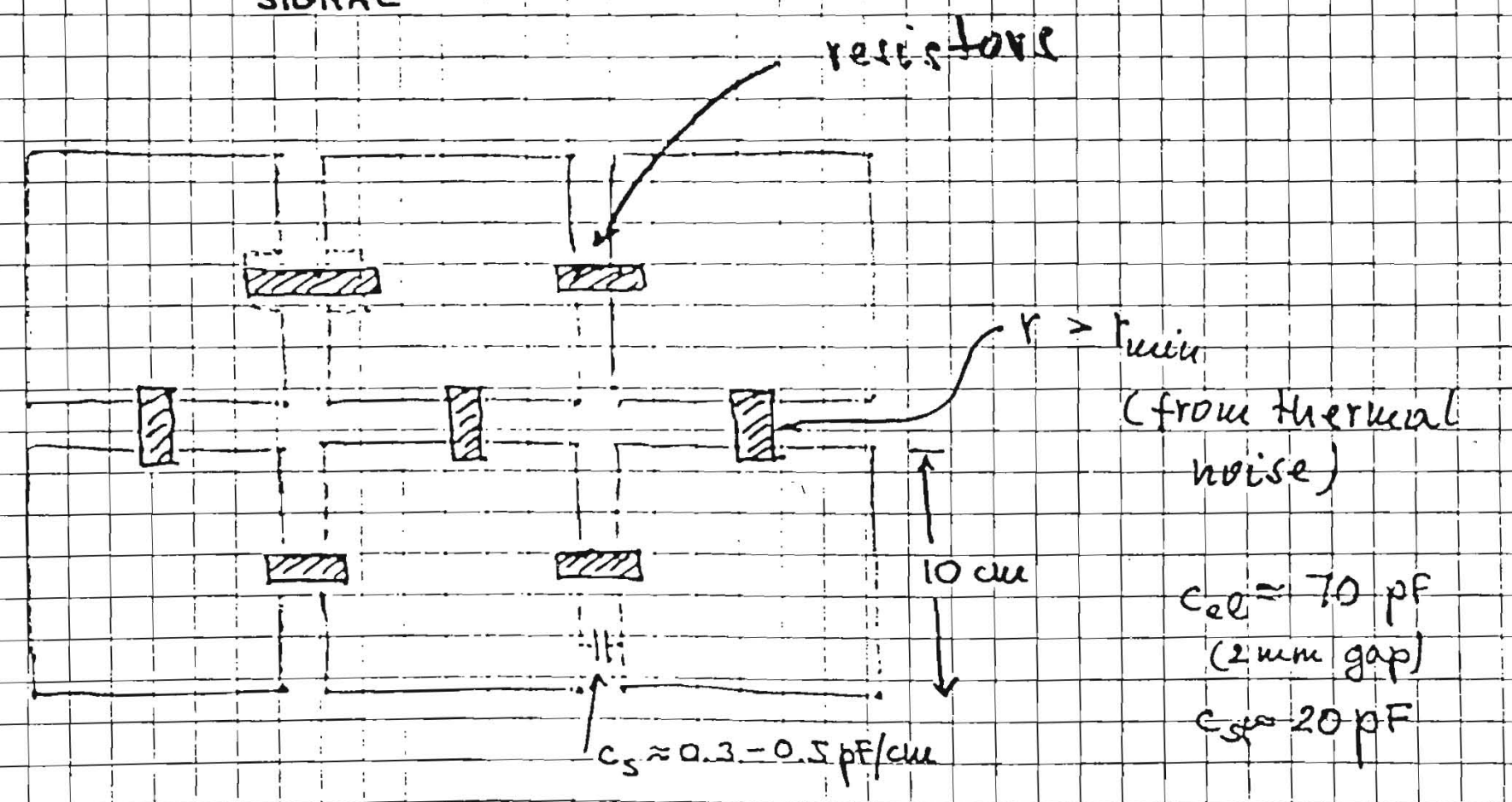

(2) Connections along the toner

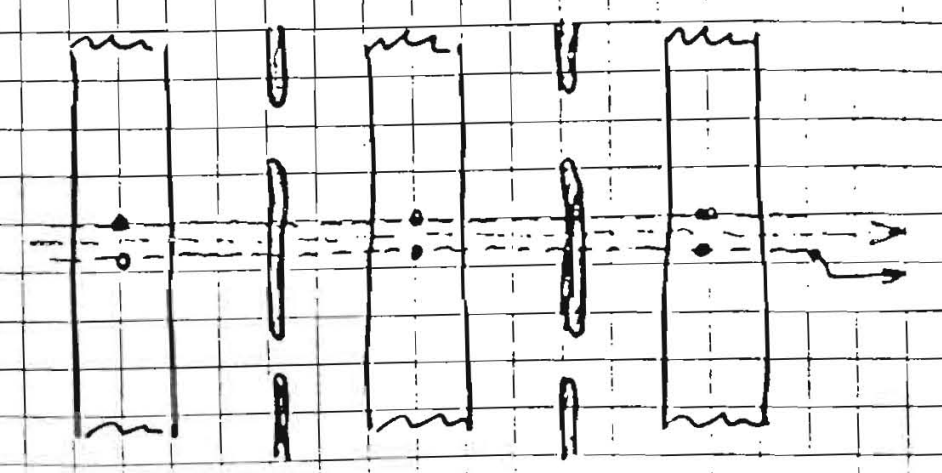




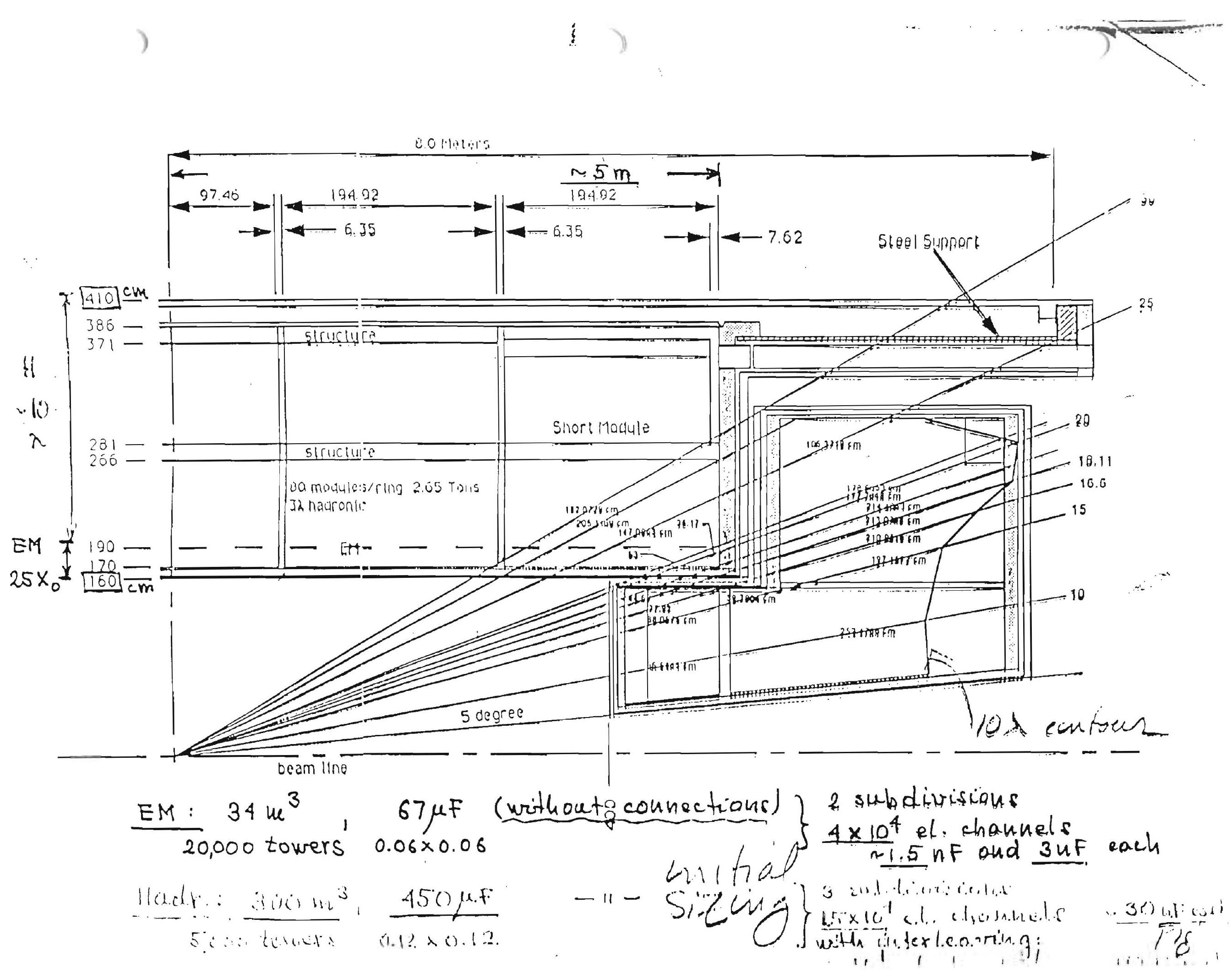


$N / s$ ws t

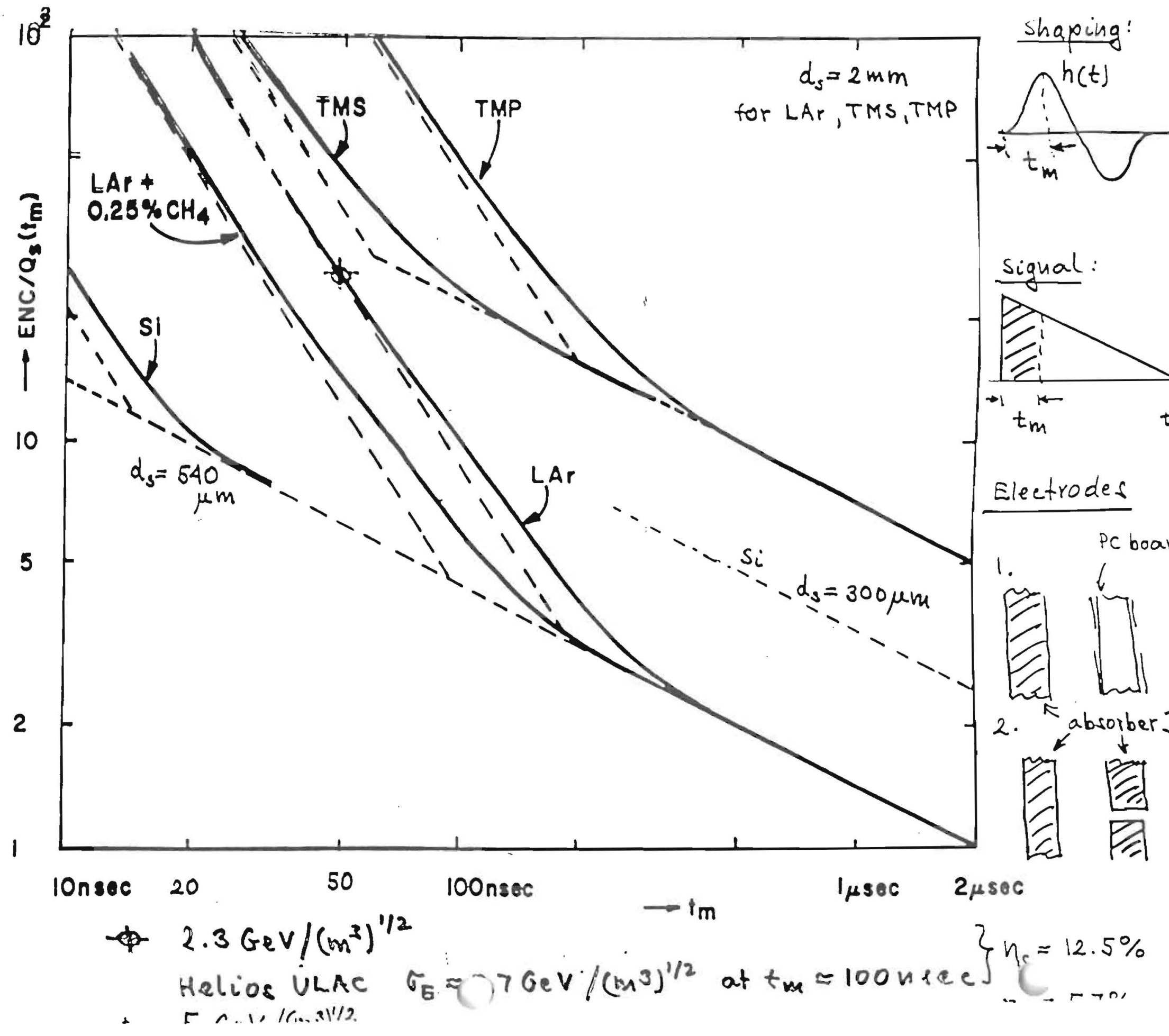




\section{$10-942-83$}

Pulse Shaping in Gas Proportional and Drift Detectors

(a)

Preakep output

\section{(b)}

Prearip tail cancelled

$\approx$ avode current
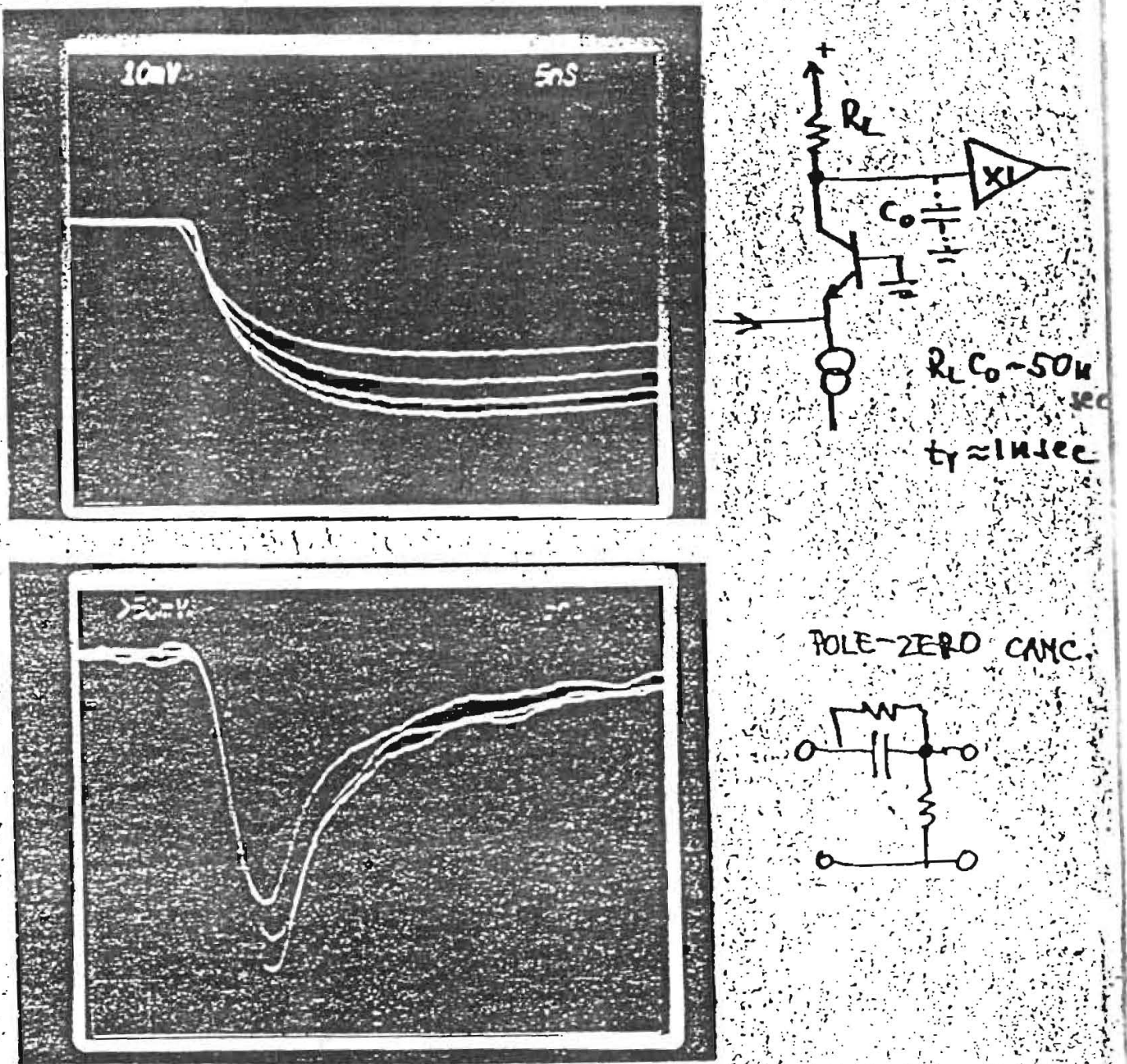

POLE-2ERO CNMC
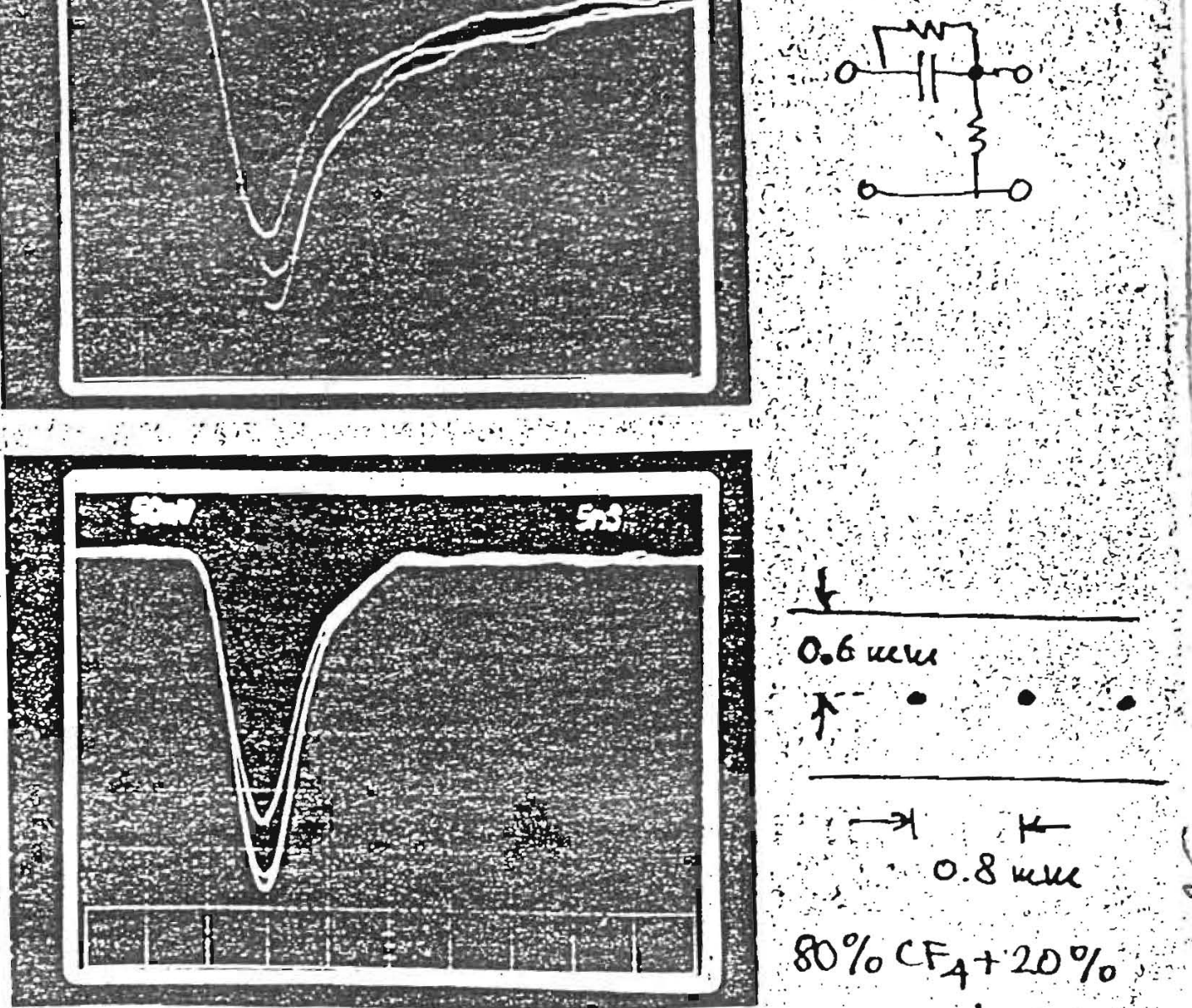

$\rightarrow$ Kurec

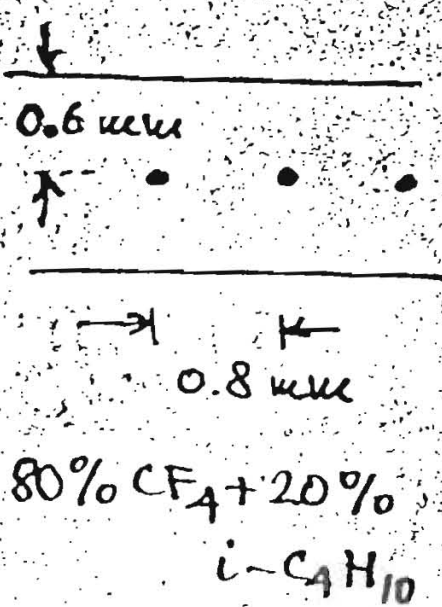


Response of Detector-Amplifier system for $t_{d}>t_{F}$

$t_{d}=400 \mathrm{nsec}, t_{F} \approx 180 \mathrm{nsec}$

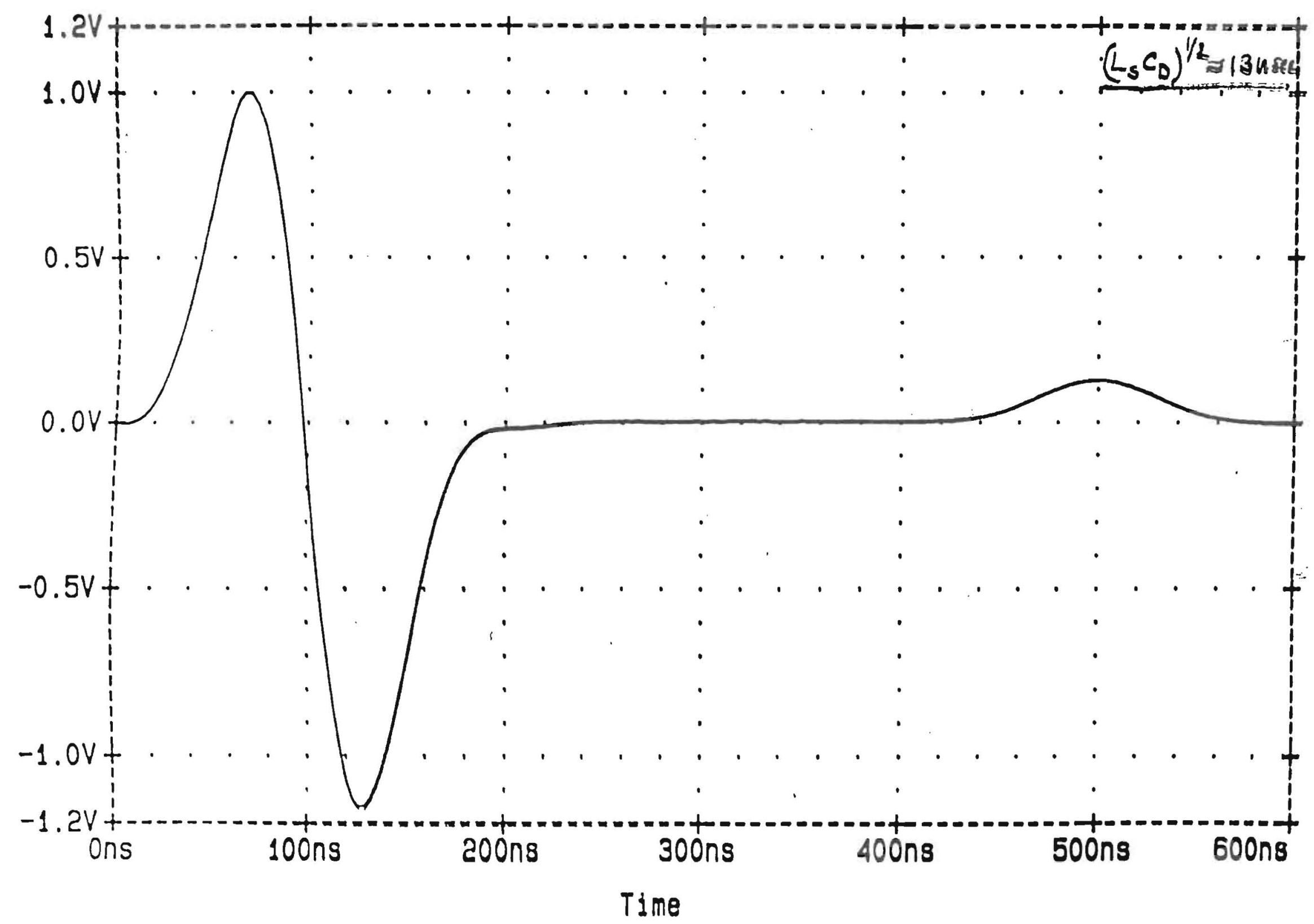

Pileup-noise integral $I_{2 p}=80$ niec 


\section{Scope of Task Force on Electronics, Triggering, and Data Acquisition at the SSC}

Front-End VLSI and Systems

from the detector elements to the long data link

Trigger Algorithms and Architectures

prompt and higher-level triggers

Architecture, Data Flow, Event Building, Online Processing, and Data Storage

from the long data link to mass storage

Project Management

including coordination and planning, design tools, and interaction with industry 
Task Force on Electronics, Triggering, and Data Acquisition at the SSC

Steering Committee

$\begin{array}{ll}\text { Ed Barsotti } & \text { FNAL } \\ \text { Bob Downing } & \text { mlinois } \\ \text { Fred Kirsten } & \text { LBL } \\ \text { Andy Lankford, Chm. } & \text { SLAC } \\ \text { Jon Thaler } & \text { mlinois } \\ \text { Yoshiyuki Watase } & \text { KEK }\end{array}$


Summary of Some Trigger Issues which Impact Electronics on the Calorimeters

TRIGGER TOWER DEFINITION

DEFINES FIRST STAGE OF SUMMING

DETERMINES * CABLES: FEEDTHROMGHS, OUTPUT DRIVE POWER

Dynamic range in trigger

AFFECTS POWER

NoIsE

"EquiVALENT NOISE ENERGY PER TRIGGeR LNIT VOLKME" ANALYZE CAREFULLY IN LIGHT OF EVENT PILEUP "PHYSICS" AND IN TERMS OF PHYSICS GOALS OF NOISE

Resolution

SETS REQUIREMENTS ON GAIN TOLERANCES OR CONTROL AND ON AVAILABILITY OF CALIBRATION CONSTANTS TO TRIGGER

TOWER THRESHOLDS IN ENERGY SUMS are Linear gates neEDED? HOW MANY?

Bunch crossing identification DETERMINES TOLERANCES ON CHANNEL-TO-CHANNEL TIMING DIFFERENCES AND AFFECTS CHOICE OF SHAPING TIME

LENGTH OF TRIGGER DECISION

DETERMINES AMOUNT OF FRONT-END BUFFERING REQUIRED. 
ARE THRESHOLD NEEDED BEFOrE I SMMMNG TOWERS? TO REDUCE EFFECTS OF NOISE AND PILEUP. AT WHAT STAGE ARE THRESHOLDS NEEDED? DIFFICULT IN ANALOG SUMS BECAME OF SWITCHING NOISE.

Digital vs. Analog DIGITAL ADVANTAGES

WELL - DEFINED SYNCHRONIZATION BASED ON CLOCK EASY TO APPLY THRESHOLDS, WRIGHTS: CALIBRATION CAN PERFORM MATH TRANSFORMS

DIGITAL DISADVANTAGES

REQUIRES HIGHER BANDWIDTH

digital bits changing every it used

vs. analog signals changing at $\gtrsim 100 \mathrm{xsec}$.

POWER REQUIREMENTS

For DIGITIZATION, ARITHMETIC, DATA TRANSFER WHEN TO GO FROM ANALOG TO DIGITAL?

Identifying Associated Beam Crossing

HOW WILL THIS BE DONE?

WITH WHAT GRANULARITY?

AT WHAT TRIGGER LEVEL?

IS IT POSSIBLE TO ALLOW SOME AMBIGUITY AT LOWEST LEV EA

WHAT ADDITIONAL COLORIMETRIC CRITERIA CAN BE DEVELOPED IN THE MICROPROCESSOR FARM?

MORE THAN IN THE PAST, SEGMENTATION, CALIBRATION, AND RESOLUTION MUST BE AVAILABLE TO PROMPT TRIGGErS REFINING ELECTRON ID POSSIBLE.

SELECT AND COMBINE CRITERIA. 
Towers va. Clustering

eeg.: Dळ 1st LeveL uses towers (pipeline processor) $C D F$ Lever 2 uses clustering (iterative processor)

What is THE BEST ALGORITMM AT EACH LEVEL? What ARE TOWER AAD CIMSTER SIZES?

The Danger of LeVels

CHOOSE COMPATIBLE SETS OF CRITERIA AT ALL LEVELS, IN WHICH EVENTS WHICH WOULD BE SELECTED BY A HIGHER LEVEL SHOULD ALSO BE SELECTED BY LOWER LEVELS.

$\Rightarrow$ SIMILAR CLUSTER DEFINITION AT ALL LEVELS

Centralized Logic va. Local, Distributed Logic

CAN WE acheNE a REDMCTION IN BANDWIDTH (AND HENCE IN POWER AND CABLES) BY DOING LOCAL PROCESSING?

NOTE THAT THE TRIGGER IS COMPOSED OF LOCAL CRITERIA AND OF GLOBAL CRITERIA COMPOSED OF LOCAL CRITERIA. ON THE OTHER HAND, BOUNDARY EFFECTS MUST BE HANDLES SOMEHOW BY LOCAL LOGIC.

Massively Parallel Architecture

A trigger processOR (simple) for eVERY tOWER, EACH EXAMINING THE HYPOTHESIS THAT IT IS THE CENTER OF LOCALIZED ENERGY DEPOSITION AND MEASURING THE PARAMETERS OF THE DEPOSITION. EMPLOY THE FULL GRANULARITY? "NEURAL NET" -LIKE APPROACH? 
Transporting DATA to the trigGer

ACHEIVE BANDWIDTH WITHOUT GIVING UP INFO $375 \mathrm{~K}$ chan $\times 2$ bytes/chan EACH 16 used $\Rightarrow 47 \mathrm{TByte} / \mathrm{sec}$ DEFINE TRIGGER TOWERS

WHAT IS THE PHYSICS PURPOSE OF GRANULARITY? eT SEPARATION, bY:

TRANSVERSE SHOWER SIZE

POSITION RESOLUTION TO RESECT OVERLAPS ISOLATION CRITERIA

$W \rightarrow g \bar{E}$ MASS RESOLUTION

AT WHICH TRIGGER LEVELS CAN WE AFFORD TO GIVE LP GRANULARITY?

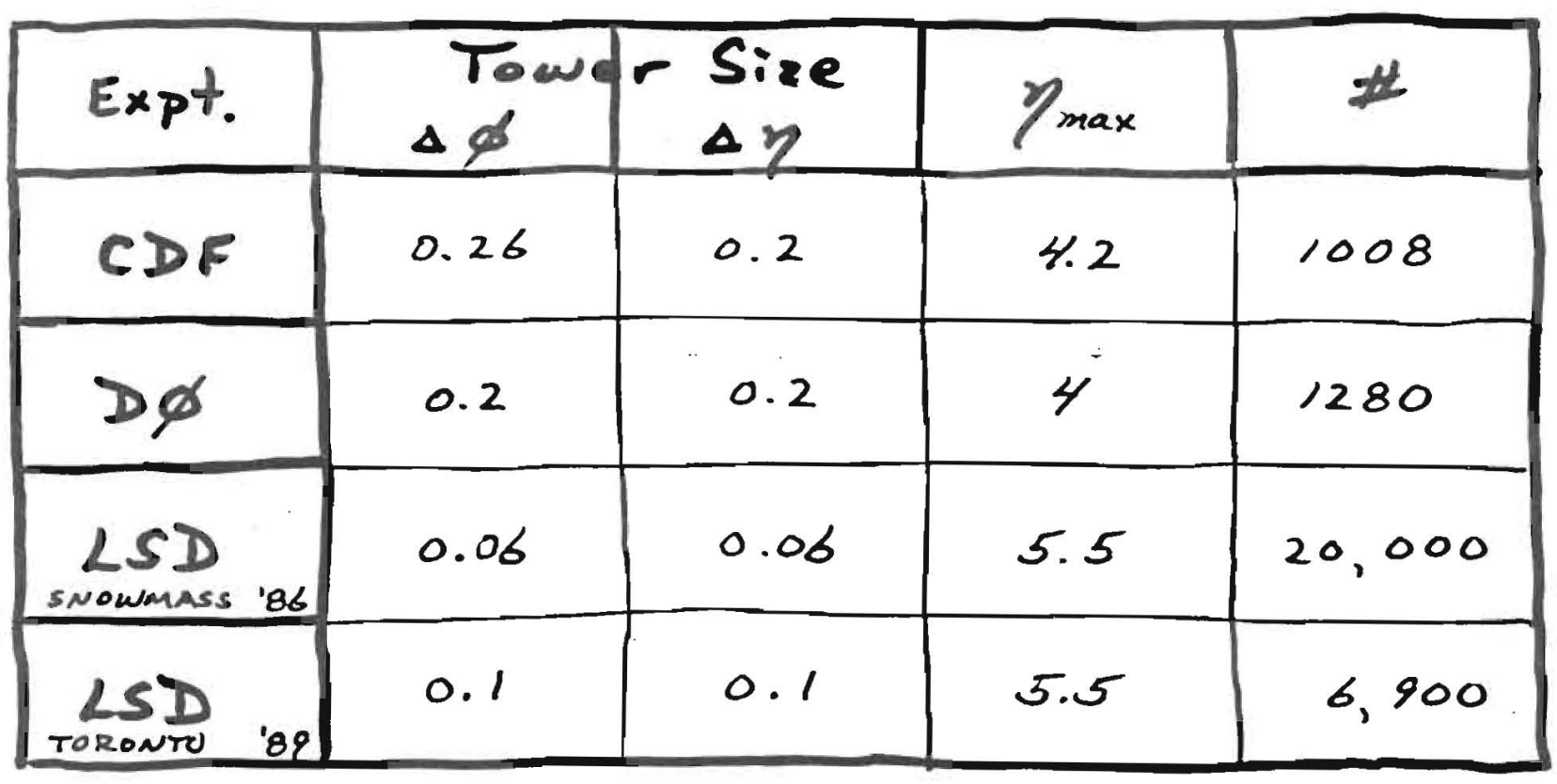

LOCAL SUMMING INTO TRIGGER TOWERS

- PROBABLY ANALOG FOR POWER CONSIDERATIONS

- CALIBRATION AND TIMING

must be sufficiently uniform to preserve resolution BOUNDARY EFFECTS MUST BE CONSIDERED IN DEFINING TOWER SIZES. 
Calorimeter Trigger Block Diagram INPUTS OUTPUTS

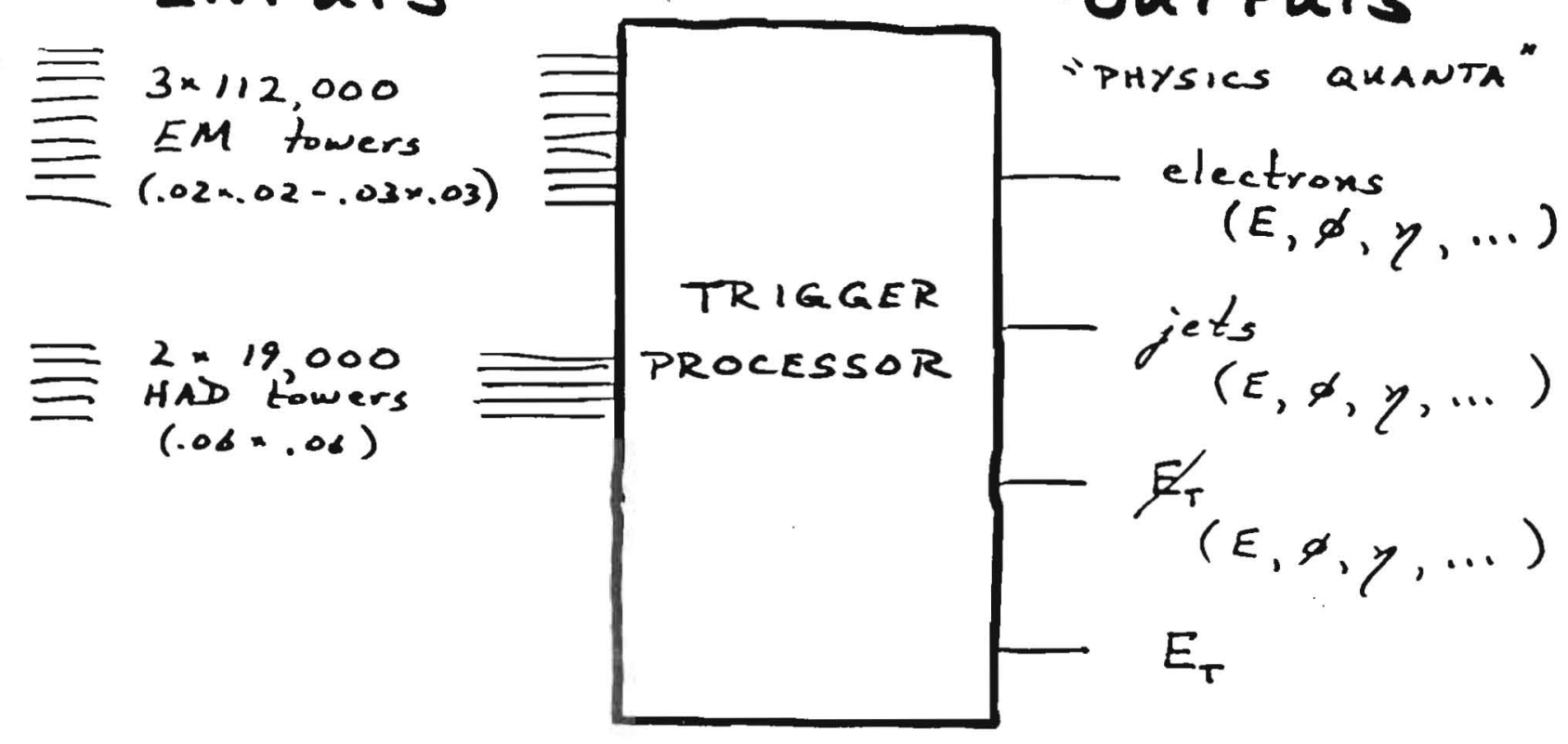

1) Choose an appropriate definition of physics quanta.

2) Mat onto fLEXIBLE processors.

Challenge = How to use the full power of OFFLINE PHYSICS ANALYSIS TECHNIQUES TO ACHIEVE THE DESIRED EVENT FILTERING ONLINE?

Another Challenge = Design trigger processors WHICH IDENTIFY AND MEASURE BASTHYSICS QUANTITIES SO THAT HIGHER LEVEL PROCESSORS CAN SELECT THE DETAILED CRITERIA APPROPRIATE TO CHOSEN PHYSICS PROCESSES. 
Trigger Requirements for Sample Physics Processes from Gilchriese at Toronto Workshop '89

Physics Example

$Q^{*} \rightarrow g Z \rightarrow j e t+Z$

$Q^{*} \rightarrow g g$ (viz change in $\left.d s / 2 E_{T}\right)$

$\left.\begin{array}{l}W^{\prime} \rightarrow \ell^{ \pm} \nu \\ z^{\prime} \rightarrow l^{+} l^{-}\end{array}\right\} \ell=e, \mu$

$H \rightarrow Z z \ell^{+} \ell^{-}$

$\underset{L \rightarrow \text { jets }}{W} \underset{\text { W }}{W} \mathrm{~W}$

$P P \rightarrow H W \longrightarrow \ell_{2}$

$L b E \rightarrow j e t$

$P P \rightarrow \underbrace{\longrightarrow w^{-} t w^{+} \bar{t}}_{\longrightarrow}$

$\Rightarrow$ Measure: $E_{T}, E_{T}$
TRIGGER INGREDIENTS

$E_{T} \geq \operatorname{TeV} \quad(" \mathrm{Z}$ ")

$E_{2} \geq x \operatorname{TeV}$

$\ell^{ \pm}$af $P_{\pi} \geq 100 \mathrm{GeV}$

$l^{+} l^{-}$or " $z^{*}$

$l^{ \pm \omega} \mathrm{PT}_{\mathrm{T}} \geq 50 \mathrm{GeV}$

Fr $\approx 50 \mathrm{GeV}$ (jets)

$F_{T} \geq$ yo GeV

$l^{2}$ wo $T_{T} \geq 20 \mathrm{GeV}$

martinet: of $T_{T} \geq 10 \mathrm{GeV}$

Q. Whf relative $T_{T}>$ i $\mathrm{GeV}$

$2 f^{ \pm} \quad \operatorname{Pr} \approx 40 \mathrm{GeV}$

$E_{T} \geqslant 100 \mathrm{GeV}$

total jet $E_{\tau} \approx 75 \mathrm{GeV}$

(momiltijets $O$ Pr $\gtrsim 20 \mathrm{Ge}$

IDENTIFY, MEASURE, cOUNT: jets, $e^{ \pm}, \mu^{ \pm}, \gamma$ 
Calorimeter Triggers

Colorimetric Energy is basic to ID of physics quant jets, $e^{ \pm}, \mu^{ \pm}, P_{T}$

ET related to $\sqrt{\frac{5}{5}}$ of parton interaction.

Calorimeter triggers are relatively simple to implement. prompt, and require minimal pattern recognition

$\because$ Natural for low.level triggers

TASKS

CALCULATE GLOBAL ENERGY-RELATED QUANTITIES e.g.: $E_{T}, E_{T}$

IDENTIFY LOCAL ENERGY DEPOSITION e.g.: em showers, jets 


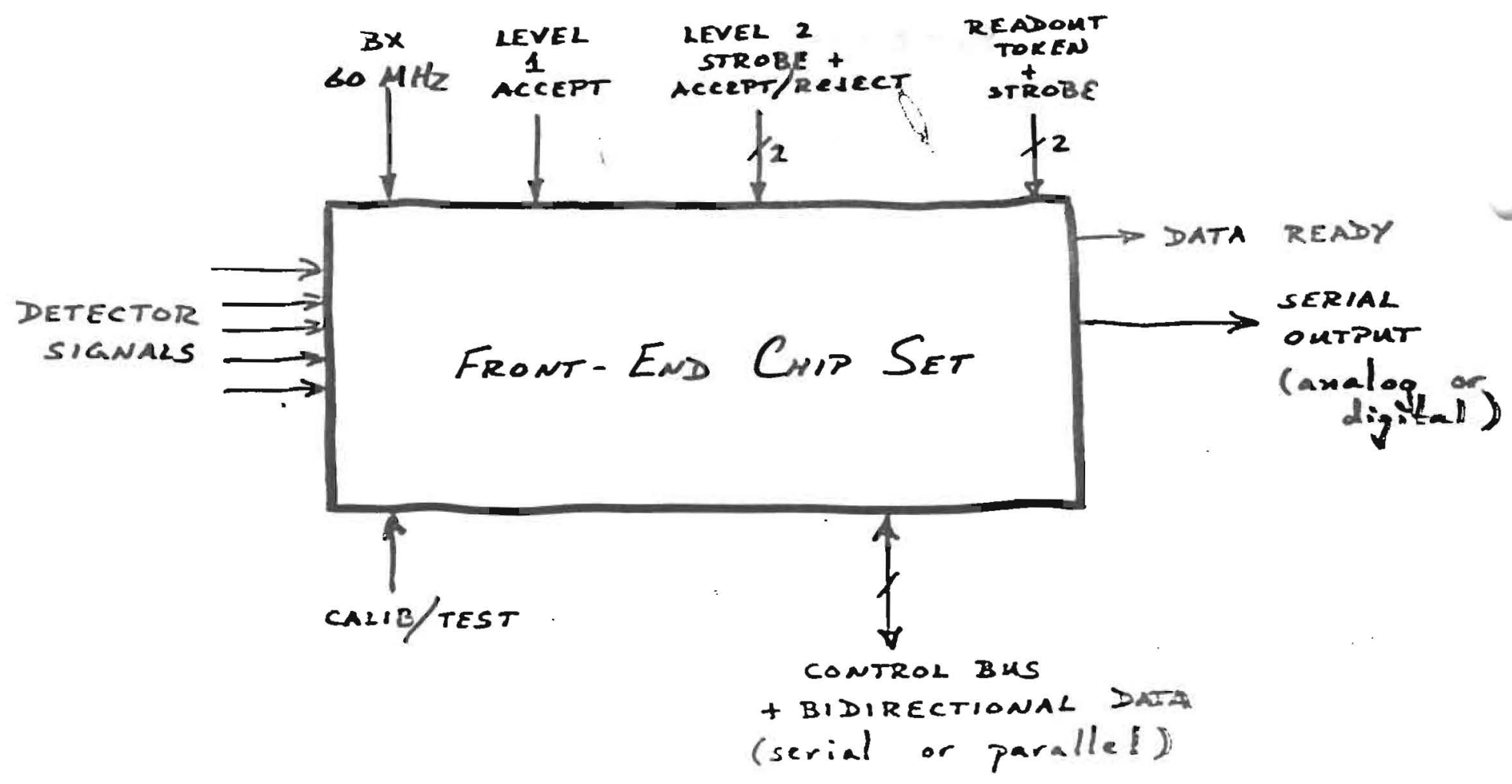

A LOGICAL "GROUP" OF CHANNELS HILL DE CONTROLLD BY CUSTOM VLSI.

THE GROUP MAY LOOK VERY MUCH THE SAME AS THIS TO TIE HIGHER LEVEL OF CONTROL.

NOTE THAT THERE IS A NON-NEGKGEIIELE AMOUNT OF POWER IN CLOCK DRIVERS. 
WhY PUT ELECTRONICS ON THE DETECTOR?

COMPELLING REASONS

IMPROVED PERFORMANCE

ELIMINATE CABLES BY MULTIPLEXING saves space, money (Feed threes) increases reliability

DisAdVANTAGES

DIFFICULT TO COOL AND TO TEMPERATURE REGULATE OCCuPIES SPACE

ACCESS IS DIFFICULT (OO EXTREMELY DIFFICULT) PACKAGING CAN BE DIFFICULT

RADIATION IMAGE

Cest:Derowe:

Dato should be sufficiently multiplexed, and if necessary sparse-scamed, ox the detector to reduce the cable plant. Other processing should be dose elsewhere. 


$$
\text { DiGitization + MuLtiplexing }
$$

THE DEGREE OF MULTIPLEXING DEPENDS OW: TRIGGER RATE

SPEED OF DIGITIZATION NUMBER OF SAMPLES PER CHANNEL EX: $\quad \angle 2=10^{3} \mathrm{~Hz} \Rightarrow 1$ use / event DIGITIZE AT $1 \mathrm{MHZ} \Rightarrow 1000$ SAMPLES 1 SAMPLE/CHANNEL $\Rightarrow 1000$ CHANNELS $(1 / 3 \times 1 / 3)$

DIGITIZATION DYNAMIC RANGE MATCHES BUFFER DIGITIZATION SHOULD PRECEDE ANY LONG DATA LNG $\Rightarrow$ ON OR NEAR DETECTOR

PREPROCESSING

AMPLY CALIBRATION CONSTANTS

WHAT DOES "PNYSICS NOSE" DEMAND writ. PROCESSING? SIGNAL SHAPE CHECKING ?

DE CONVOLUTION?

ZERO-SMPPRESSION - WHAT IS A ZERO?

Is TMERE PROCESSING DEDICATED TO MONITORING PERFORMANCE OR TO CALIBRATION? 
SAmpling + Buffering

DIGITAL vS. ANALOG

ANALOG uSS LESS POWER, by AVOIDING $60 \mathrm{MH} Z$ DIGITIZATION (Is there a low power technique for fast digitization which takes advantage of limited bandwidth of the input signal?

DYNAMIC RANGE OF ANALOG STORAGE

15-16 BITS using MULTIPLE RANGES

DYNAMIC RANGE US. POWER AS FUNCTION OF HAMES

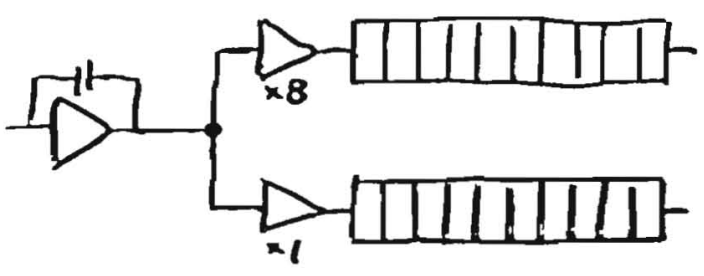

HOW MANY CAMERRATION CONSTANTS ARE REQUIRED?

WHAT I NS THE APPROPRIATE SAMPLING RATE?

116 resect SEEMS THATURAR

(Car we sample slow newly for stow signals without requiring excessive suigmall processing?

CAN DATA BE BUFFERED IN A ZERO-SUPPRESSED FORM? PROBABLY NOT, since

CHANNEL WORLD DE INEFFICIENT IF BUFFER FILLS WHICH IS UNACCEPTABLE FOR CALORIMETER

WHAT IS THE IMPACT OF LONGER DECISION TIMES?

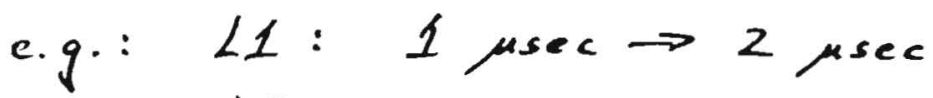

or L2: 10 sec $\rightarrow 100$ pec

IMPACTS POWER BUDGET AMD AREA OF SILICON

SPEED, LOW POWER, RAD haRD, DYNAMic RANGE, Ease of cakibiatioi 


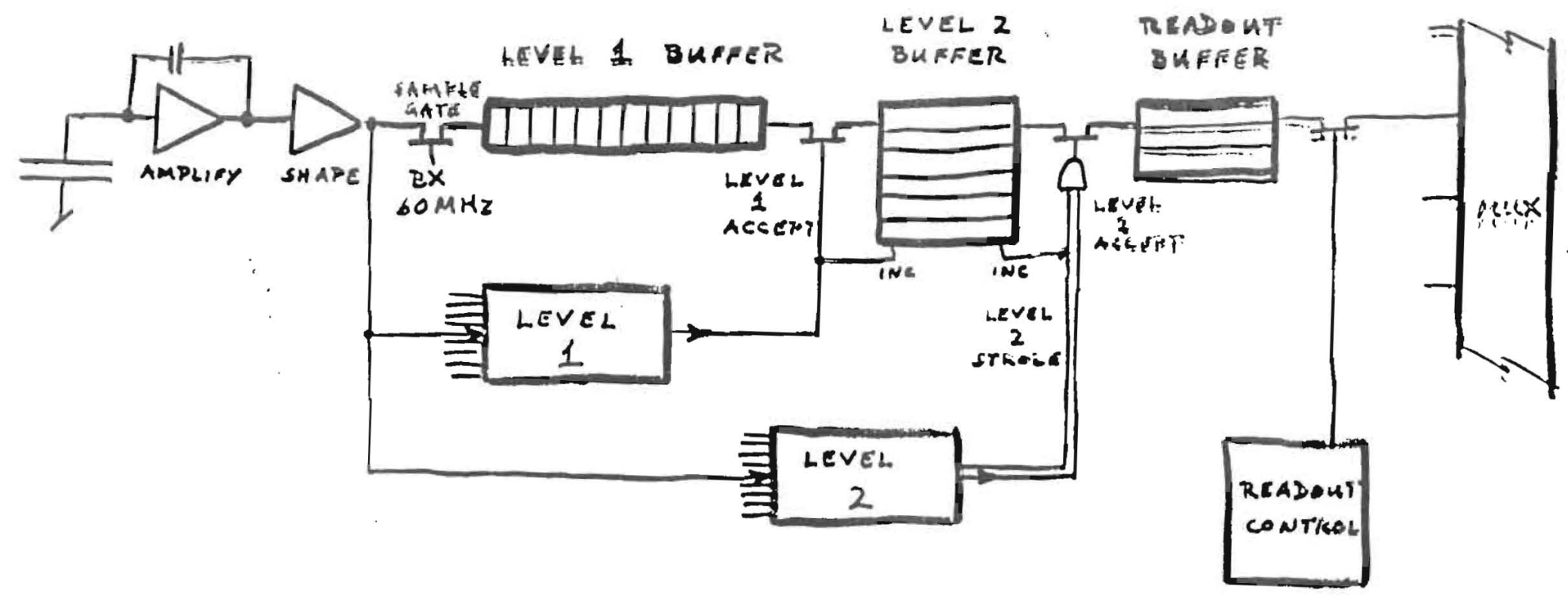

Front. End Electronics Block DiaGram

Data INPUT and OUTPUT ARE NOW SIMULTANEOHS!

THIS ARCHITECTMRE IS CONCEIVABLE; HOWEVER, it is aLSO AMBITIOUS AND CHALLENGING.

FunCTIONS:

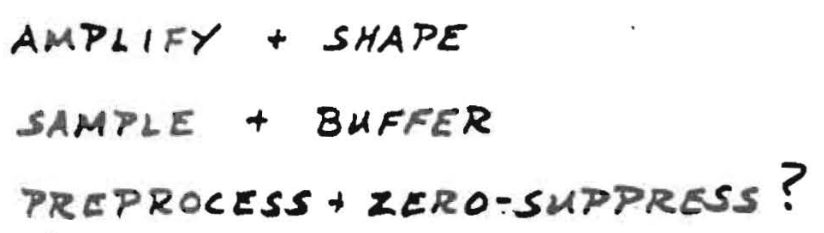

DERIVE A CREDIBLE OVERALL SCHEME TO PERFORM THESE FMNCTIONS. 
HOW MUCH CALORIMETER DATA IS THERE?

CHAnEL COMNT:

$$
\operatorname{Em}\left\{\begin{array}{llll}
0<y<2 & 0.02 \times 0.02 & \times 3 \text { long. neg. } & 188,500 \\
2<y<5.5 & 0.03 \times 0.03 & \times 3 \text { bong .up. } & 146,600 \\
\text { mat } 0<y<5.5 & 0.06 \times 0.06 & \times 2 \text { long. mg. } & \frac{38,500}{373,500}
\end{array}\right.
$$

Occupancy rom nOISE:

$$
\begin{array}{ll}
10 \mathrm{CKT} & \Rightarrow 60 K \text { HITS } \\
26 & \Rightarrow 8.6 K \\
36 & \Rightarrow 0.6 K
\end{array}
$$

OCCUPANCY FROM TRACKS:

100 tracks \& 5 channels each $=0.5 \mathrm{~K}$ mors

e 14 channels $=4 K$

e 20 channels $=2.0 K$

If necessary, data rate can mande MULTIPLE SAMPLES PER CMANUELE. 
Summary of Trigger Rates

Toronto Workshop

DISCUSSED WHAT RATES WERE POSSIBLE INTO AND out of Level 3

InTO:

$10 \mathrm{~GB}$ Bytes/sec $\div$,MByte/evert $=10^{4}$ evert $/ \mathrm{sec}$

From:

$$
\begin{aligned}
100 \mathrm{MB} \text { Bes/sec } \div 0.1-1.0 \mathrm{MBy} \text { te } / e v e x t \\
=10^{2}-10^{3} \text { evexts/sec }
\end{aligned}
$$


Trigger Rates

\begin{tabular}{|c|c|c|c|}
\hline Lacation & Expected Rejection & Expected Output & Acceptable Output \\
\hline Input rate & & $10^{8}$ & \\
\hline Level 1 Output & $10^{3}-10^{4}$ & $10^{4}-10^{5}$ & \\
\hline Level 2 Output & $10^{2}$ & $10^{2}-10^{3}$ & $10^{4}$ \\
\hline Level 3 Output & $10^{2}-10^{3}$ & $1-10$ & $10^{2}-10^{3}$ \\
\hline
\end{tabular}




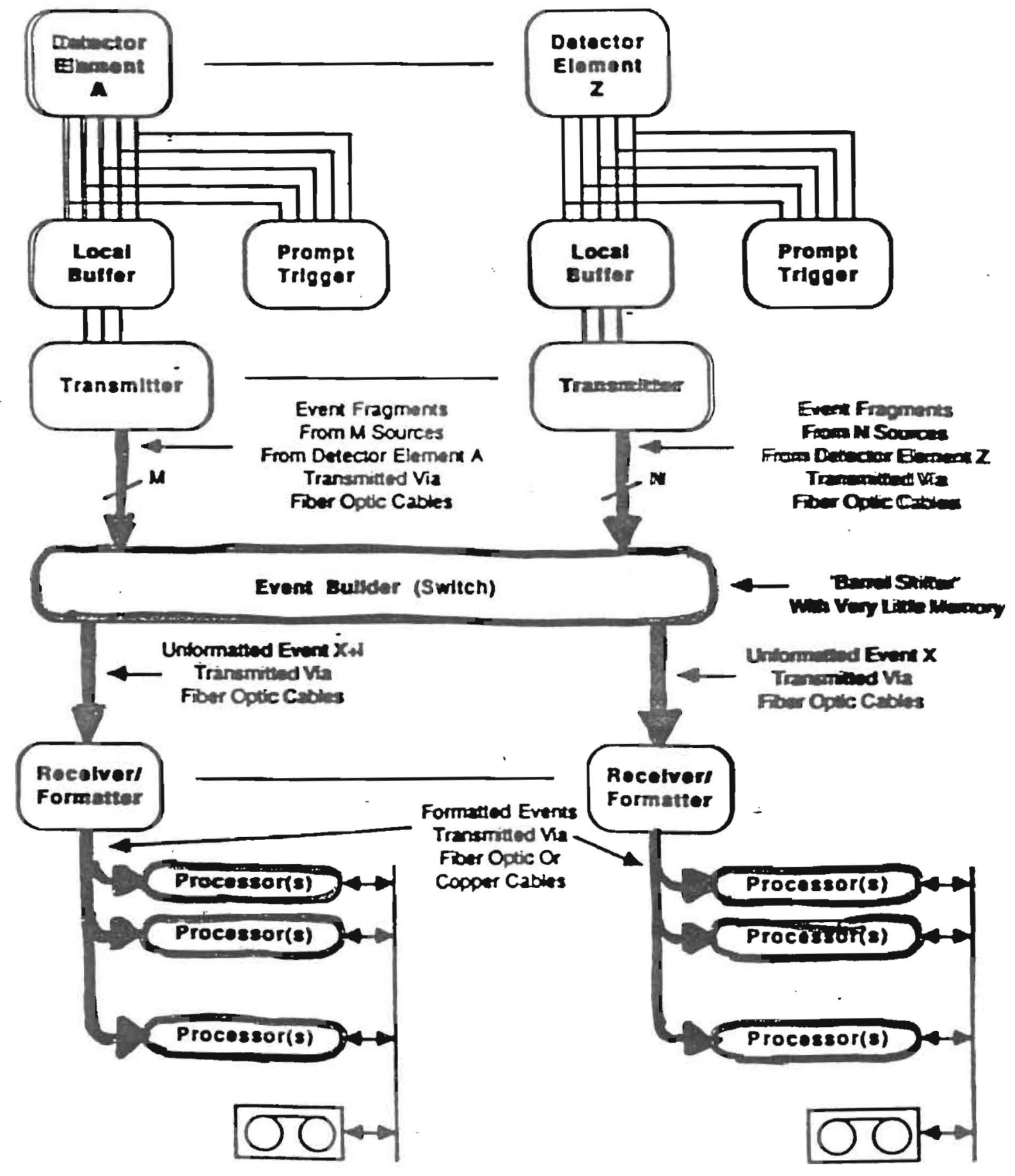

Figure 23: Block diagram of the proposed data-acquisition system. 
Level 3

FULL POWER AND FLEXIBILITY OF GENERAL PURPOSE PROCESSORS

AS muCH AS $10^{6}$ vax-eguiv

based on for instance (2000 * $500 \mathrm{MIP}$ RISC's!

SEE NASH at SNOWMASS 88

Barsotrl at Toronto 89

Gaines at Toronto 89

ENTIRE EVENT and FULL DETECTOR RESOLUTION are available

Store data in processor 
Level 2

MORE TIME AVAILABLE (10-100 ps ec)

but not enough $\sum_{0}, \mu$ 's

REDUCE RATE BEFORE PROCESSOR FARM

SPECIALIZED, AT LEAST SOMEWHAT PROGRAMMABLE PROCESSORS

OPPORTUNITY TO USE TRACKING INFO

AND TO LINK TRACKING TO CALORIMETER

STRATEGY: REJECT AS FAST AS POSSIBLE

... (accept time is irrelevant since Few accepted)

HOW $E V \in R$,

PARALLL TRIGGERS SEARCHING FOR SEVERAL PHYSICS

$\Rightarrow$ MUST WAIT FOR SLOWEST ONE PROCESSES

PROCESSING ... CAN BE ITERATIVE

A PROCESSING TIME CAN DEPEND ON EVENT COMPLEXIoN, egg.: tracks. aFfects tire needed by a shared track processor

DECISION TIME IS VARIABLE?

EVENT ORDER IS PRESERVED?

(by bookkeeping logic in trigger, if necessary)

$\Rightarrow N \in \mathbb{2} 2$ signaLs out

LeVEL 2 strobe

LEVEL 2 ACCETT/REVECT

Store data in "fifo" 
ARCHITECTURE

FAMILIAR

PROBLEM: $10^{6}$ chan $10^{8} \mathrm{~Hz} \longrightarrow 10^{5}-10^{6}$ Bytes $\times$ Sea $\mathrm{Hz}$ REDUCTION OCCURS IN STAGES/ LEVELS

EACH. STAGE REJECTS AN ADDITIONAL FRACTION AFFORDING NEXT STAGE MORE TIME FOR 1 MORE SOPHISTICATED DECISION

QUICK LOOK AT NATURE OF EACH LEVEL OF TRIGGER ALTHOUGH LEVELS IS ARBITRARY

Level 1

As fast as possible to...minimize bufFering of all data PROPAGATION DELAYS $(40+40 \mathrm{~m}) \Rightarrow 1 / 2$ SEC ABSOLUTE MIN. TALK ABOUT 1.2 peC

DECISION EACH 16 rEC af 1 y sec DELAY $\Rightarrow$ PIPELINES PROCESSOR + MUCH PARALLELISM

HARDWARE PROCESSOR BASED ON $C A L+\mu$... (subset of signals) FIXED DECISION TIME! (no conditional branching) STORE DATA IN "PIPELINE" could be DELAY LINE, SHIFT REGISTER, CCD, RING BUFFET. 


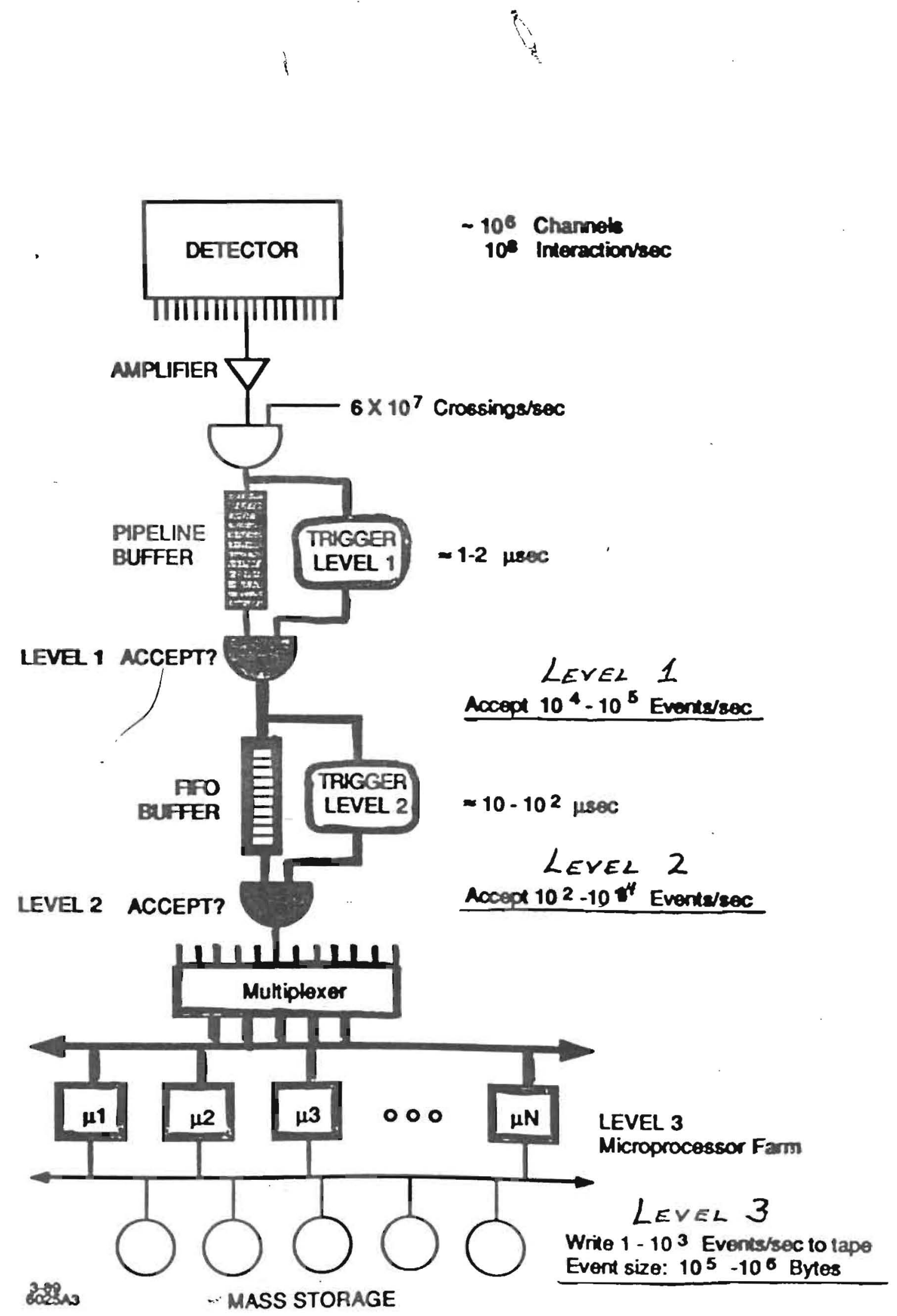


Principal Characteristics -Contd.

7-8 charged PARticles/ unit ?

+ comparable \# of $\gamma^{\prime}$ s

$$
\eta=-\ln (\tan \theta / 2) \quad \text { ipseudo-rapidity }
$$

Detector Coverage $-5.5<\eta<+5.5$

\begin{tabular}{|c|c|}
\hline$\eta$ & $\theta(\mathrm{deg})$ \\
\hline 0 & 90 \\
\hline 1 & 35 \\
\hline 1.64 & 22 \\
\hline 2 & 15 \\
\hline 3 & 6 \\
\hline 5.5 & 0.5 \\
\hline
\end{tabular}

30-40 CHARGED PARTICLES/500 GeV jet

EVENT af 2 jell 2150 cHARGED PARTICLES

i) 4 jets $\sim 200$

Tracking devices dominate event size BECAUSE OF MULTIPLE $(12-100)$ SAMPLES PER TRACK.

In ADDITION, CROSSING AMBIGMITY INCREASES DATA VOLUME egg.: chamber af $100 \mathrm{nsec}$ Drift

6 Wings $\Rightarrow 10$ add'l 1 . events $\Rightarrow 800$ extra tracks.

$200+800=1000$ tracks

$\times 100$ hits/track $=10^{5}$ hits

$\times 4$ bytes $/$ hit $=400$ Kbytes 
Principal Characteristics of the SSC

\begin{tabular}{|l|c|c|}
\hline \multicolumn{1}{|c|}{ SSC } & TEV \\
\hline Luminosity & $10^{33} \mathrm{~cm}^{-2} \mathrm{sec}^{-1}$ & $10^{30}$ \\
\hline Finelastic & $100 \mathrm{mb}$ & 50 \\
\hline Hixteractions/sec & $10^{8}$ & $5 \times 10^{4}$ \\
\hline Trassing & $16 \mathrm{nsec}$ & 3500 \\
\hline interactions/crossing & 1.6 & $1 / 3$ \\
\hline
\end{tabular}

$<$ interactions/crossing $>=1.6$

\begin{tabular}{|c|c|c|}
\hline$N$ & $\mathrm{P}(N) \%$ & $\mathrm{P}(\boldsymbol{N}: \boldsymbol{N}>\mathbf{0}) \%$ \\
\hline 0 & 20 & \\
\hline 1 & 32 & 40 \\
\hline 2 & 26 & 33 \\
\hline 3 & 14 & 17 \\
\hline 4 & 6 & 8 \\
\hline 5 & 2 & 2 \\
\hline
\end{tabular}

$$
\begin{gathered}
\mathrm{P}(N>1)=48 \% \\
\mathrm{P}(N>1: N>0)=60 \%
\end{gathered}
$$

Pileup within crossings, as well as amona crossings. 
Considerations for Scintillation Calorimeters

ReADOUT techNique: PMT'S vs. alternatives INSIDE VS. OUTSIDE MAGNETIC FIELD DYNAMIC RANGE SPEED OF RESPONSE: SIGNAL-TO-NOISE

Signal Processing for uniform response ARRIVAL TIME OF LIGHT VARIES BY ABOUT $30 \mathrm{xSEC}$

Signal Processing for longitudinal deposition TO DISTINGUISH EM AND. HAD COMPONENTS

SIGnal Processing for bunch IDEntification Calibration, incl. of deGRadation of $\lambda$ Attenuation 


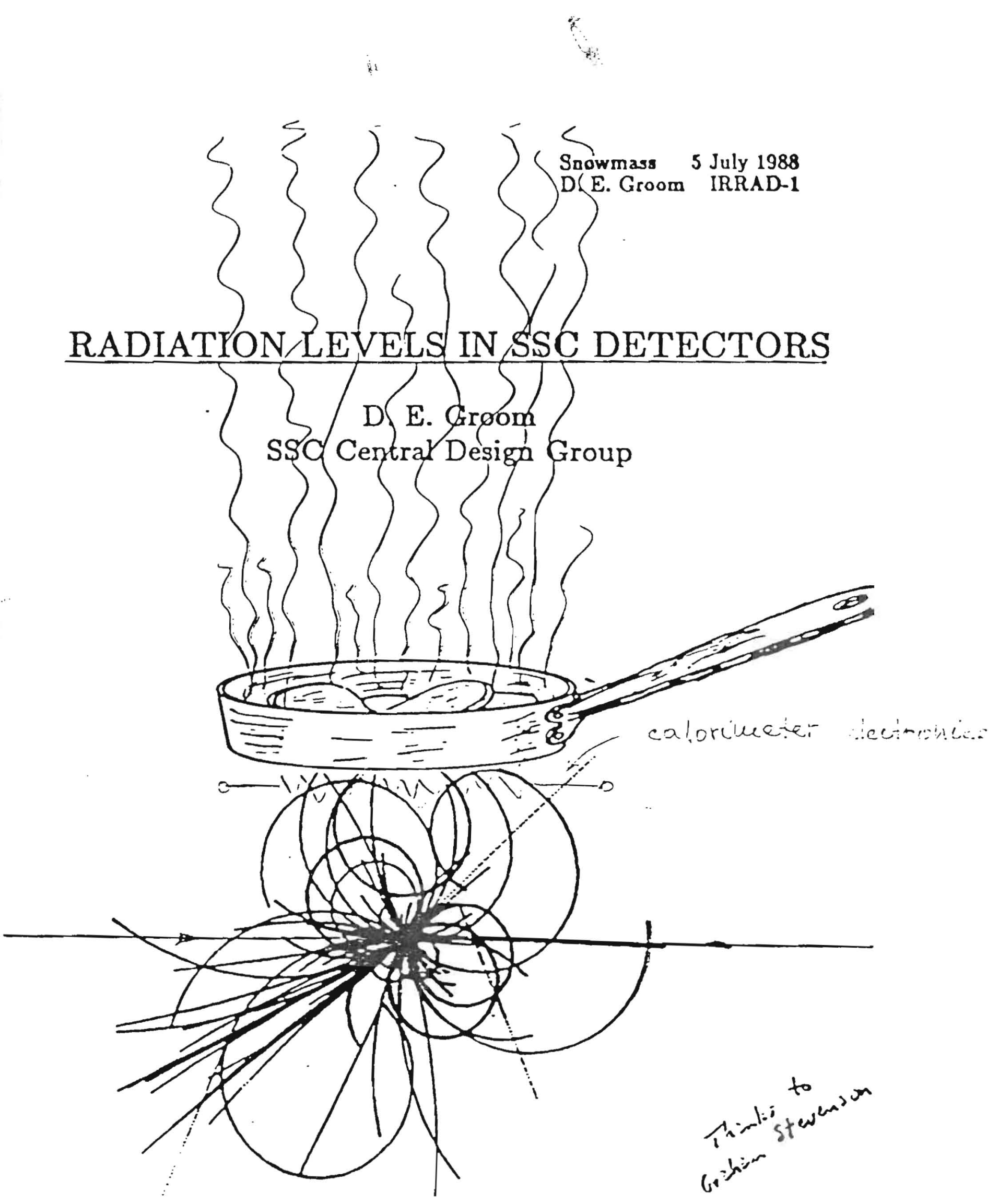


I- FET Preamplifier for Low Temperature Operation

a)
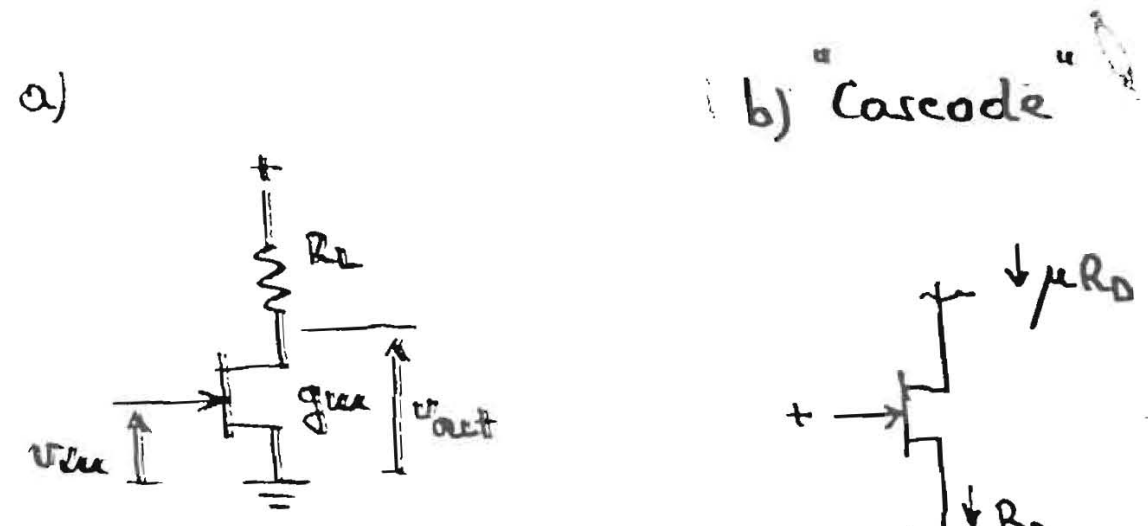

$$
\text { Gail }=y_{k e} \frac{R_{L} R_{D}}{R_{L}+R_{D}}
$$

Both $R_{L}$ and $R_{D}$ too low

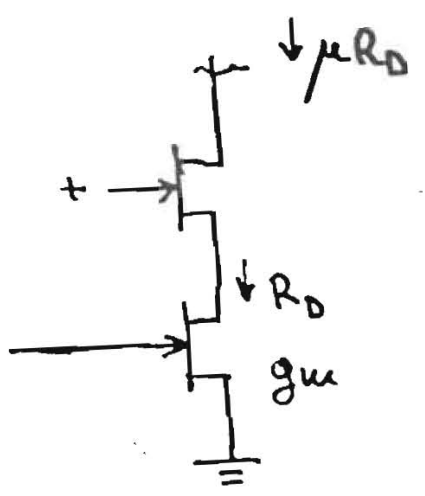

c) "Amplified Lar" resistance"

amplified output

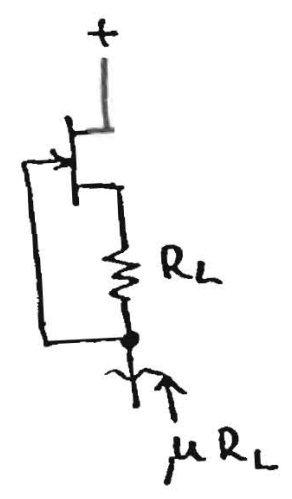

resistance

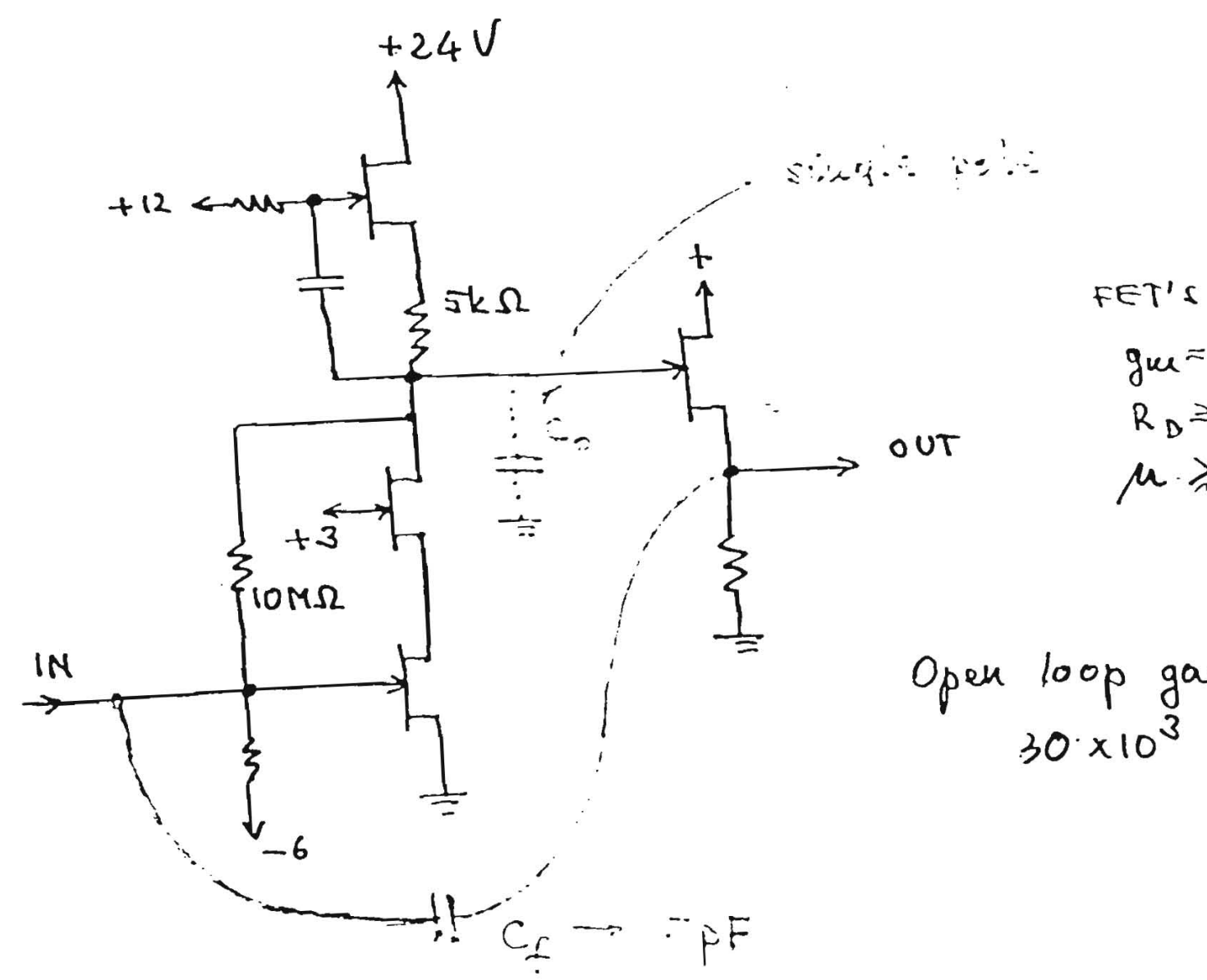

Large dynamic range in calorimeters determines de voltages and power dissipation $(2100 \mathrm{~mW})$

12 
Cold - ALC FET preamplifier

FET Operating temperature $T=150^{\circ} \mathrm{K} \quad\left(110-150^{\circ} \mathrm{K}\right)$ Hermetic enclosure at $85^{\circ} \mathrm{K}$ FET's on higher resistivity si operate at LAr temperature.

Done pole
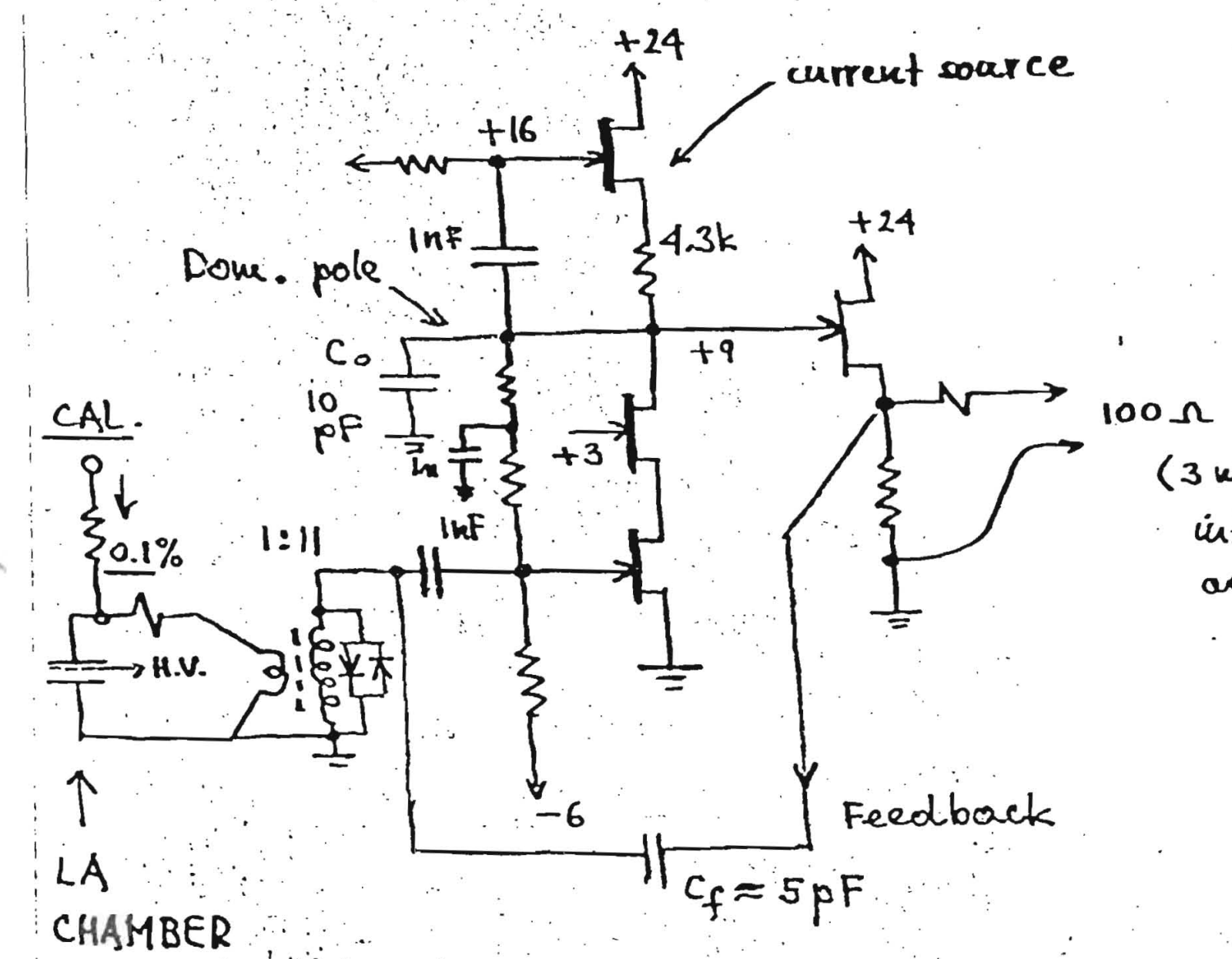

( 3meters to intermediate areepl.).

$C_{D}=3.5 \mathrm{hF} /$ channel

For 576 channels: $c_{\text {tot }} \approx 2 \mu \mathrm{F}$
Max signal: $Q_{s} \approx 2 v \cdot 5 p F \cdot n_{t r}=\frac{I l}{\mathrm{pC}}$ $v_{\text {out }}=2 \mathrm{~V}$.

Dynamic range for file up: $\pm 4 \mathrm{~V}$

Power dissipation: $\approx 100 \mathrm{~mW}$ $10^{5}$ channels $\rightarrow \sim 10 \mathrm{~kW} ! !$

13 In EM cal. at SSC $Q_{\text {star }} \approx 1$ InC

(3-4 ReV electron dis single tower) 
Readout Transistor Capacitance Matching (no transformer!)

Assumptions: Max. mismatch $\frac{C_{D}}{C_{A}} \approx 14$ Noise increase:

$$
\frac{1}{2}\left[\left(\frac{C_{D}}{C_{A}}\right)^{1 / 2}+\left(\frac{C_{A}}{C_{D}}\right)^{1 / 2}\right] \approx 2
$$

Operating conditions for min noise:

$$
F E T\left\{\begin{array}{l}
C_{A} \approx 20 \mathrm{pF}, C_{D} \approx 300 \mathrm{pF} \\
g_{\mathrm{m}} \approx 20 \mathrm{~mA} / \mathrm{V}, V_{D S}=3 \mathrm{~V}, I_{D S}=3 \mathrm{~mA} \times 10 \mathrm{~mW}
\end{array}\right.
$$

Preamplifier with small dynamic range $\vec{P} 30$ ww "targe II $\rightarrow 100 \mathrm{mw}$

Dynamic range: $1 \mathrm{TeV} / 25 \mathrm{MeV}=4 \times 10^{4}$ !

Power dissipation $0.3 \mathrm{kw} / \mathrm{pF}$

For silicon detectors:

$$
\text { For } 300 \mu \mathrm{m} \rightarrow 36 \mathrm{pF} / \mathrm{cm}^{2} \rightarrow 10 \mathrm{kw} / \mathrm{cme}^{2}
$$

( for pixel duets, $\sim 100 \mathrm{kw} / \mathrm{cm}^{2}$

Af $60 \mu \mathrm{f} / \mathrm{m}^{3} \longrightarrow 20 \mathrm{kw} / \mathrm{w}^{3} !$

For Liquids (LA, TMS,TMP) aced gas calorimeters: For $i-c^{3}-C_{\text {min }} \approx 1.5 \mu \mathrm{F} \rightarrow 450 \mathrm{w} / \mathrm{m}^{3}$ For $\sim 300 \mathrm{~m}^{3}: 135 \mathrm{kw} !$

For transformer watching! $P$ oc number of channels $10^{5}$ channels $\rightarrow \sim$ rok 
Snowmass $5 \mathrm{July} 1988$

D. E. Groom IRRAD-26

(a) Typical annual doses (Gr) in the central calorimetry,$G_{y}=100 \mathrm{rads}$

$\frac{\sqrt[3]{3}}{n=10}$

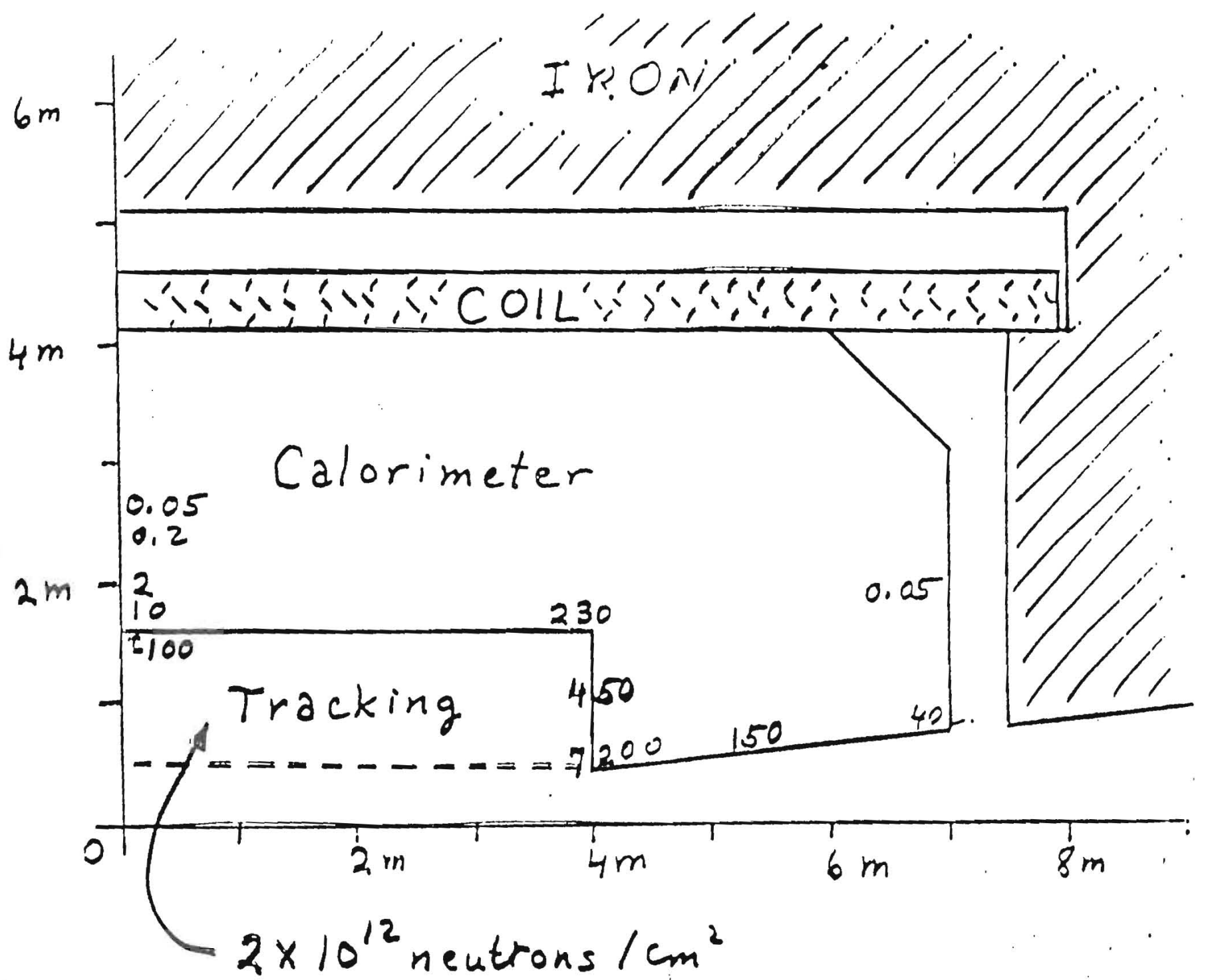




\section{BIPOLAR NEUTRON RESPONSE}
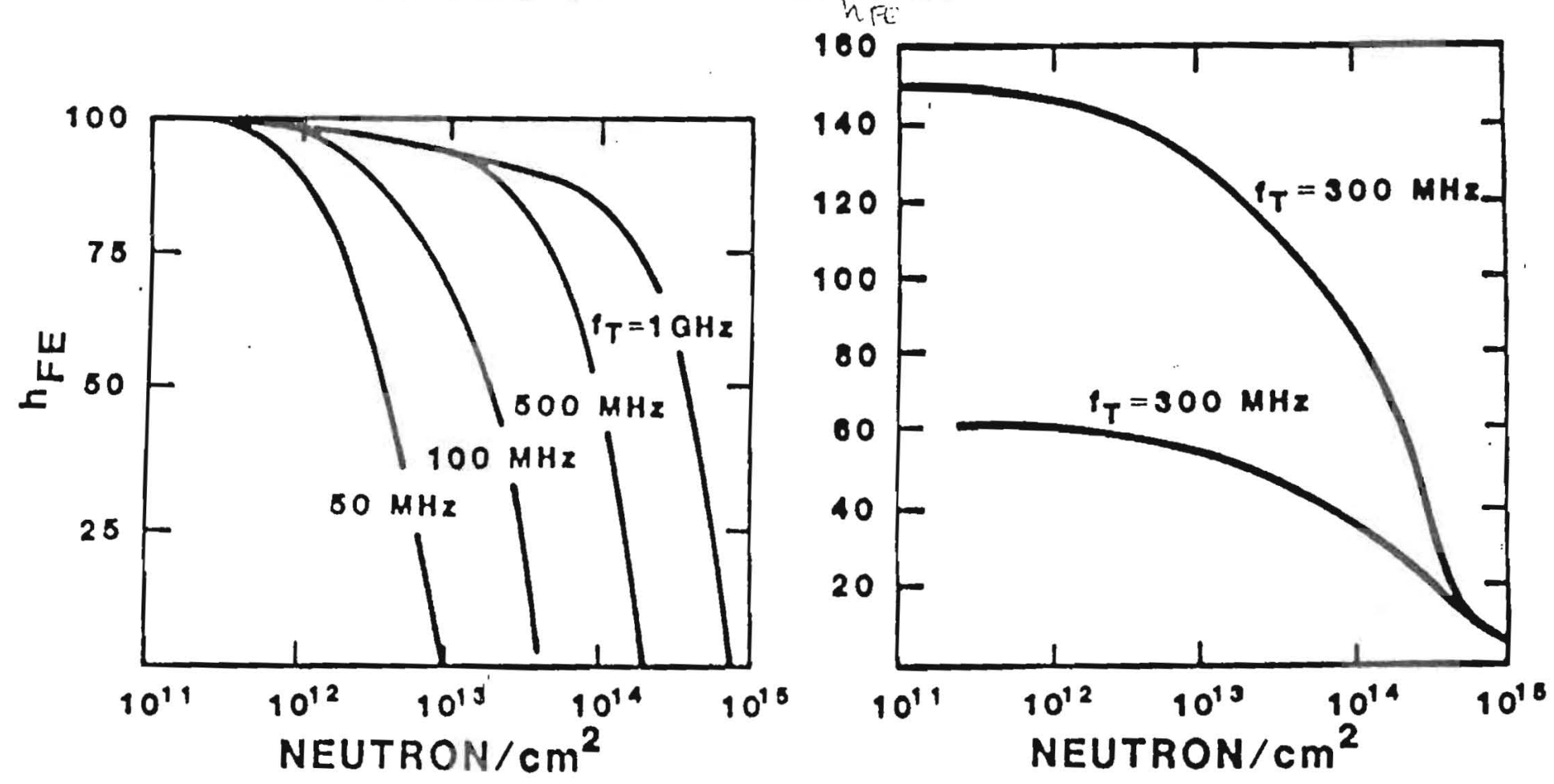

From: (4) DAWTES (nil, itia IA IA 


\section{HARDENED JFET}

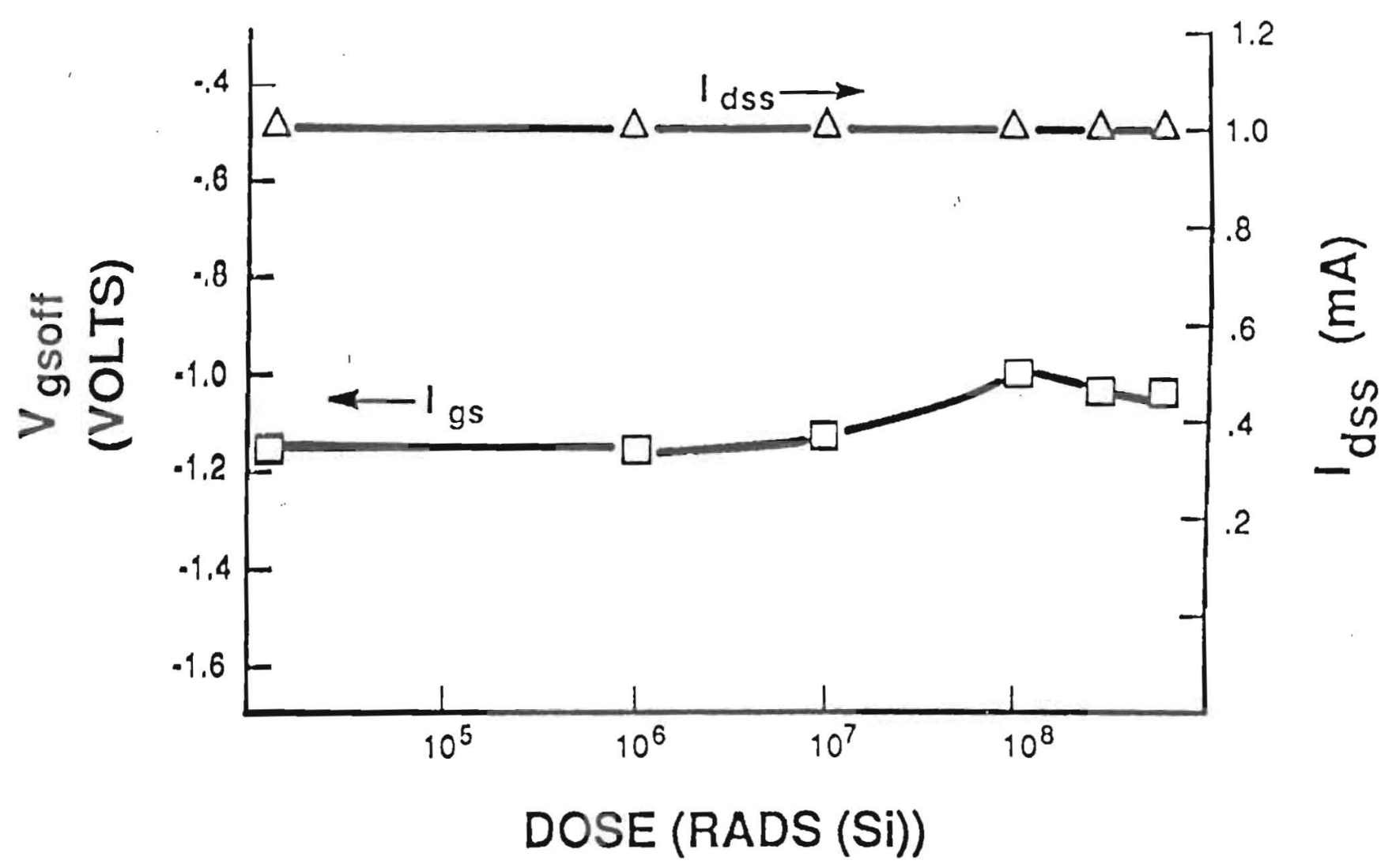

TADO12.08.01

$\Rightarrow$ Frome: W. DAWE, sandia habs. 
1. Trigger sums and noise levels.

2. Dynamic range, moximune signals le EM oud Had:

3. Power dissipation of any proposed solution

4. Segmentation $\rightarrow$ power

5. What electronics where

6. Transformers and protection.

Answers:

1. Any solution should take into account : "Any thing installed in the calorimeter we shall never see again!

2. Quantitative answers essential 


\section{WORKSHOP ON CALORIMETRY \\ FOR THE SUPERCONDUCTING SUPER COLLIDER ROOM ASSIGNMENTS}

MARCH 14-16, TUESDAY, WEDNESDAY, AND THURSDAY

MORNINGS : GROUP

ROOM

Liquid Argon

Scintillaton

Gas

Warm Liquid

Silicon

AFTERNOONS :

Requirements

simulation

Electronics
Birmingham

Central Bank

Logan Young

Mason

Mobile

Birmingham

Central Bank

Mobile 


\section{Agenda for Summary Talks \\ Friday, March 17, 1989}
8:20 - 8:30 Proceedings and Copies of Summary Talks - B. Harms
8:30 - 9:30 Report of the Liquid Argon Group
9:30 - 10:30 Report of the Warm Liquid Group
10:30 - 11:00 Break
11:00 - 11:30 Report of the Silicon Group
11:30 - 1:00 Lunch
1:00 - 2:00 Report of the Scintillating Calorimetry Group
2:00 - 2:30 Report of the Gas Calorimetry Group
2:30 - 3:00 The SSC Experimental Program and Calorimetry - M. Gilchriese
3:00 Adjourn




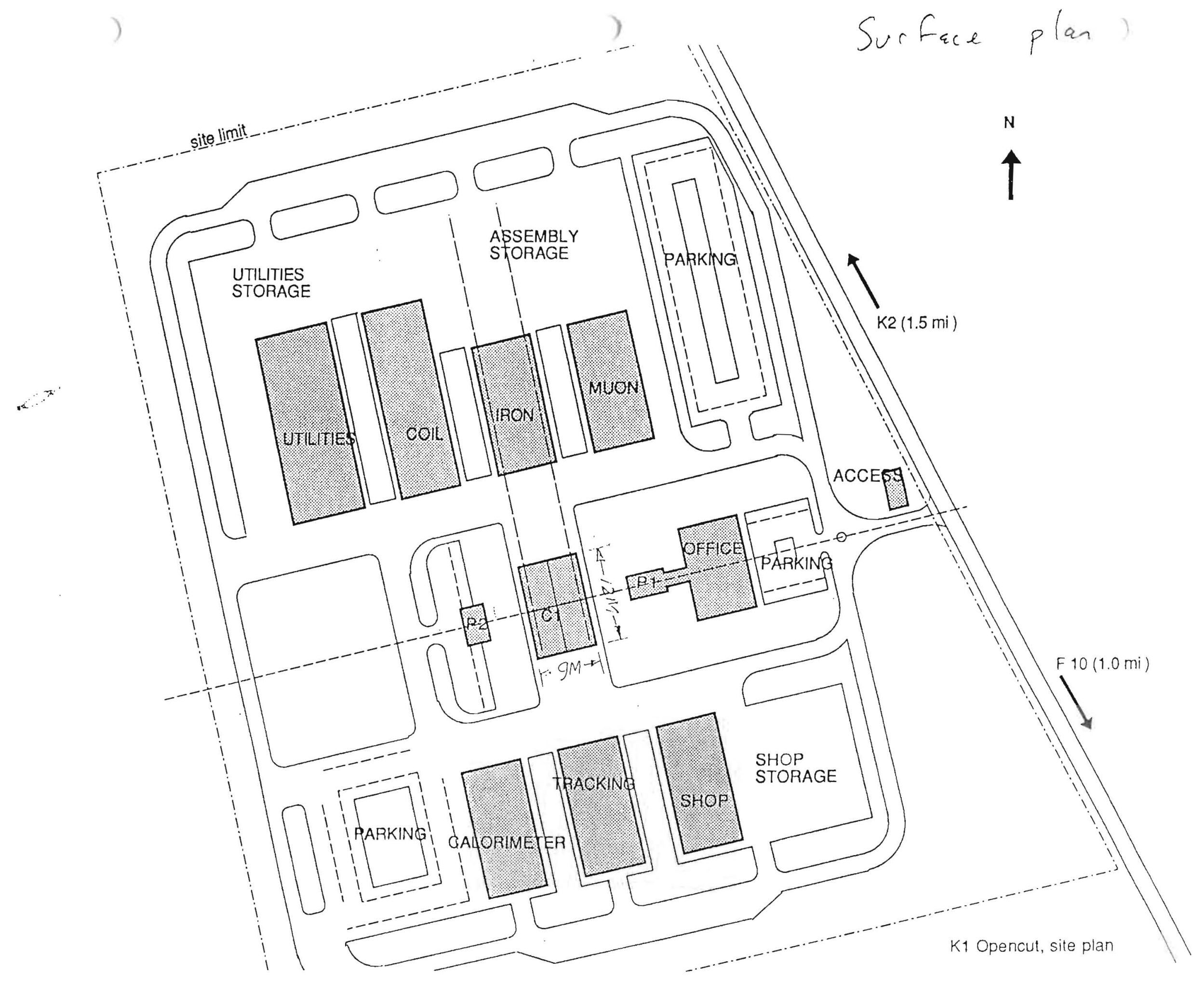




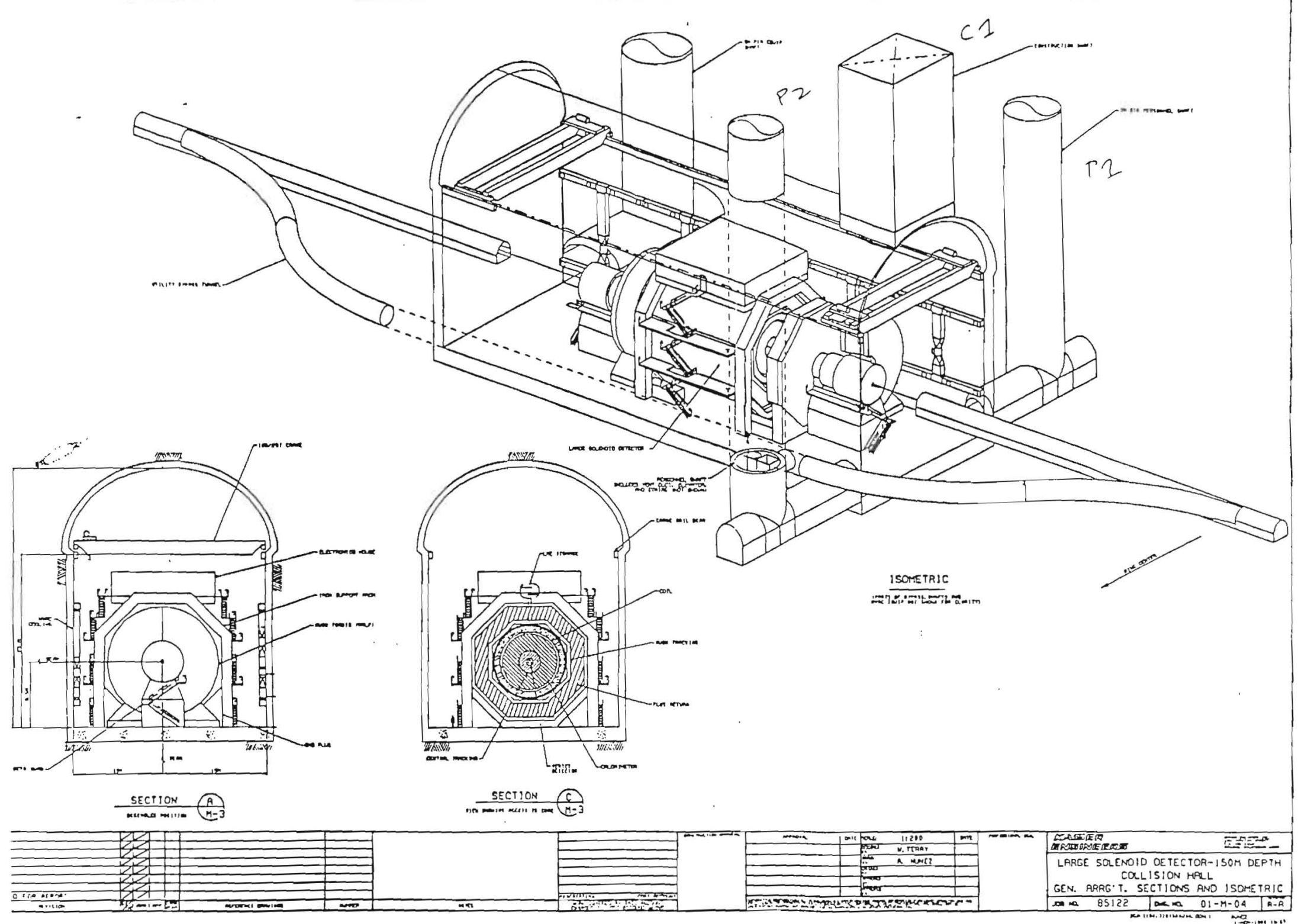




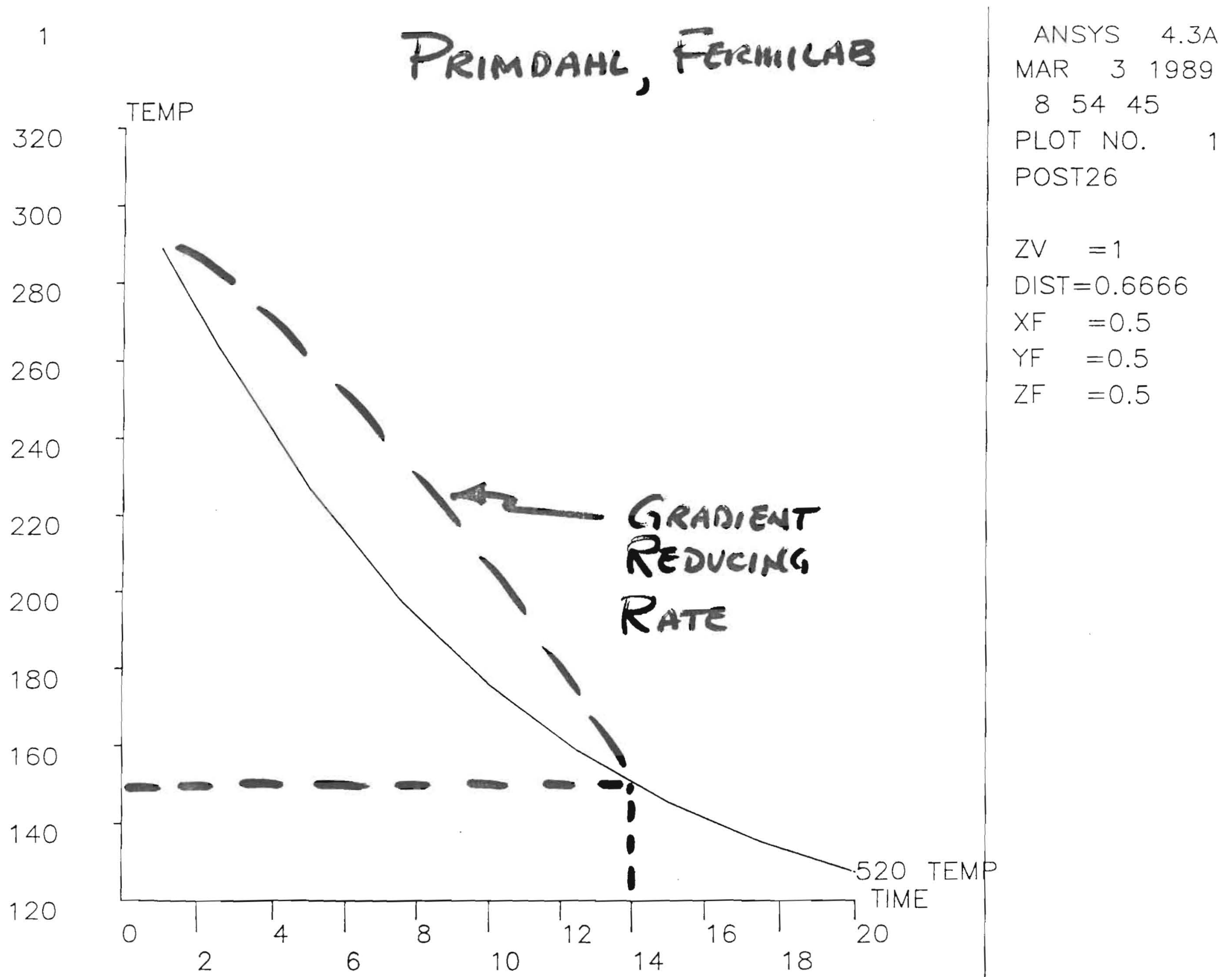

IC SKIN NI TEL. ARGON VAPOR COOL-DOWN 


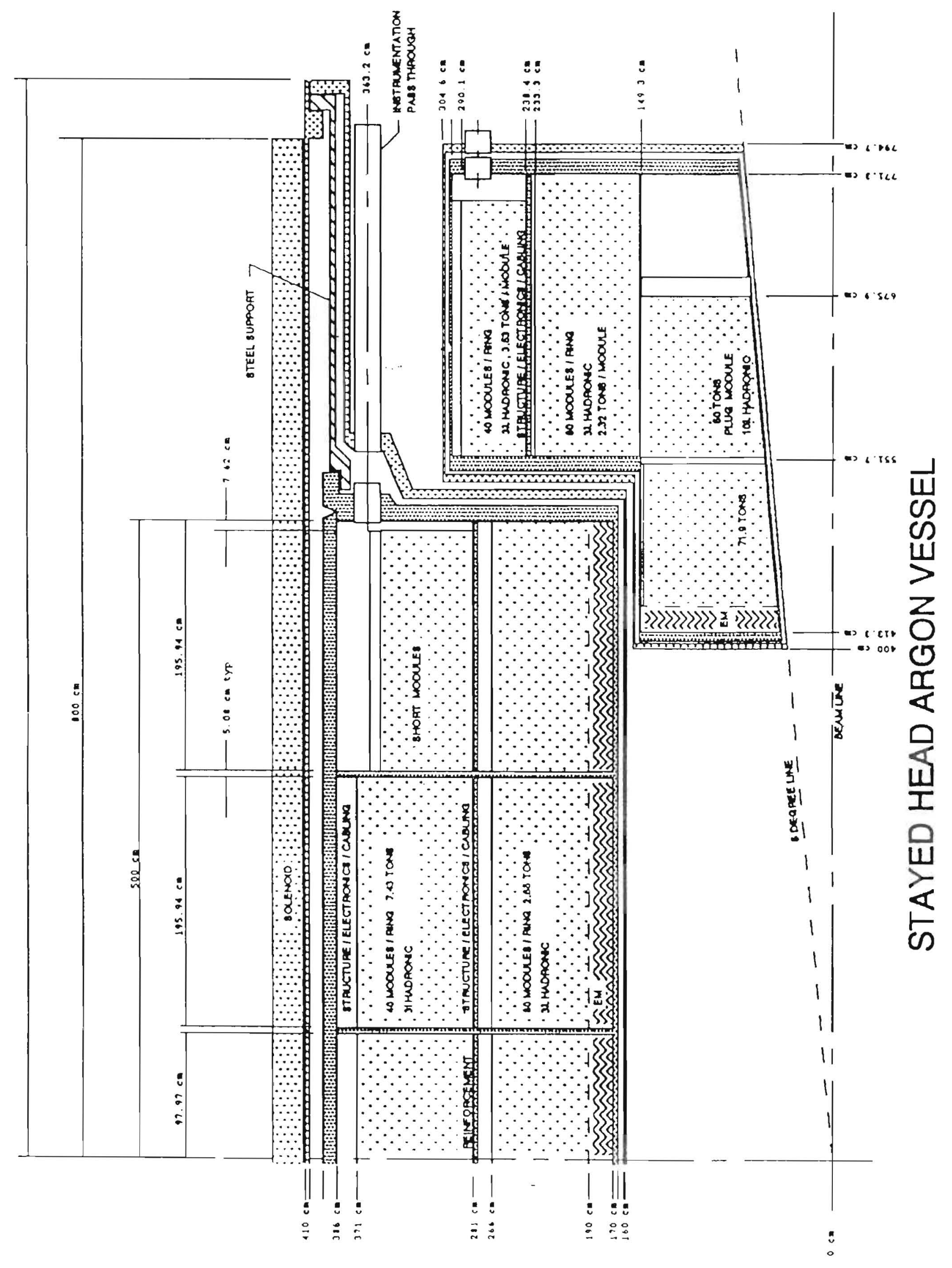


5

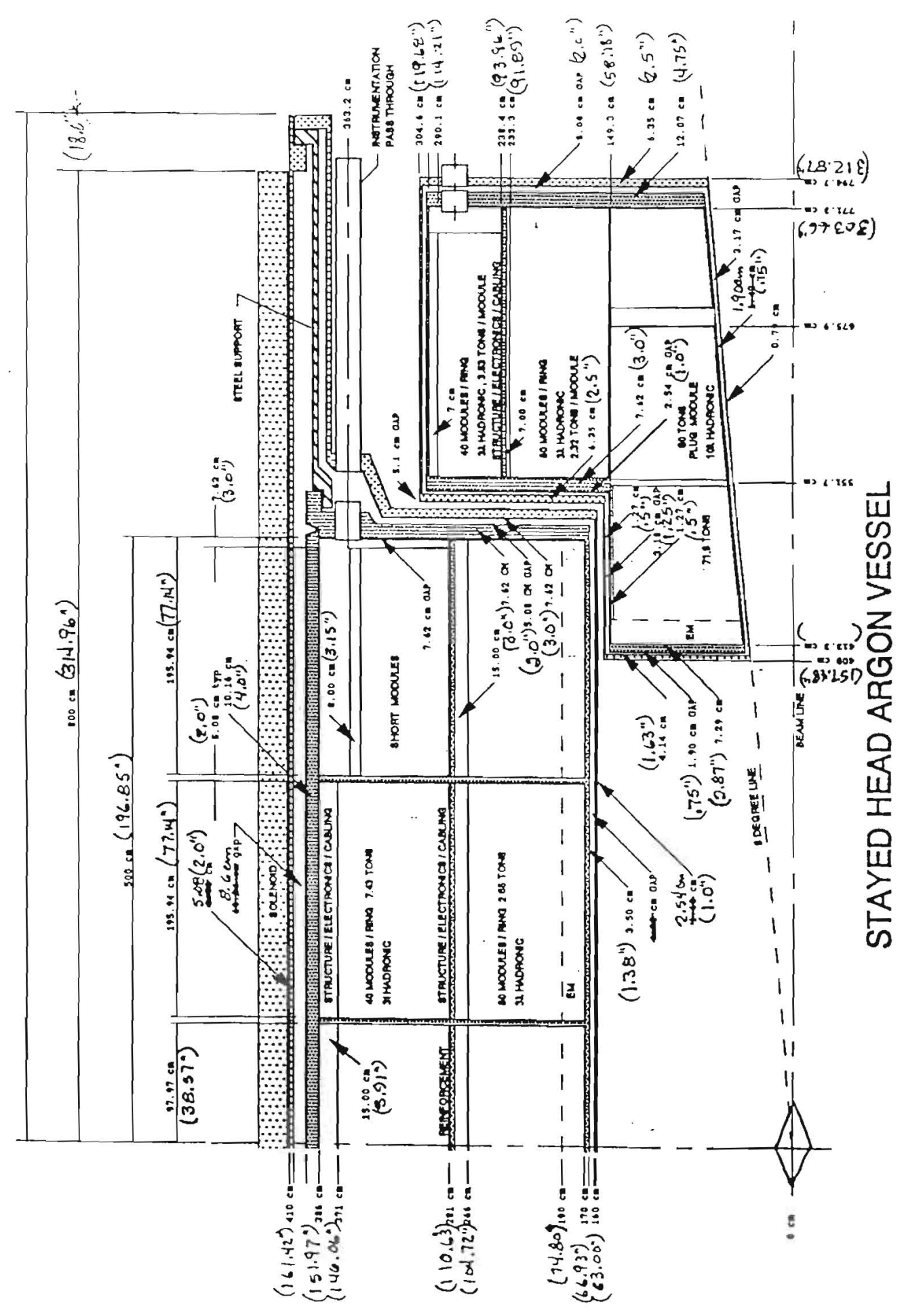



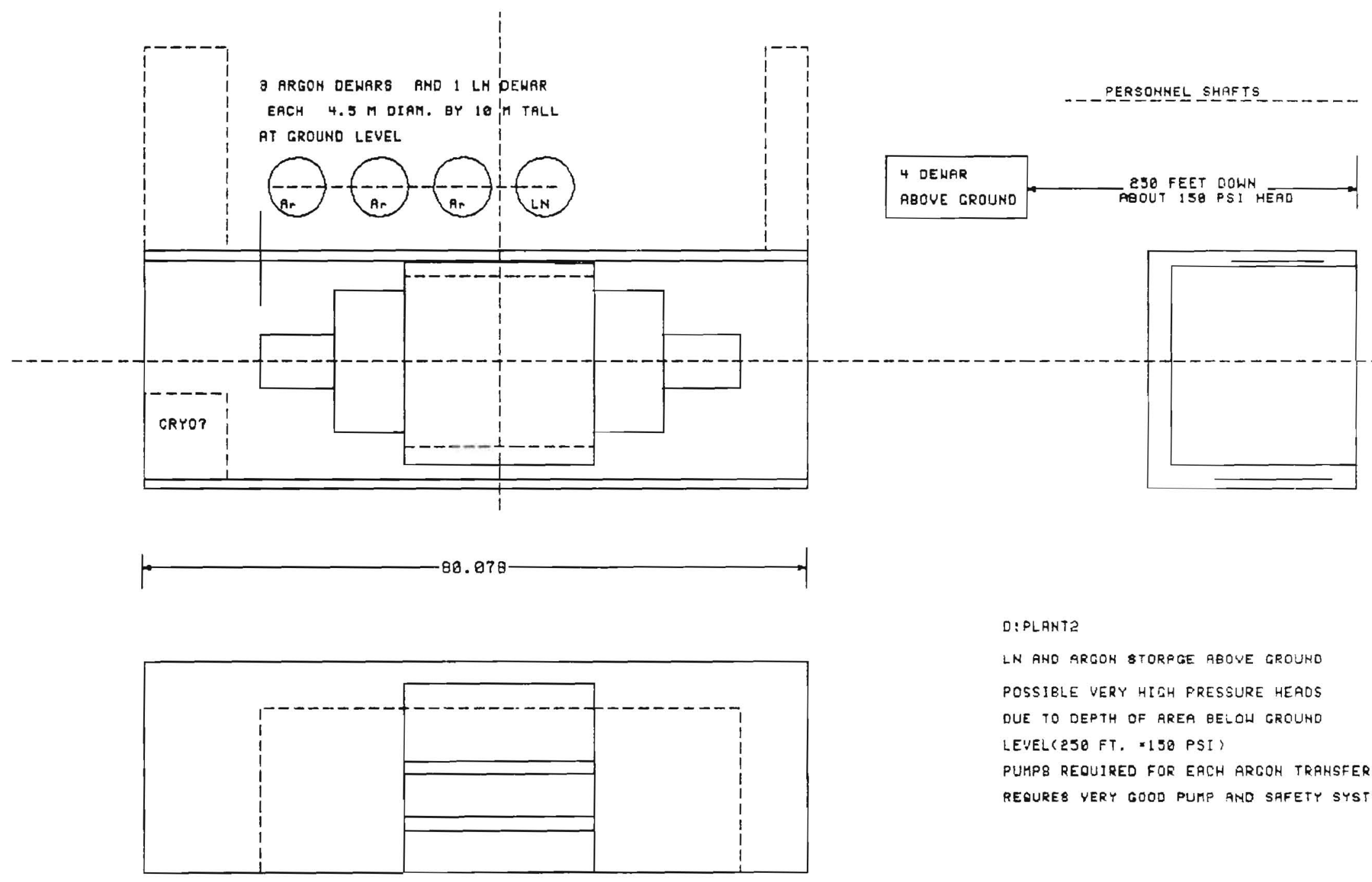

D:PLANT2

LN ANO GRGOH STORPGE RBOVE GROUND

POSSIBLE VERY HICH PRESSURE HEAOS DUE TO DEPTH OF RREA BELOW GROUHD LEVEL (250 FT. ×150 PSI)

PUMPS REQUIRED FOR ERCH RRCOH TRPHSFER REQURES YERY GOOD PUMP AND SAFETY SYSTEM 


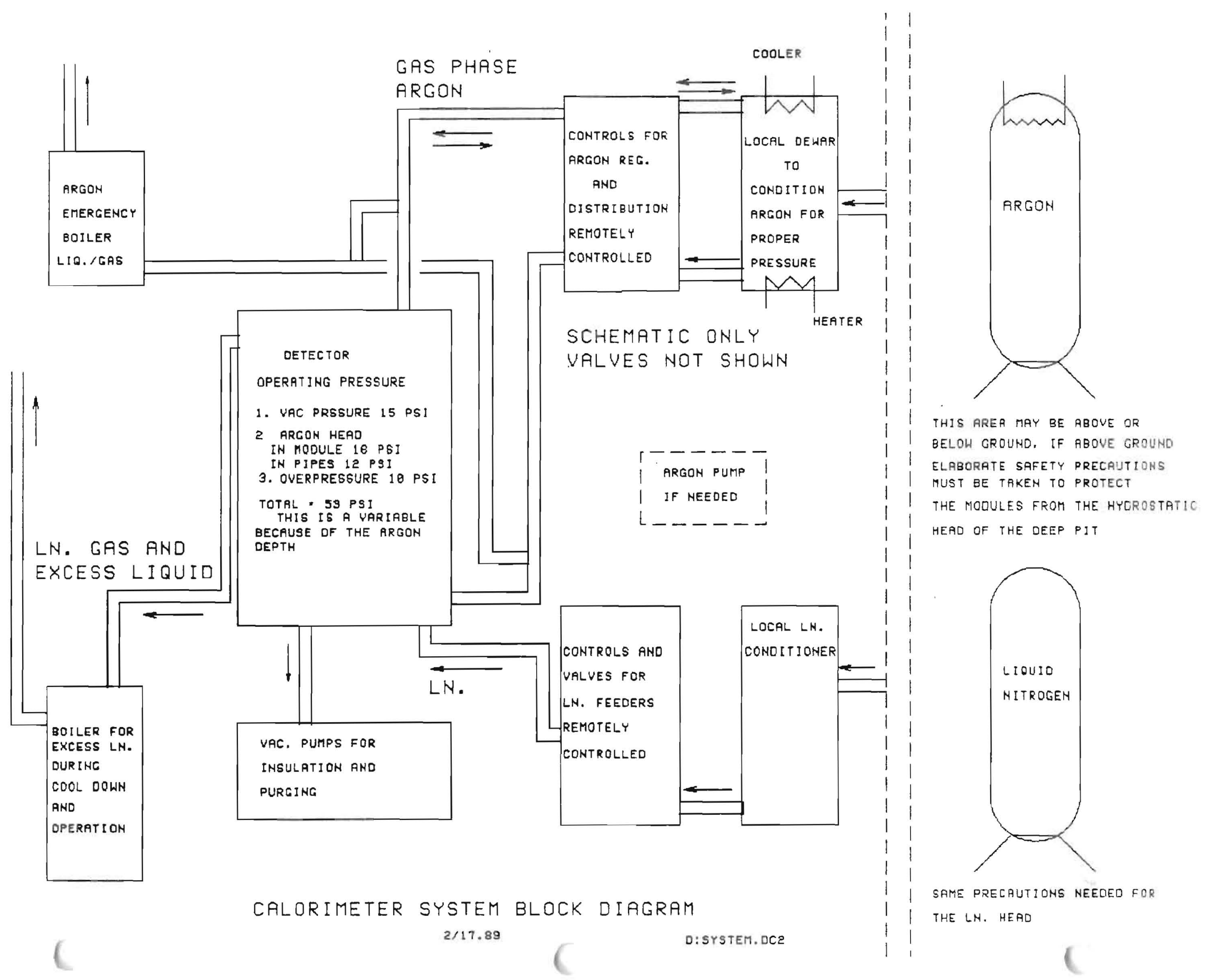


The Spaghetti Calorimeter

(SPACAL)

R. Wigmans

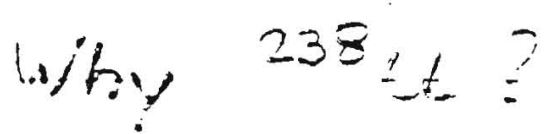

- Iense $\rightarrow$ compar. detectors

- "uatrersating" $\rightarrow$ iet detection te $=$ !)

However:

- Compensaxion NOT unique property ${ }^{23} U$ irer dos: 238 U quarantee $e ! n=! "$

- ACTINE maberial crucial f-u-arbert:

- Many combinations can te made comperisatinx e.g. P/ trart. 


\section{ZEUS Calorimetry - LESSONS FOR THE FUTURE}

DESY 87-Cu! (1987)

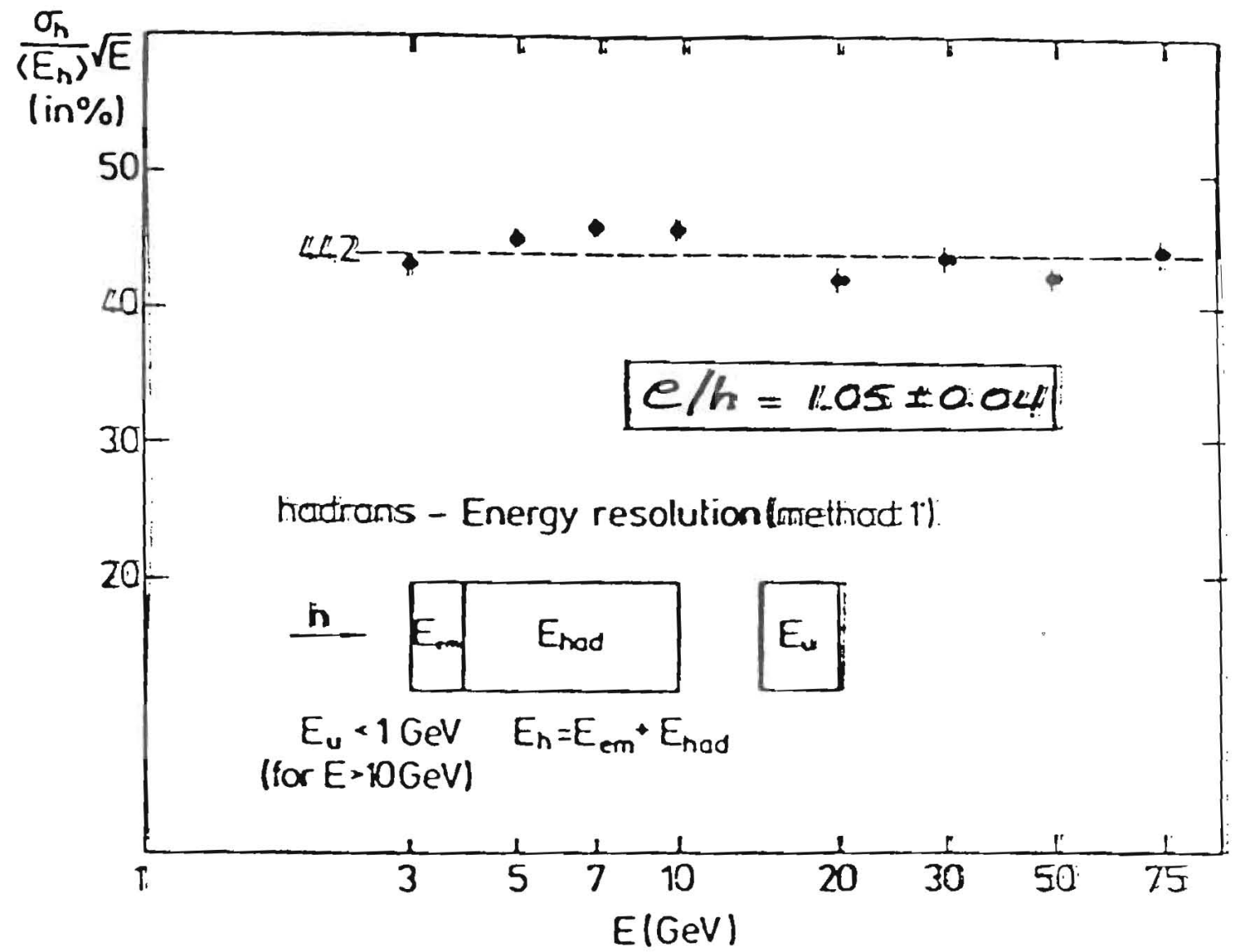

Figure 2

2. The hadronic energy resolution $\sigma / \sqrt{E}$ as a function of $\mathrm{E}$, measured with a $10 \mathrm{~mm}$ $\mathrm{Pb} / 2.5 \mathrm{~mm}$ plastic-scintillator calorimeter. Data from ref. 2. 
COMPENSATING Pb/SCINT CALORIMETRY AT SSE

- Need Pb: scent $\simeq 4: \|$ in volume $\rightarrow \lambda_{\text {eff }}^{\text {int }} \sim 20 \mathrm{~cm}$

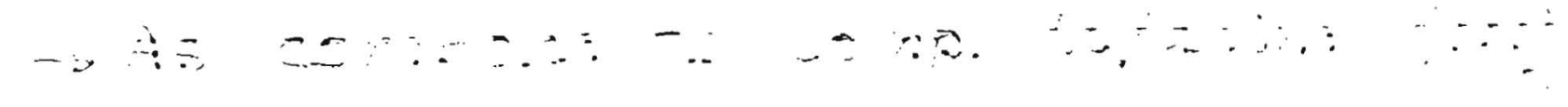

$$
\begin{aligned}
& \text { - } \sigma / E=\sqrt{\left(\sigma_{\text {SAP }} / E\right)^{2}+\left(\sigma_{\text {INTR }} / E\right)^{2}} \\
& \text { - } \because \because \frac{1}{1}
\end{aligned}
$$

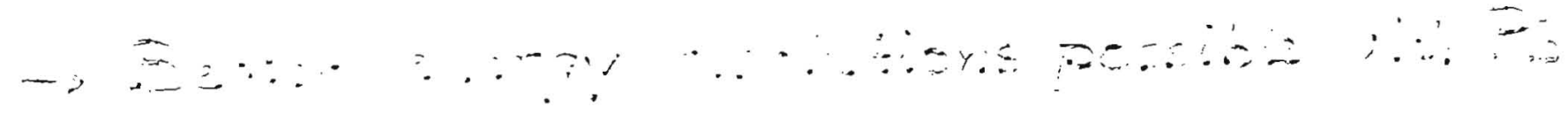

- Time structure compensation

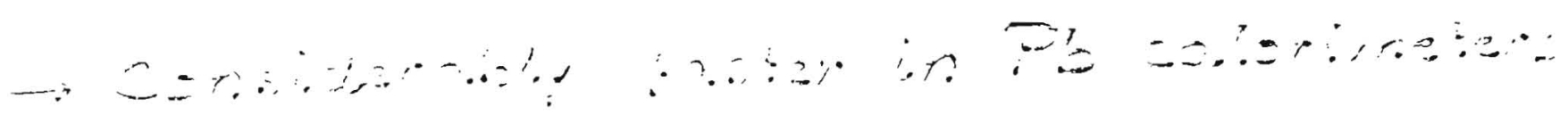

- Neutron production. Pb $\sim 1 / 3 U$ 
MEASUREMENTS COMPENSATING Pb CALORIMETERS

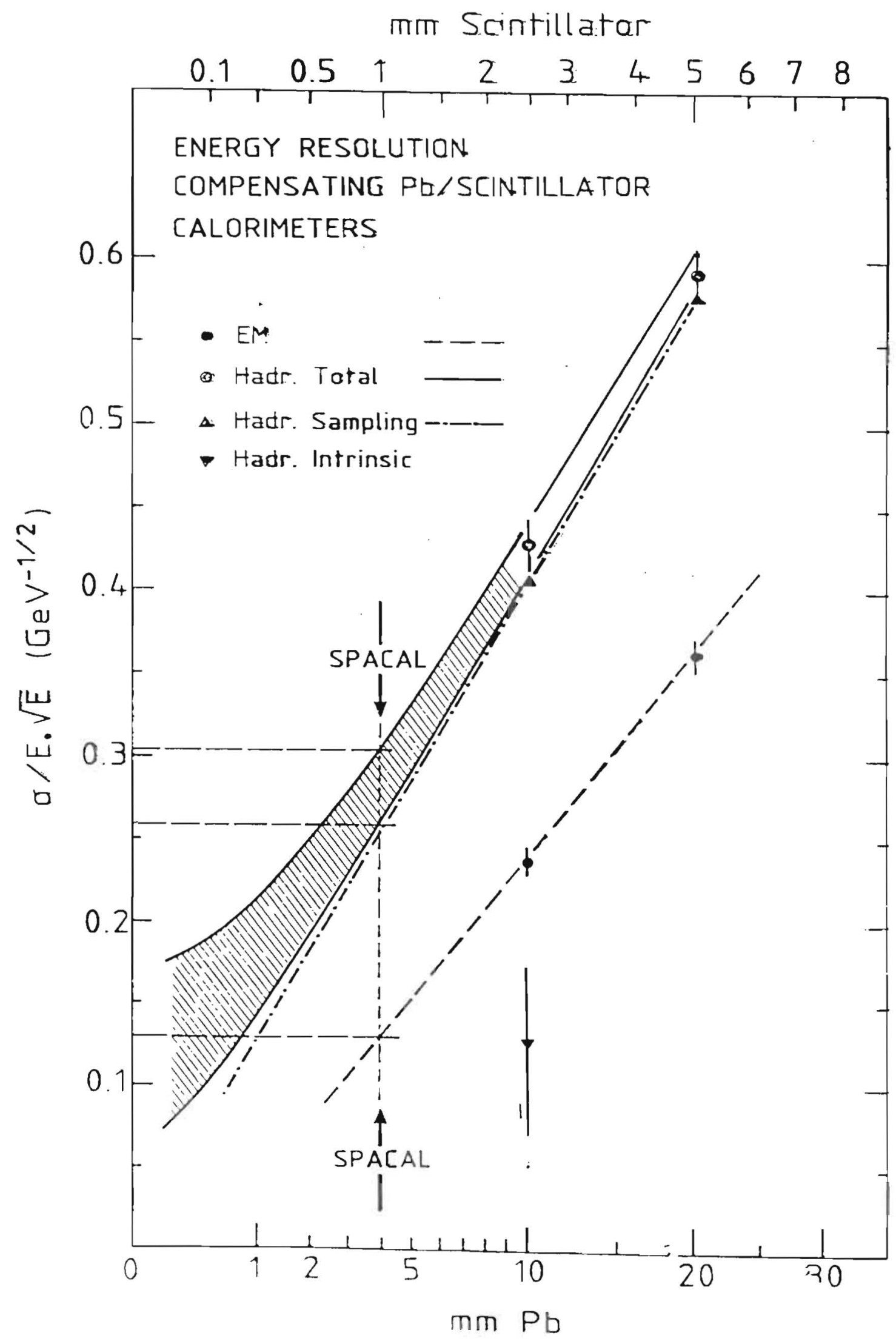


TIME structure compensation (neutron component)

${ }^{238} \mathrm{Cl}=\sim \mathrm{N}$. Gel max produced (most of them at fer Mev)

Neutron contribution to cal signal:

- Clastic scattering $n+p \rightarrow n^{\prime}+p^{\prime}$ Time scale $\sim 10 \mathrm{~ns}$

- new tron capture (ny) $300 \mathrm{MeV} / \mathrm{GeV!}$ Time scale $\sim 0.5$ us $\left(E_{n} \sim \mathrm{eV}\right)$

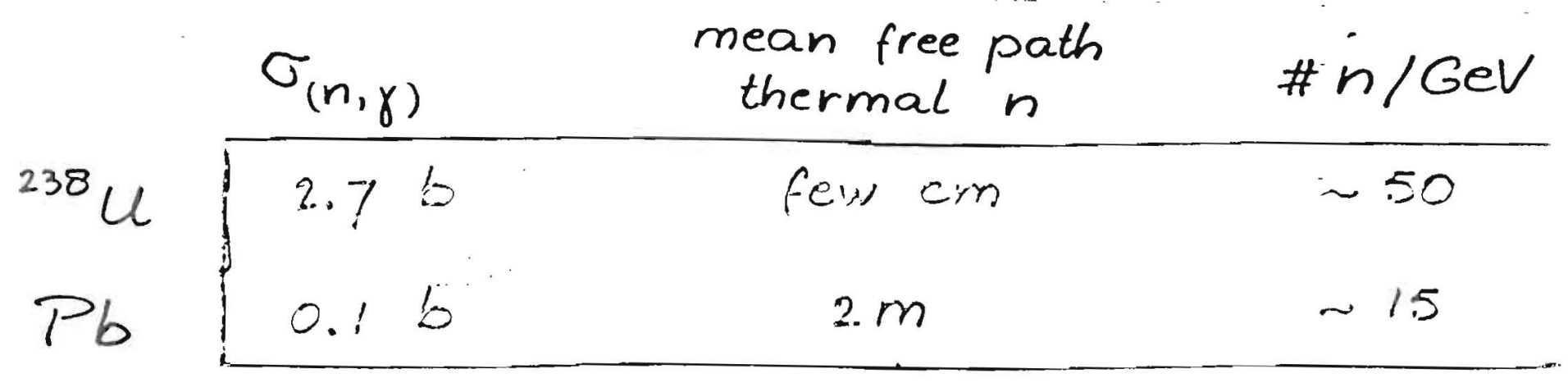




$$
\text { TIME STRUCTERE DALARITETER SIGNALS }
$$

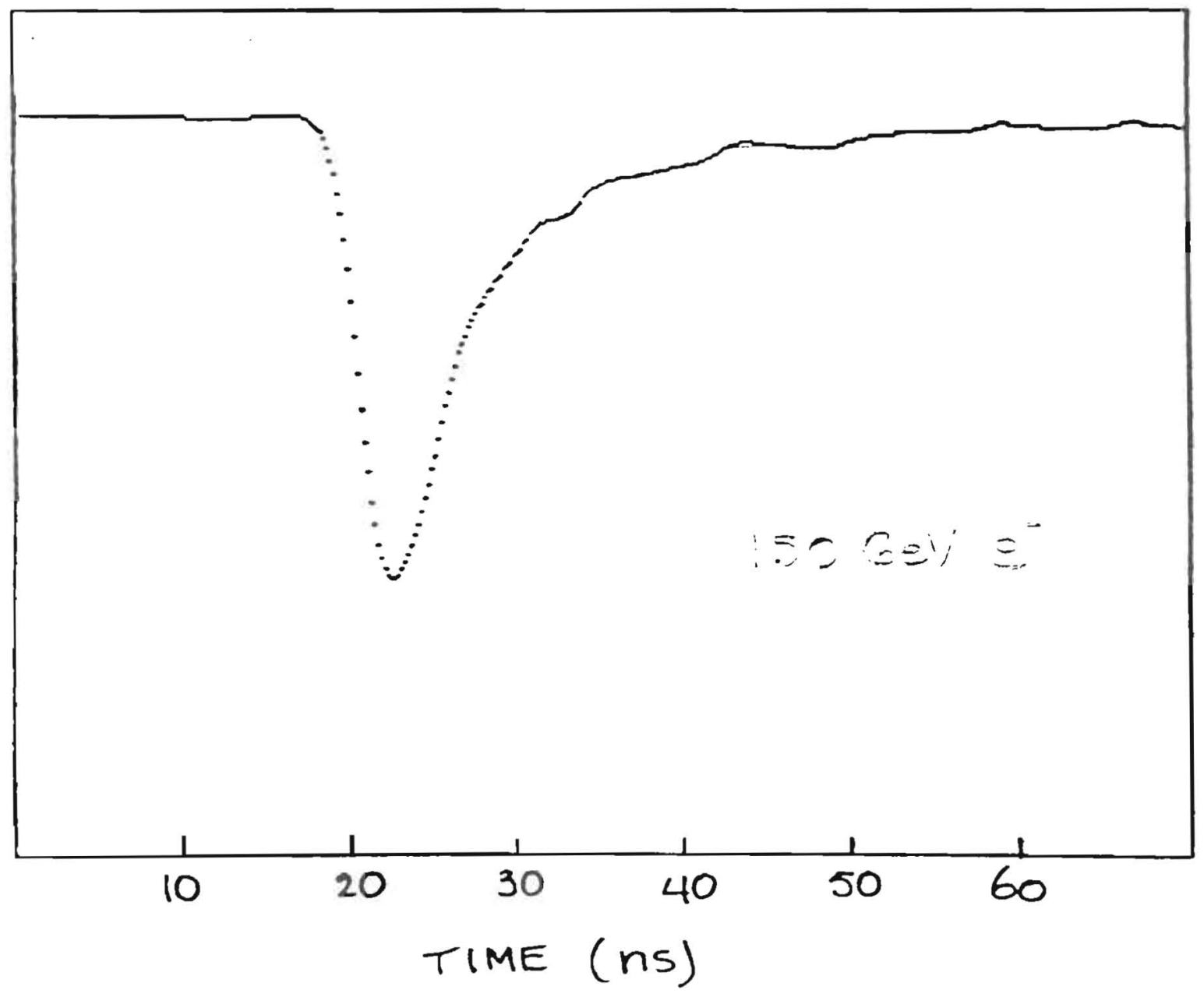




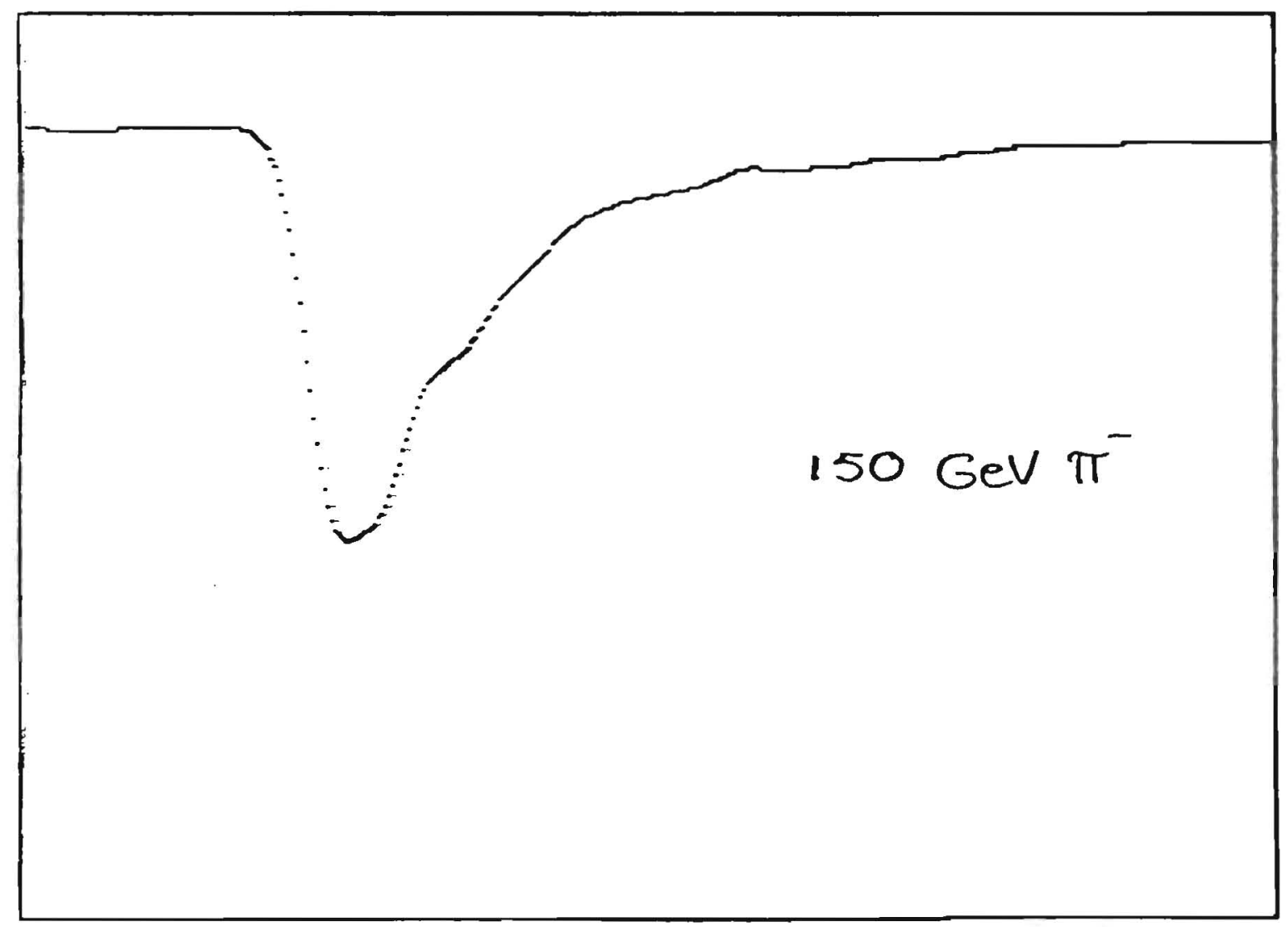


$\rightarrow$ compensating $\mathrm{Pb} /$ saint calorimeter properties:

- As compact as U

- Better energy resolution

- Taster compensation

- Less radiation clamage

WHO WANTS URANIUM?

Availability:

$$
\begin{aligned}
& { }^{238} u: \sim 250 \text { tons } / y-r+\$ 16 / 26 \\
& P_{b}: \sim 10^{7} \text { tons } / y^{\prime 2} \quad(20 \mathrm{cts} / \mathrm{dt})
\end{aligned}
$$

$\rightarrow 5000$ tons takes a few hrs to produce. 


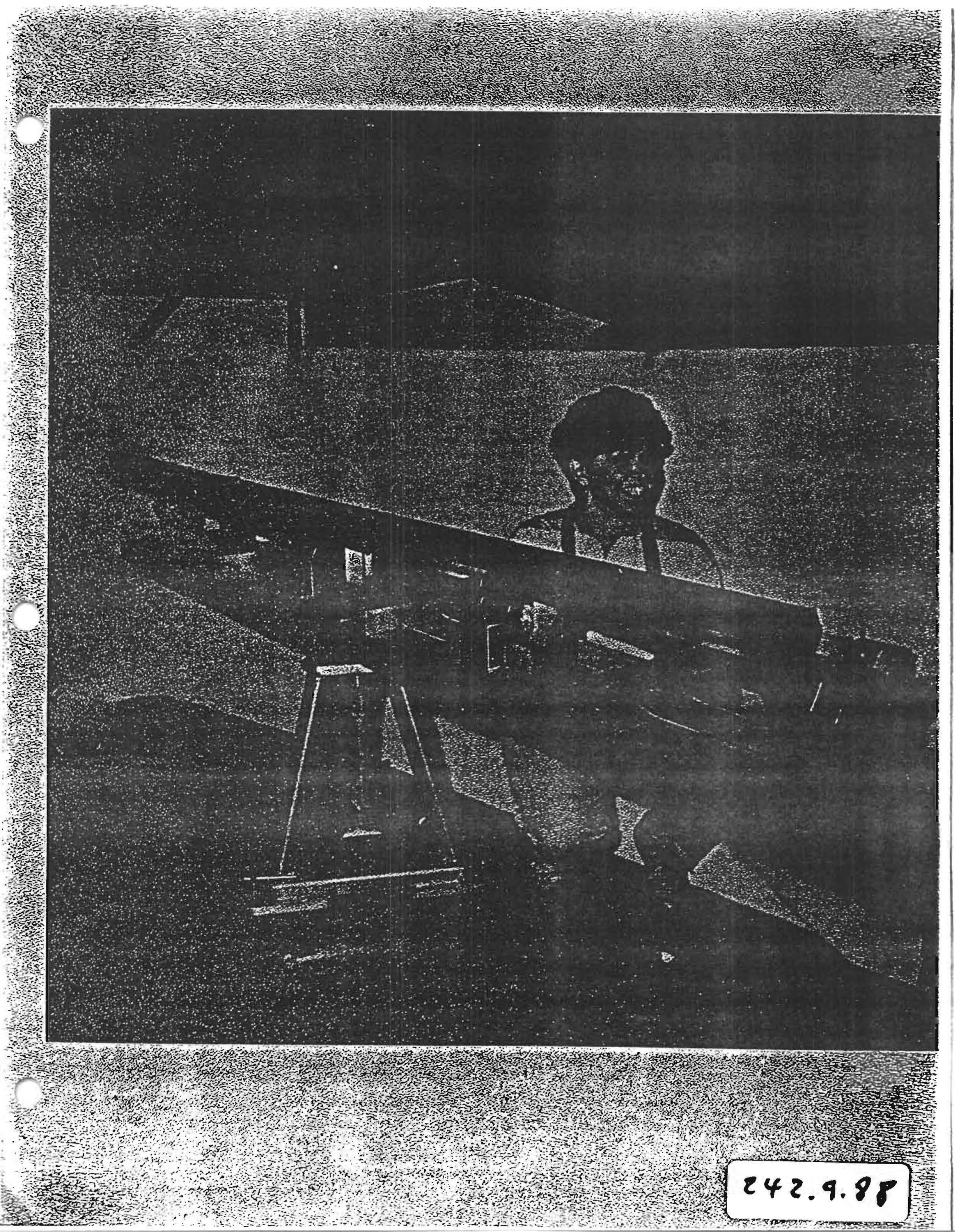




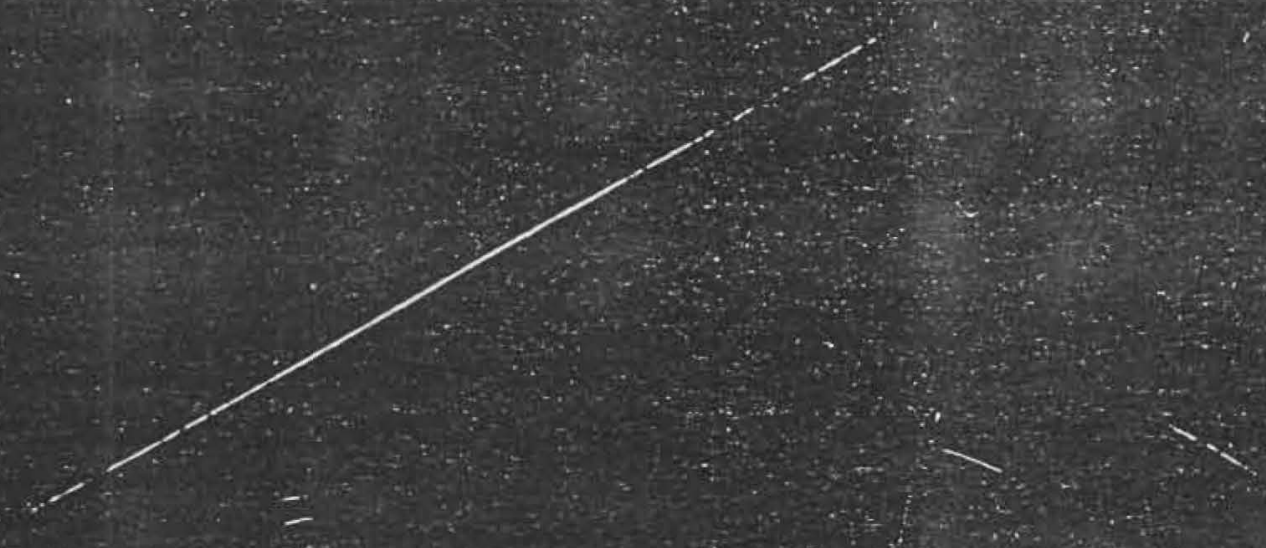

a)
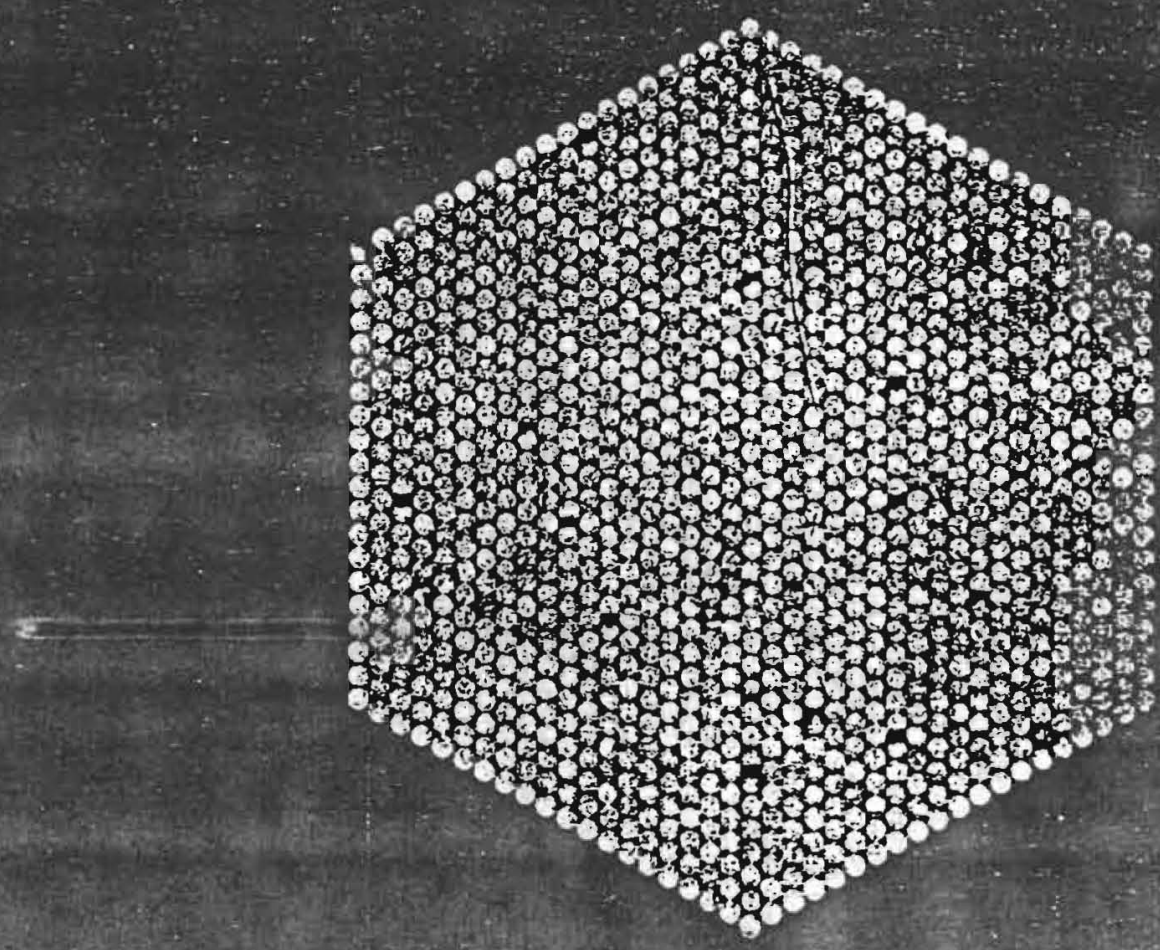


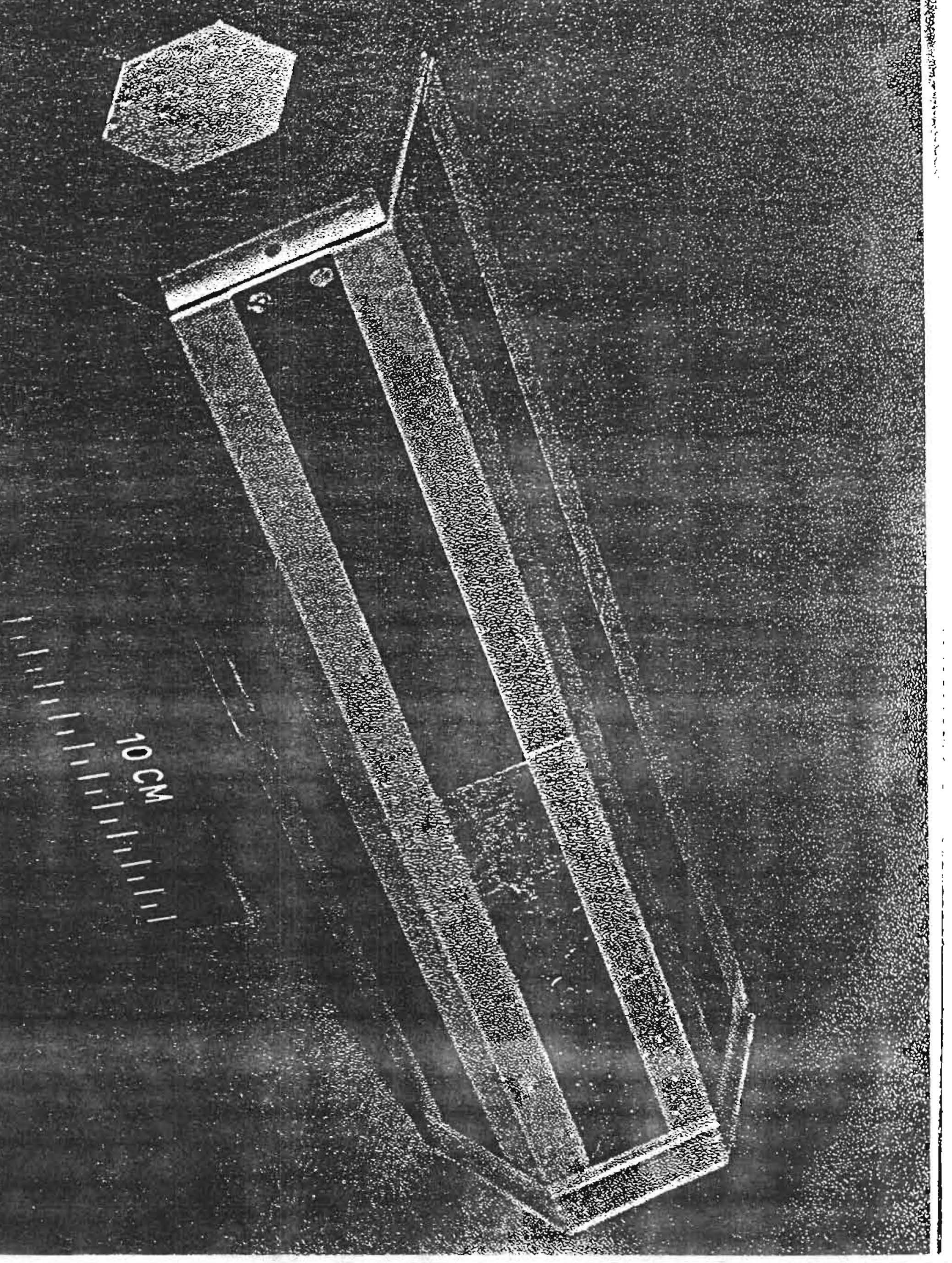


WHY FIBERS?

- Very frequent shower sampling (sampling fraction only $2.3 \%$ for showers)

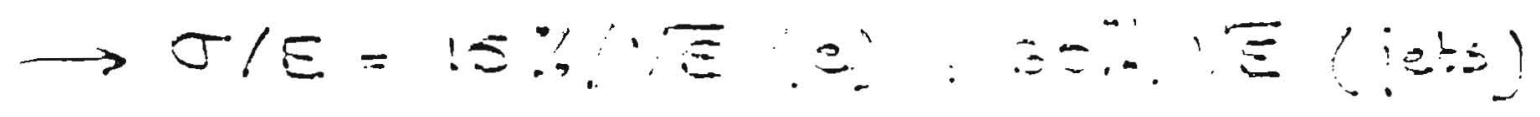

- Granularity arbitrarily fine

- Extremely fast (no wees plates) $\rightarrow=! \pi$ sep.

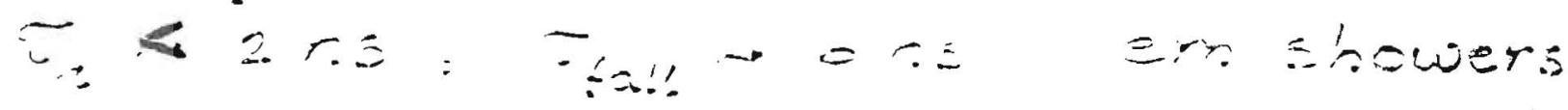

- Excellent signal uniformity

- Perfect hermeticity

- Easy access to readout

- Active material can be easily replaced 


\section{TIME STRUCTURE \\ CALORIMETER SIGNALS}

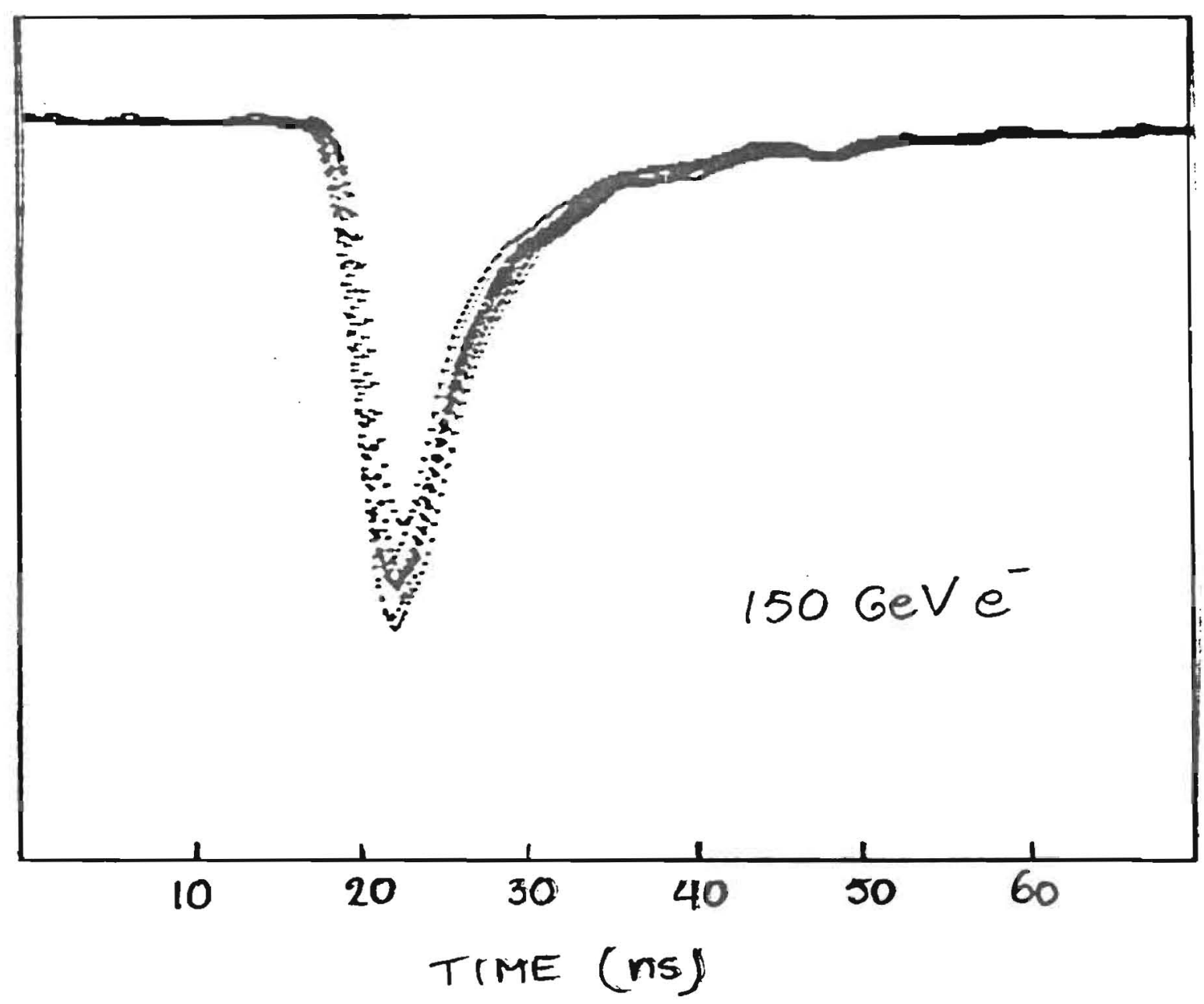




\section{TIME STRUCTURE CALORIITETER SIGNALS}

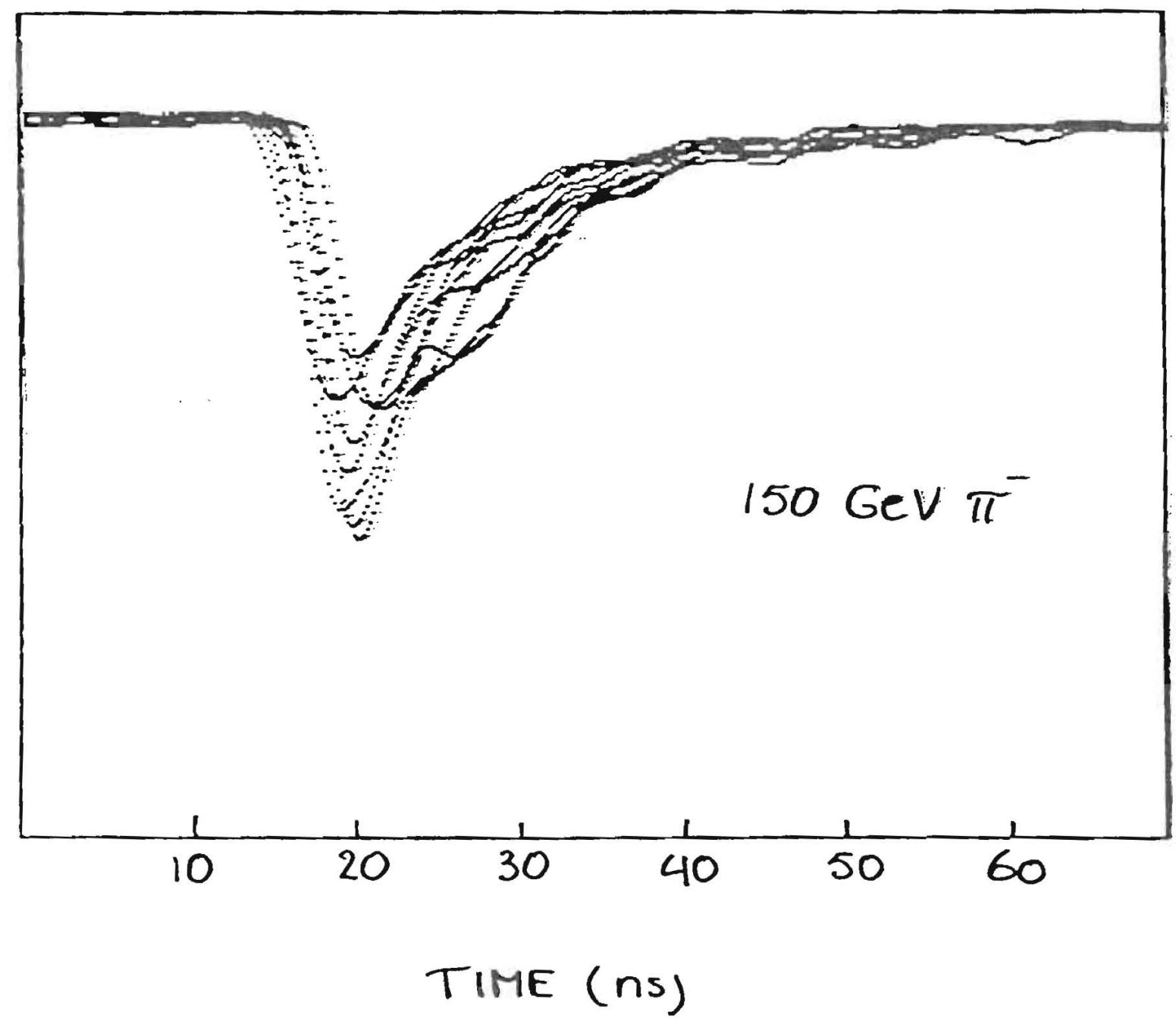


sPACAL R\&D PROJECT

$$
\text { (CERMI - UCSD - NIKHEF - INFN - LIP) }
$$

- Buulid 12 ton prototype hadr. cal. (10 $\left.\lambda_{\text {int }}\right)$

- Develop alternalive for PM (HPD) stability, dynomic range: foujer consumption. magn! (ie!d e!c)

Think of applications (LEP 200, LHC, SSC, Eloisation, UNK) 


\section{LAYOUT SPAGHETTI CALORIMETER}

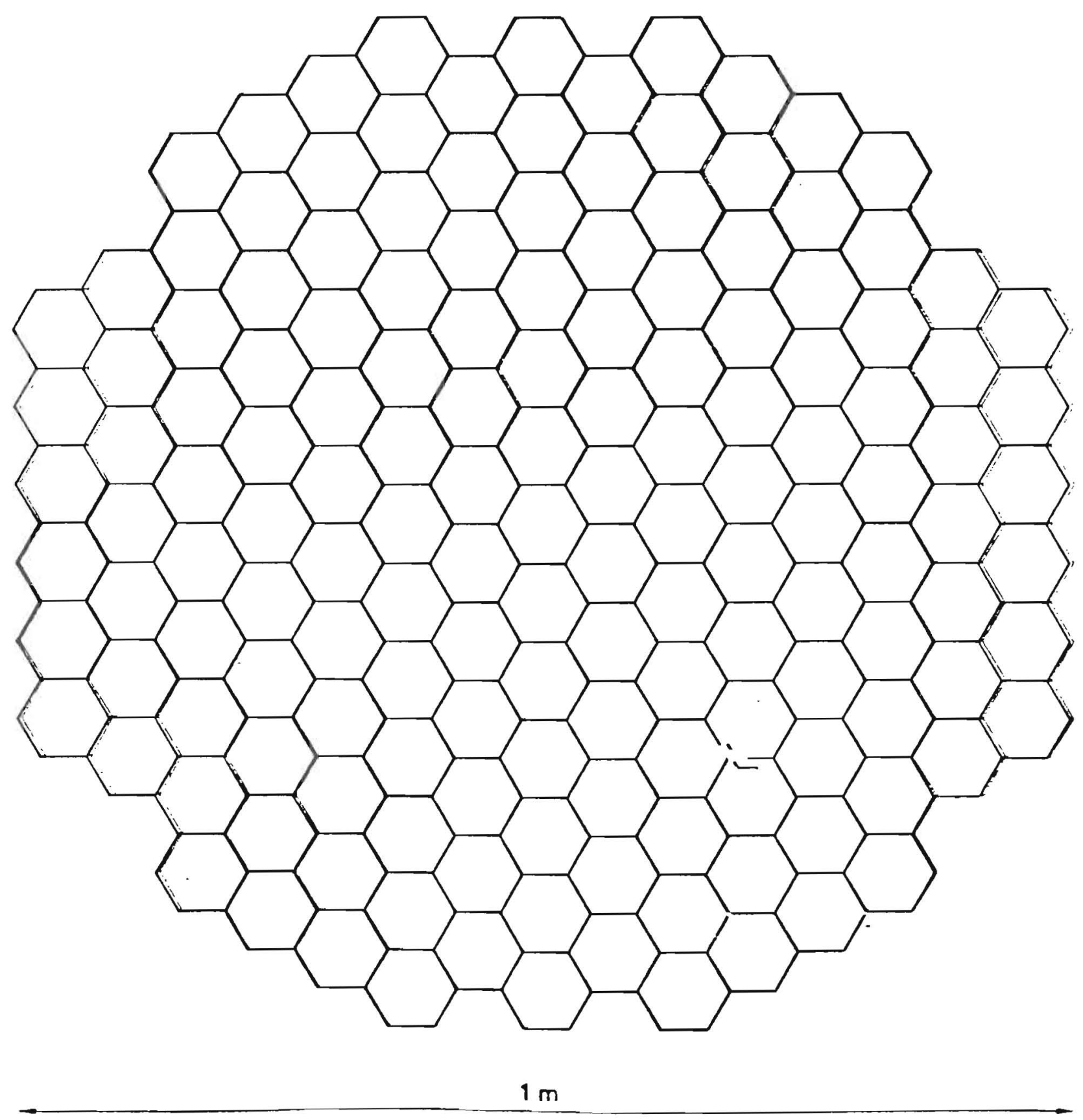

155 MODULES 


\section{SPAGHETTI MULTI-TEV CALORIMETER}
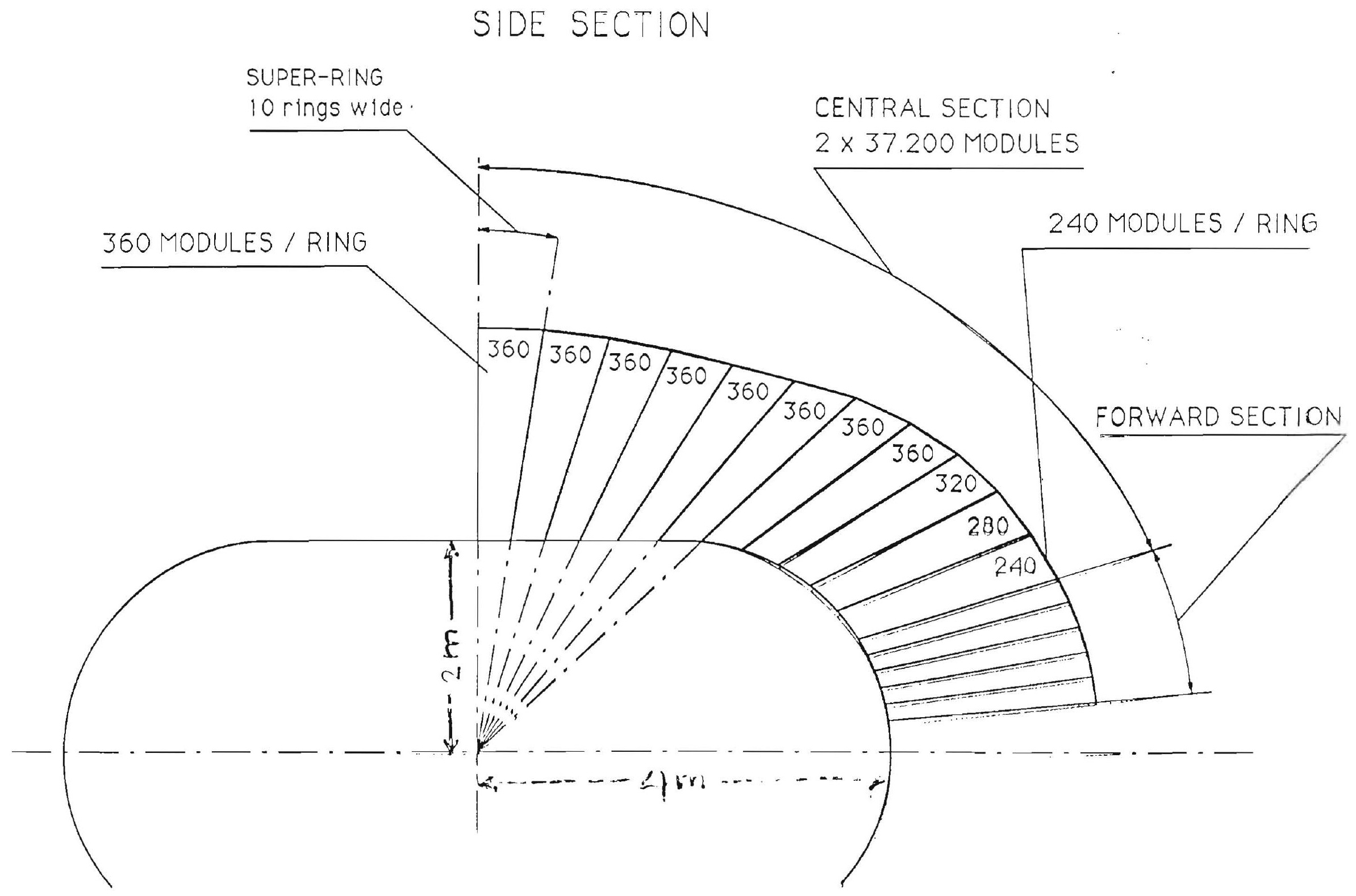


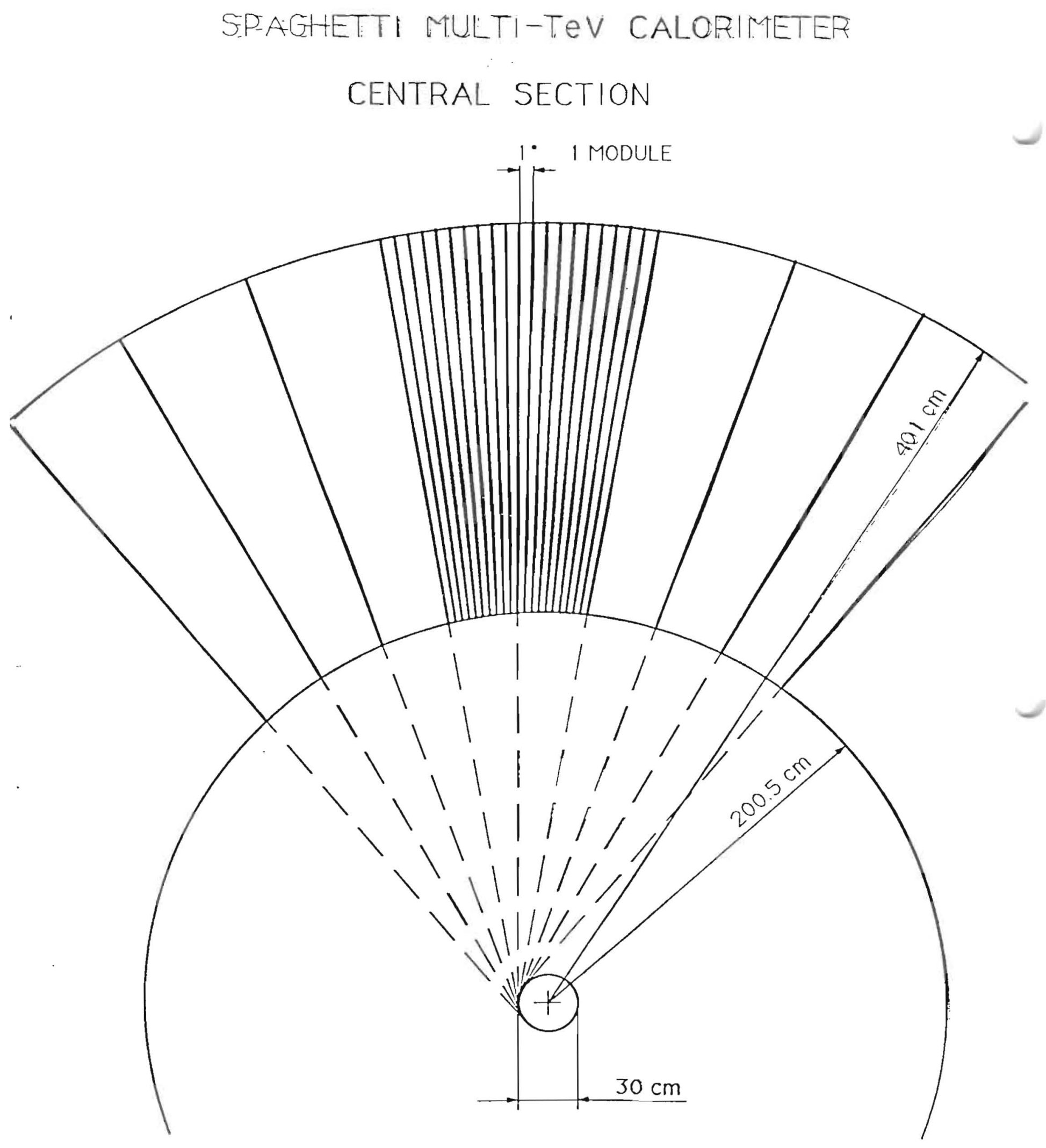




\section{LATERAL NON-UNIFORMITY}

ANGULAR DEPENDENCE CM SIGNALS
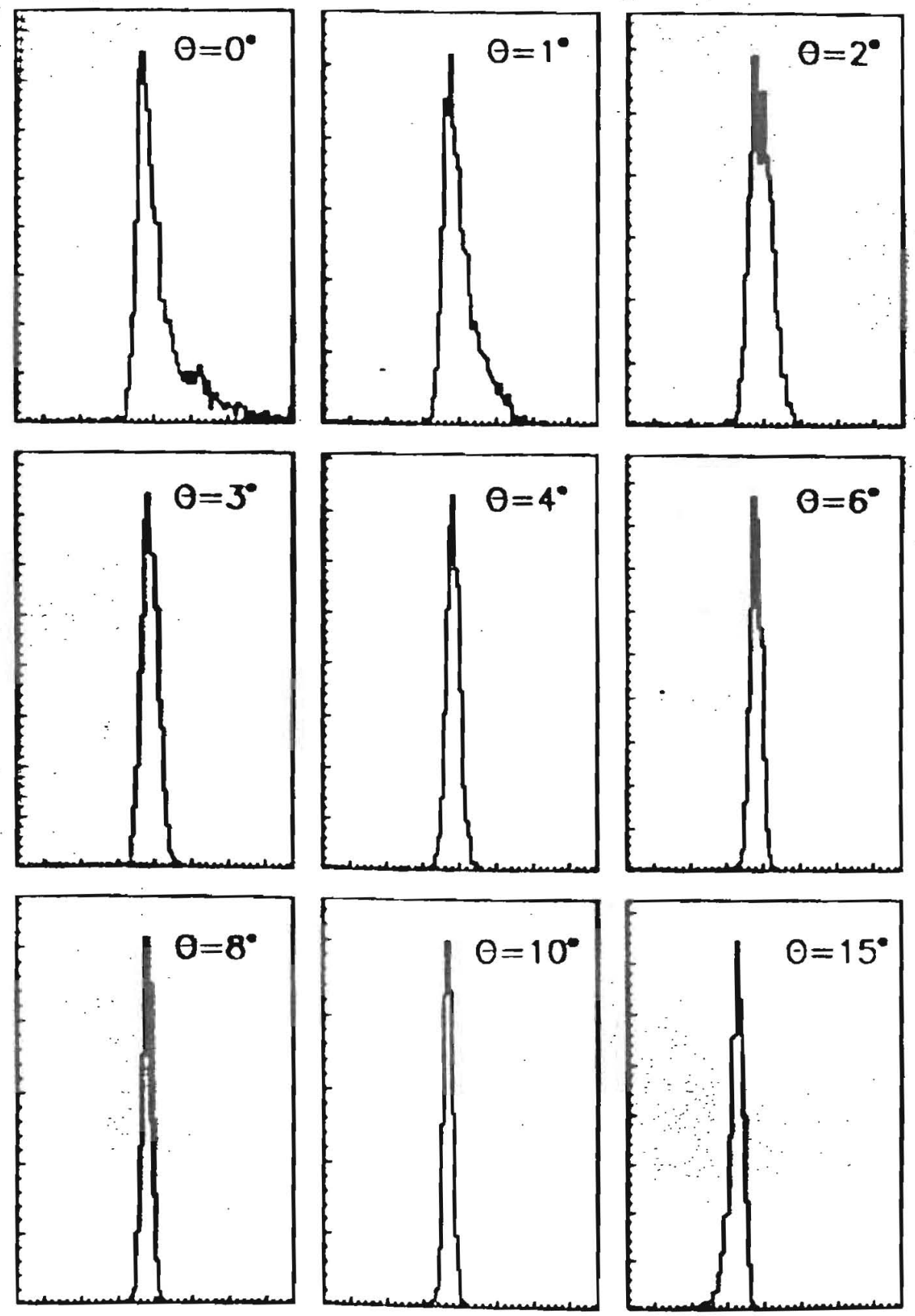


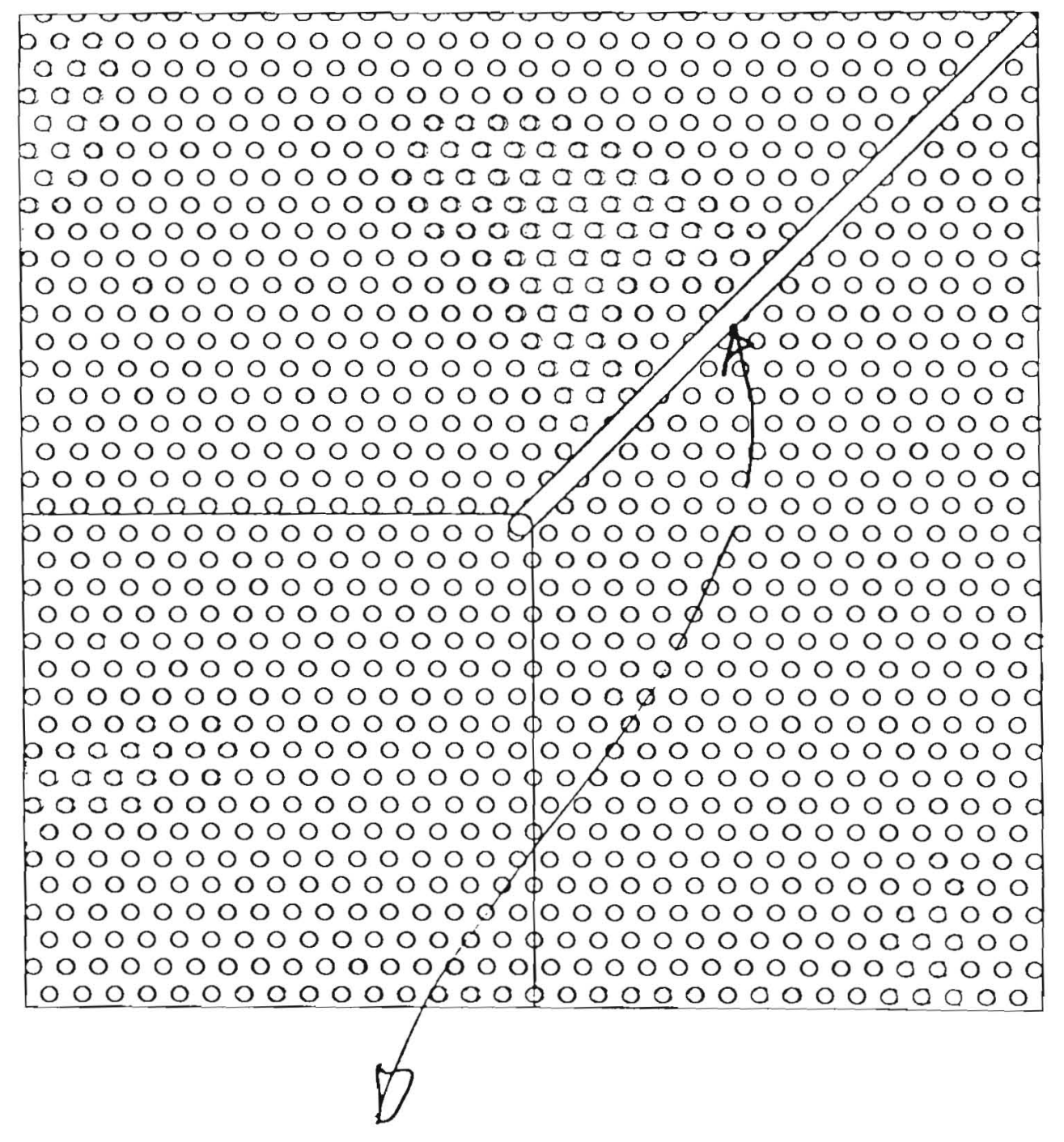

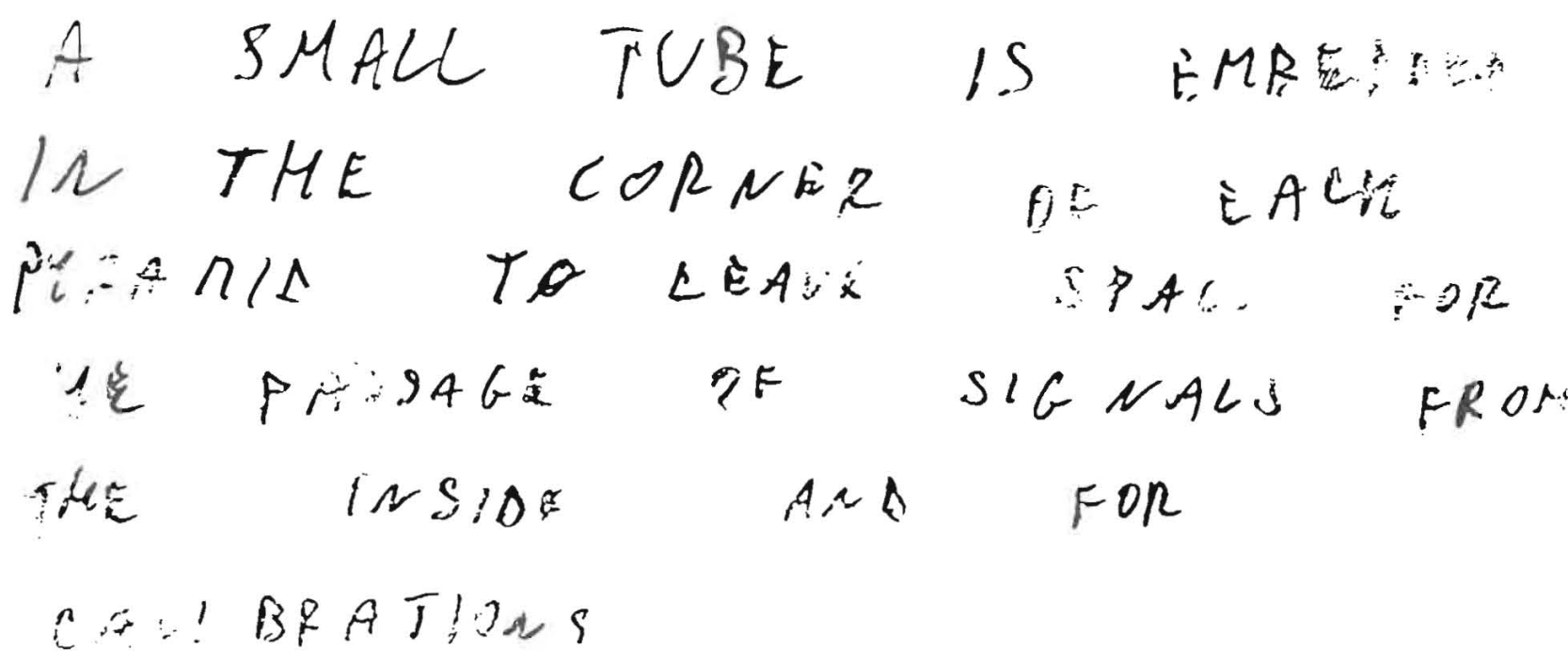




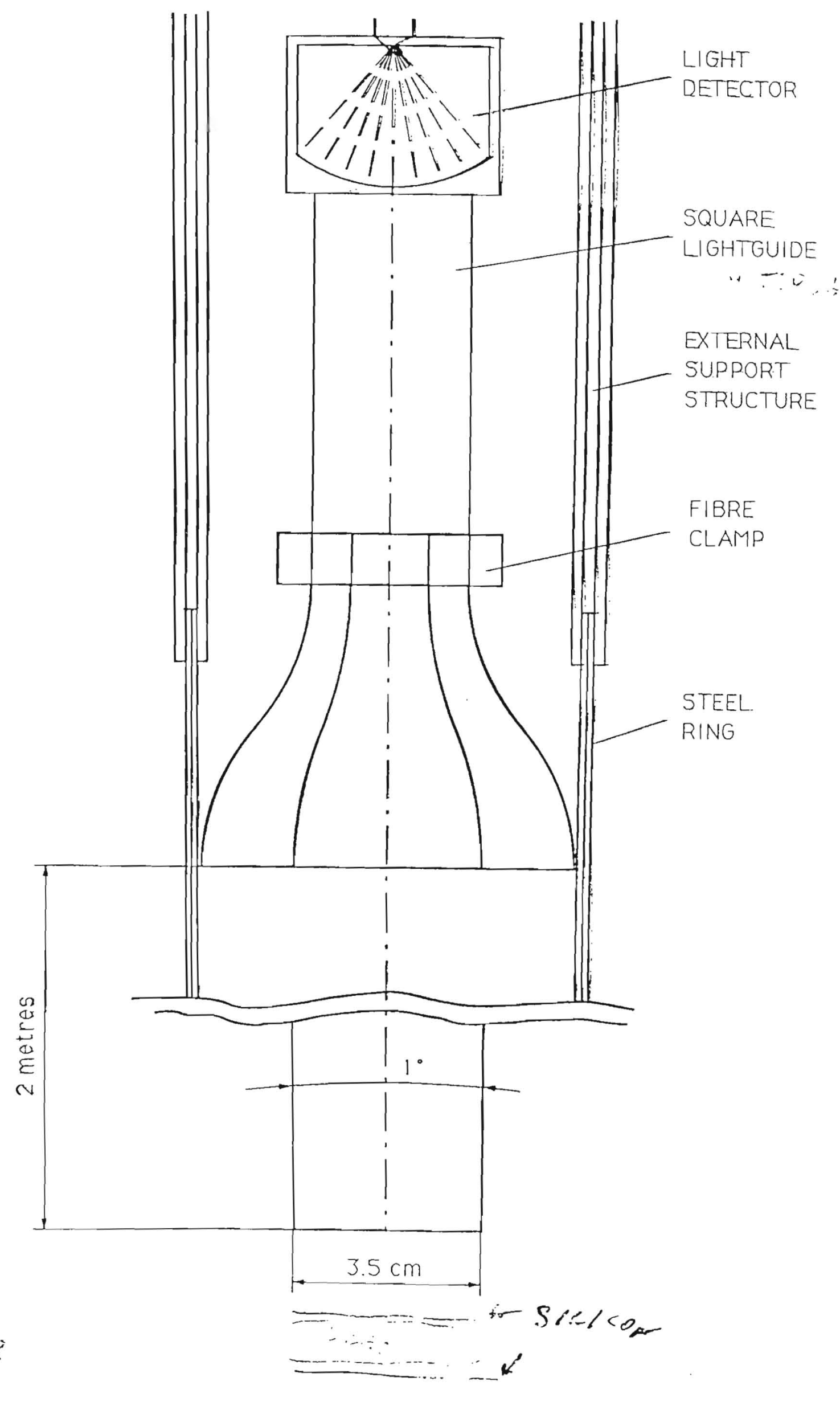


CIT SEPARATION WITH

PRESHOWER COUNTER
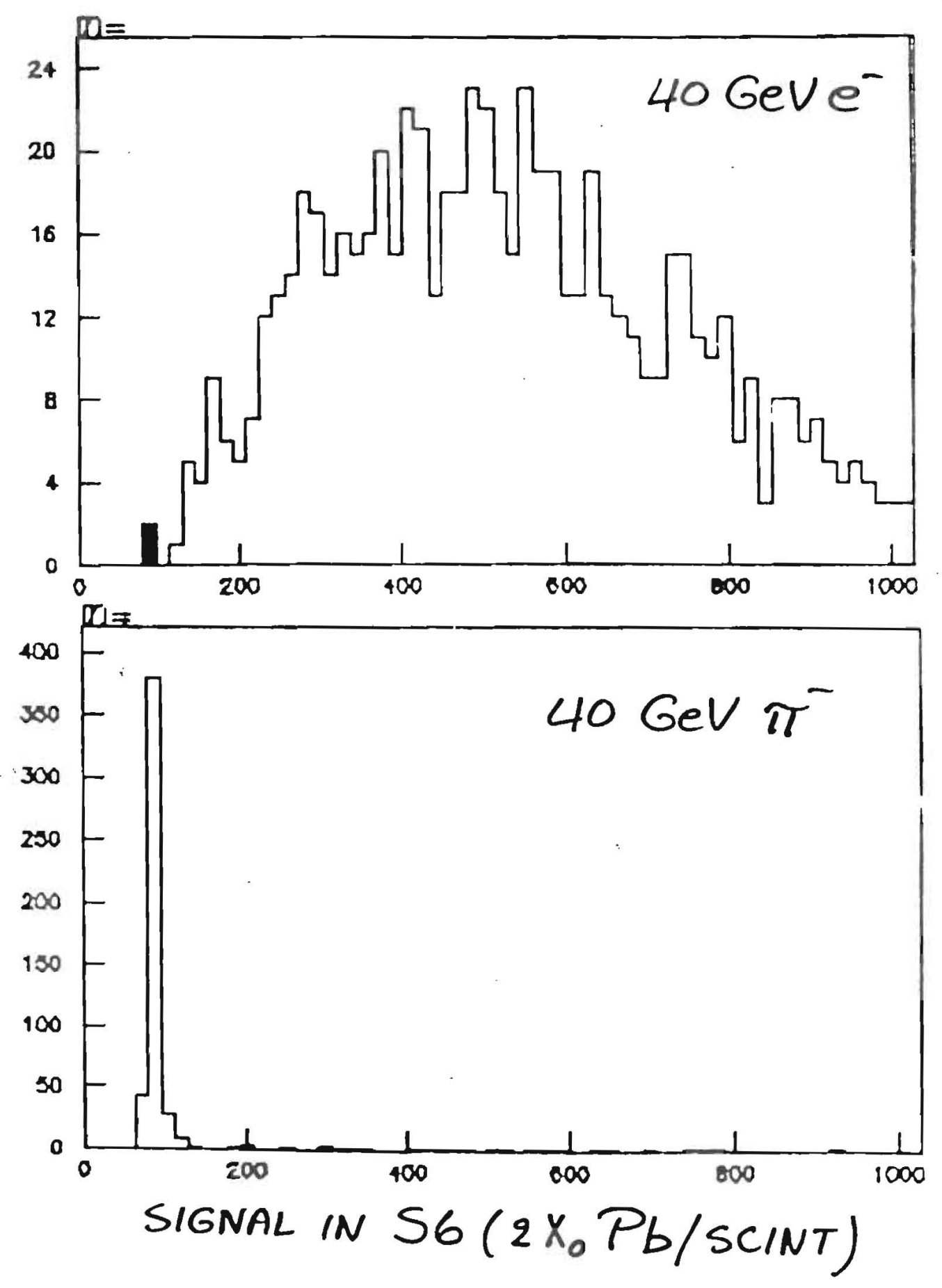
SPACAL at SSC

Active volume

Weight

Fibre length

\# channels
$352 \mathrm{~m}^{3} \quad\left(10 \lambda_{\mathrm{in}}\right)$

$3200 t$

$100000 \mathrm{~km}$

$80000 \quad(3.5 * 3.5 \mathrm{~cm}$ cells $)$

COST (M\$) based on prototype prices

Lead structures 35

Fibre

50

Light detectors

40

Assembly

30

Preshower del.

15

Trigger + DAQ

25

Total

195 


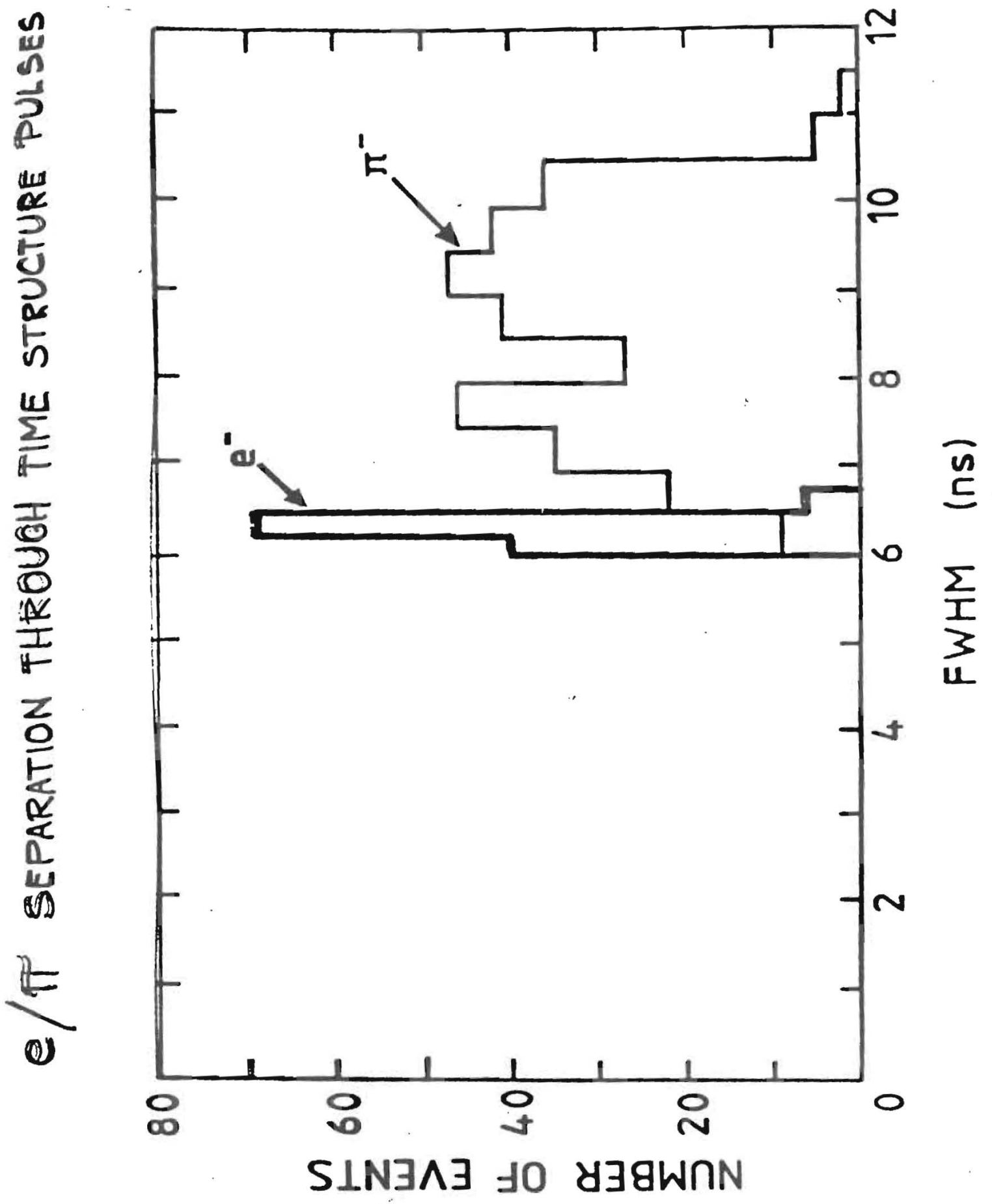




\section{CRACK SCAN GLUELESS MODULES \\ (B-SOURCE)}

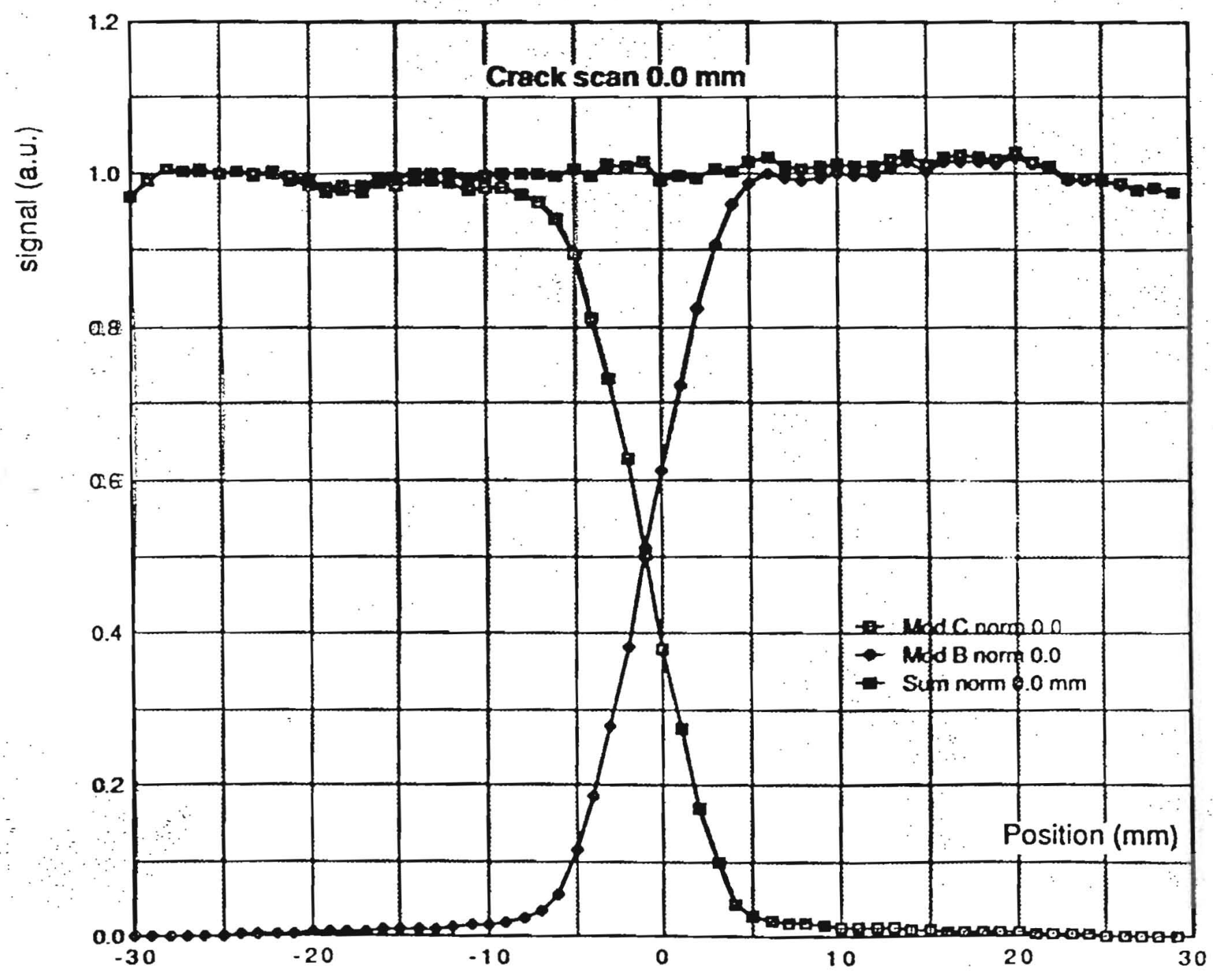




\section{EFFECT OF MIRROR AND FILTER ON ATTENUATION CEARACTERISTICS}

("14i fibre modiule)

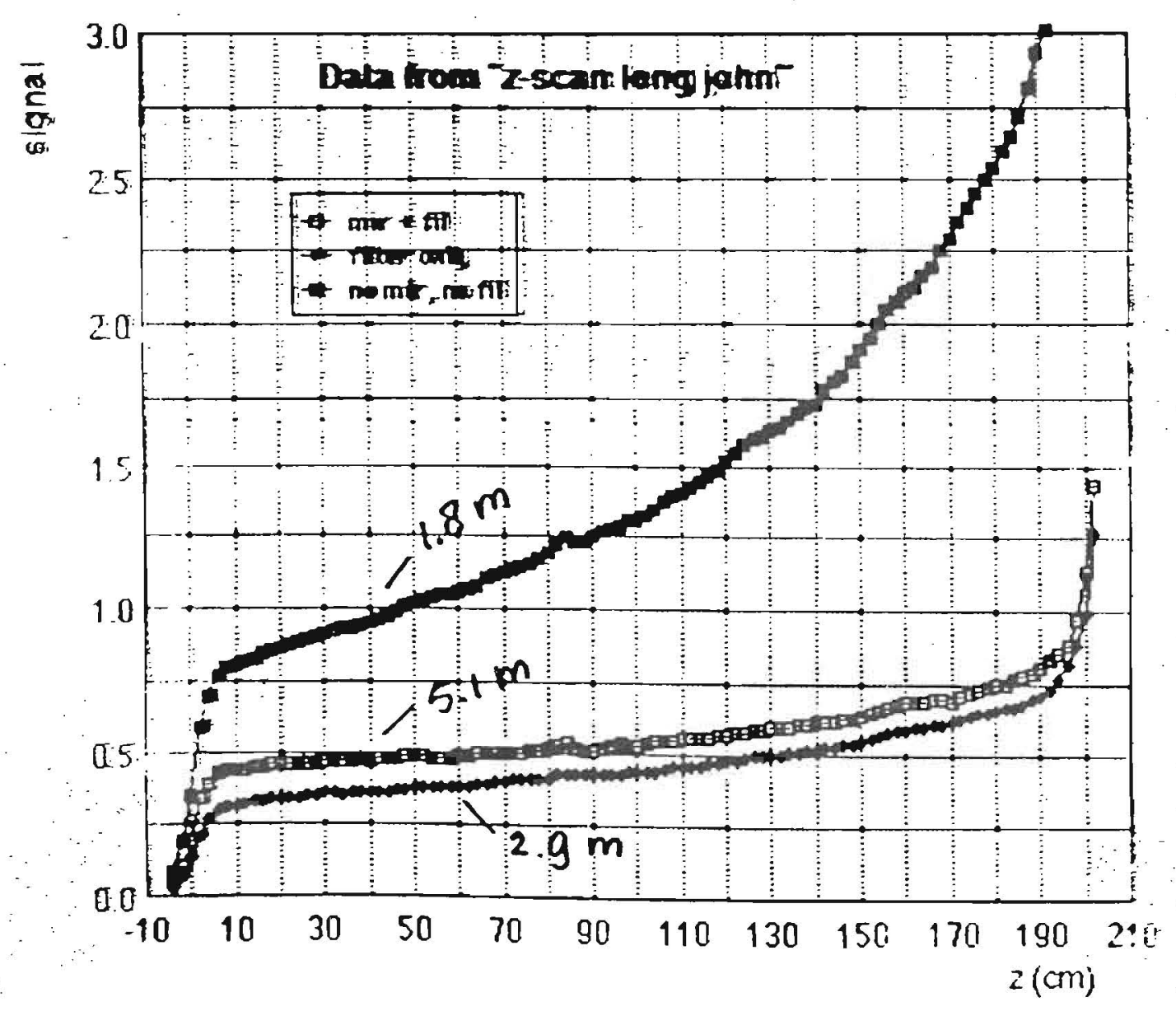




\section{LATERAL UNIFORMITY \\ REFLECTION OPEN END}

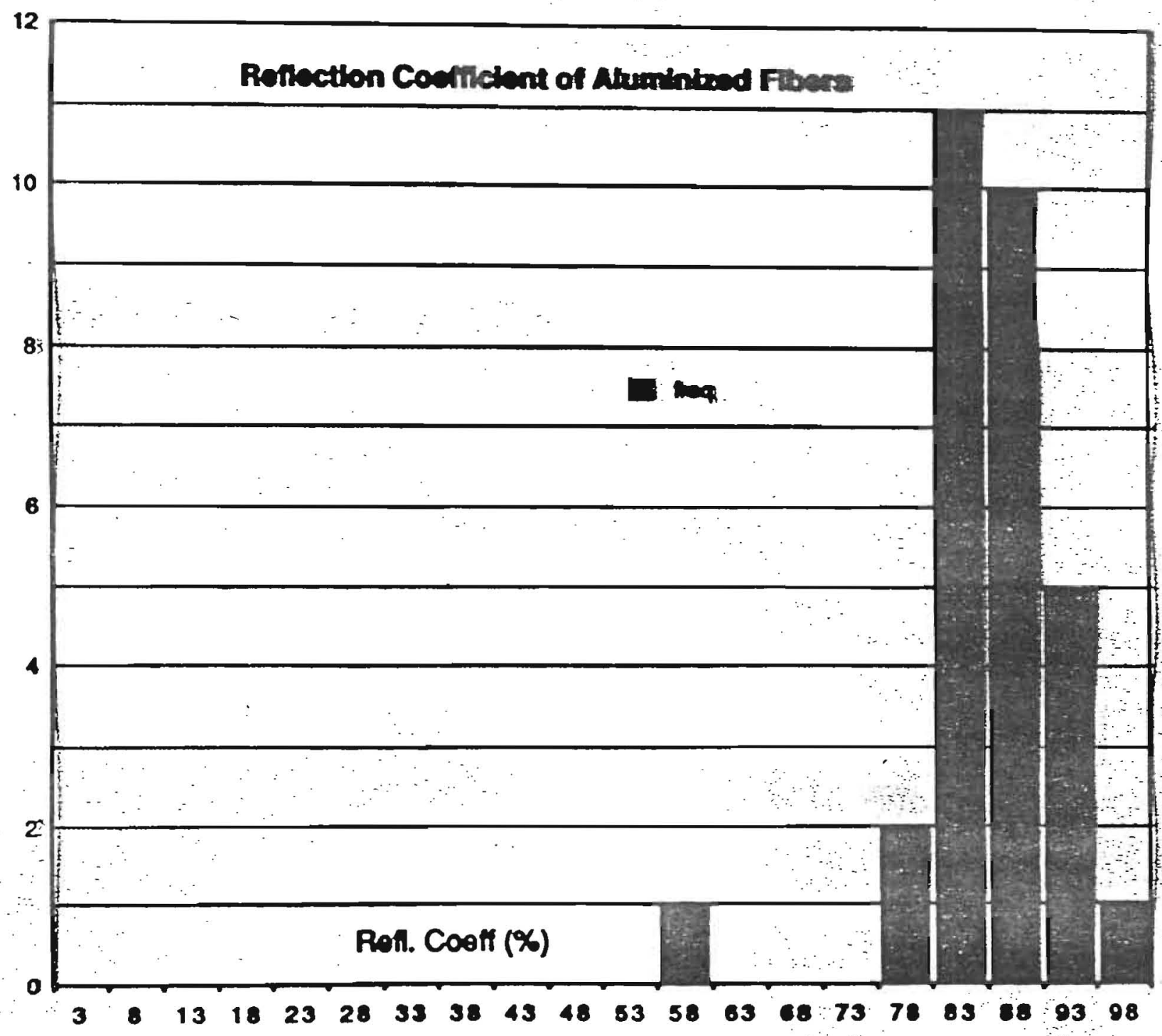


RADIATION DAMAGE

- Main problem is decreased light transmission ( $\lambda_{a l t}$ ) Sirsug!y wave long th dependent

- $3 \mathrm{HF}$ No effect on $\lambda_{\text {att }}$ at $10 \mathrm{MRad}$ $\rightarrow$ No problems (or $r$ ? 3.3 .5

HOW ABOUT $\eta>3.5$ ?

$$
\because<3^{\circ}, F<30 \text {, }
$$

- We don't know limits $3 \mathrm{HF}$

- Radiation damage only in first few $\mathrm{cm}$ depth

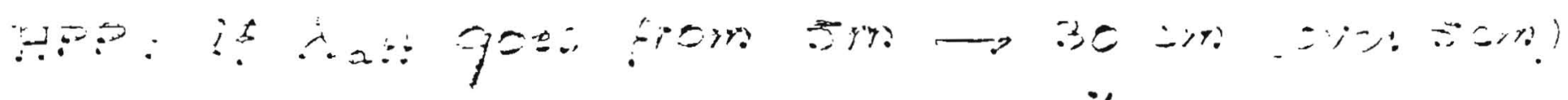
$\rightarrow(O) \equiv$ ? ext increases by $1.4 \%$

- Don't need excellent performance for $\eta>3.5$

- Fibres easily replaceable

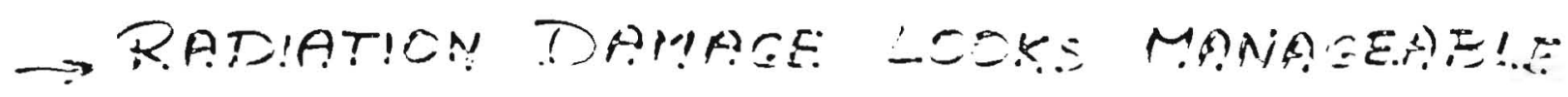


Radiation levels at SSC

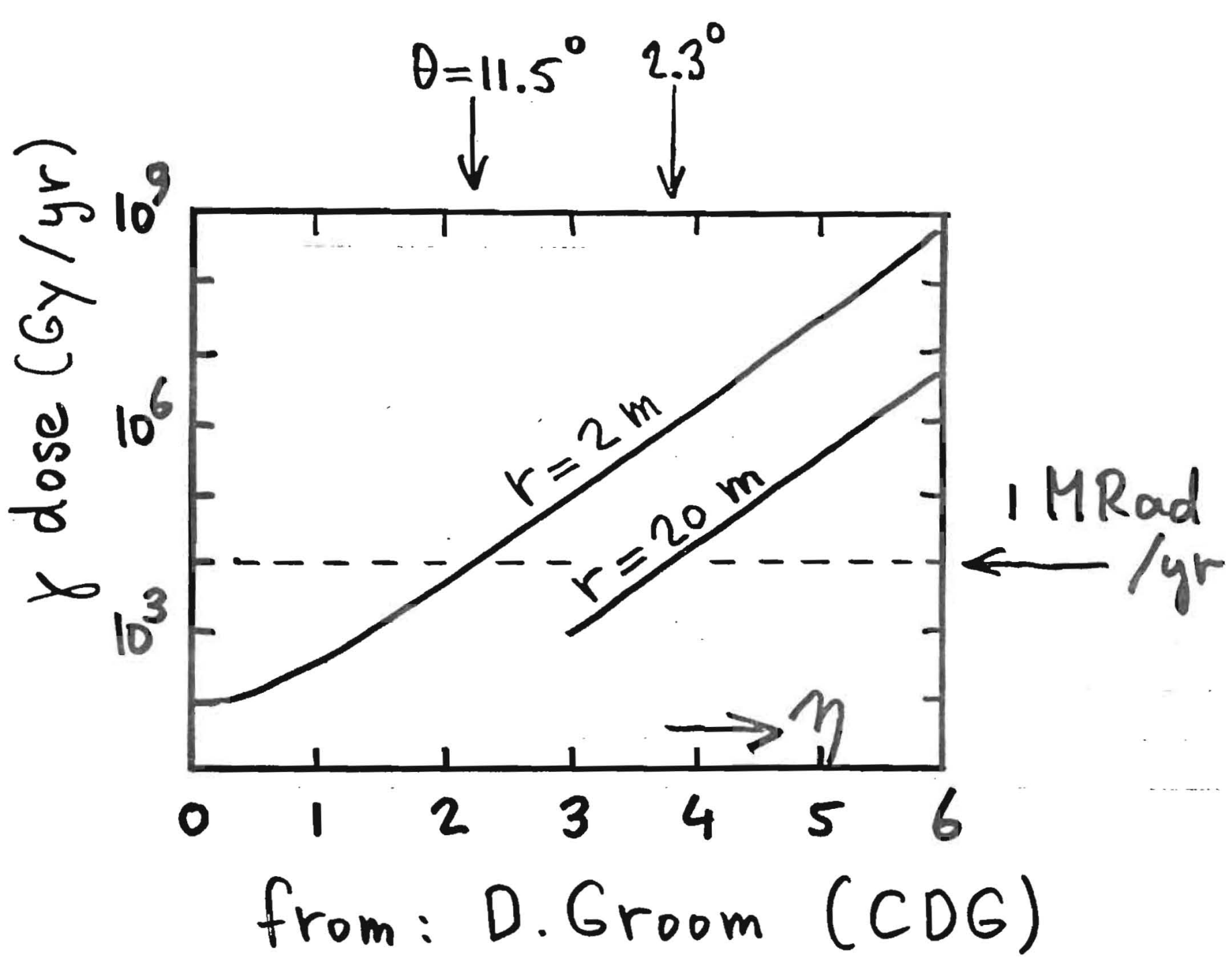




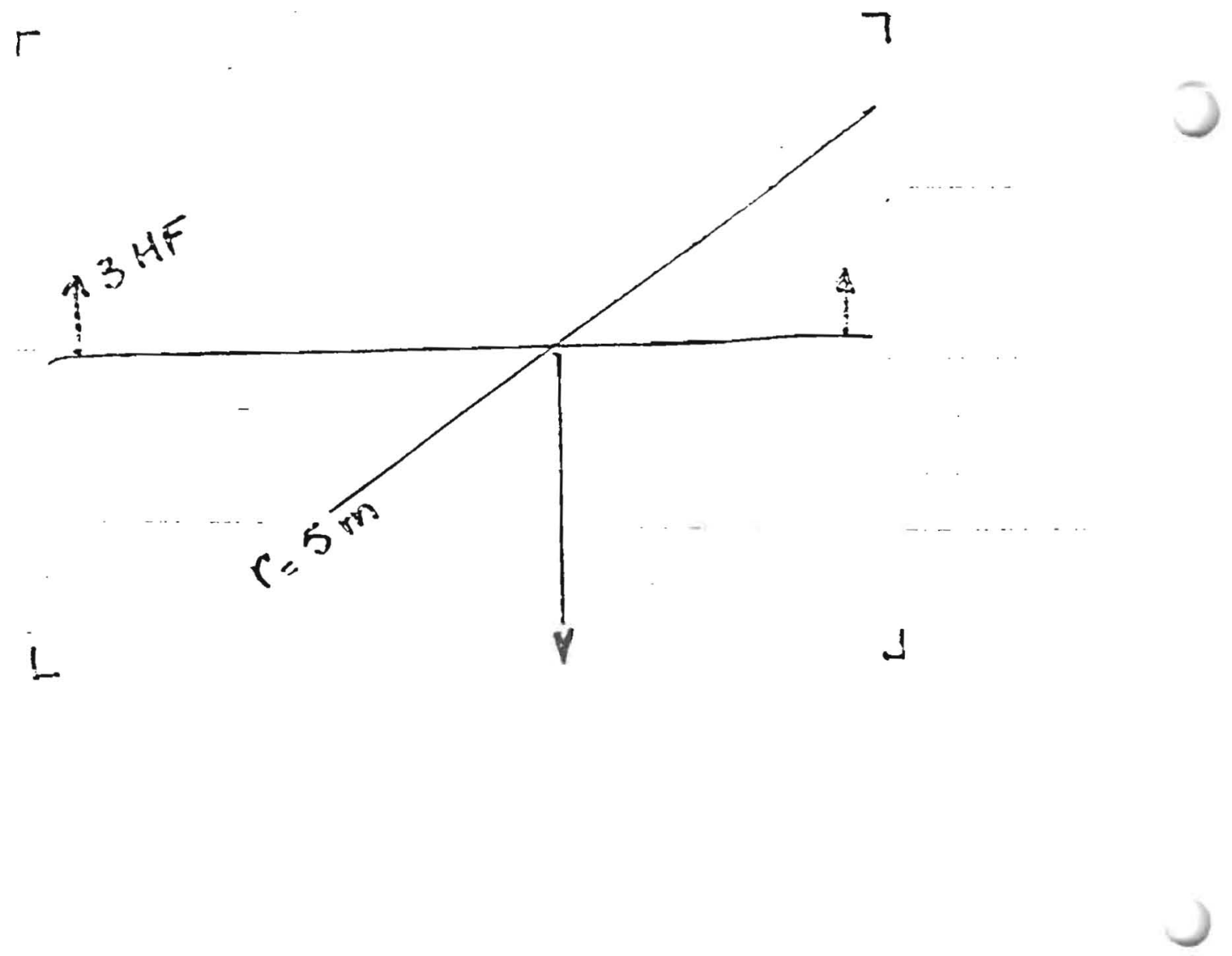




\section{RADIATION STABILITY}
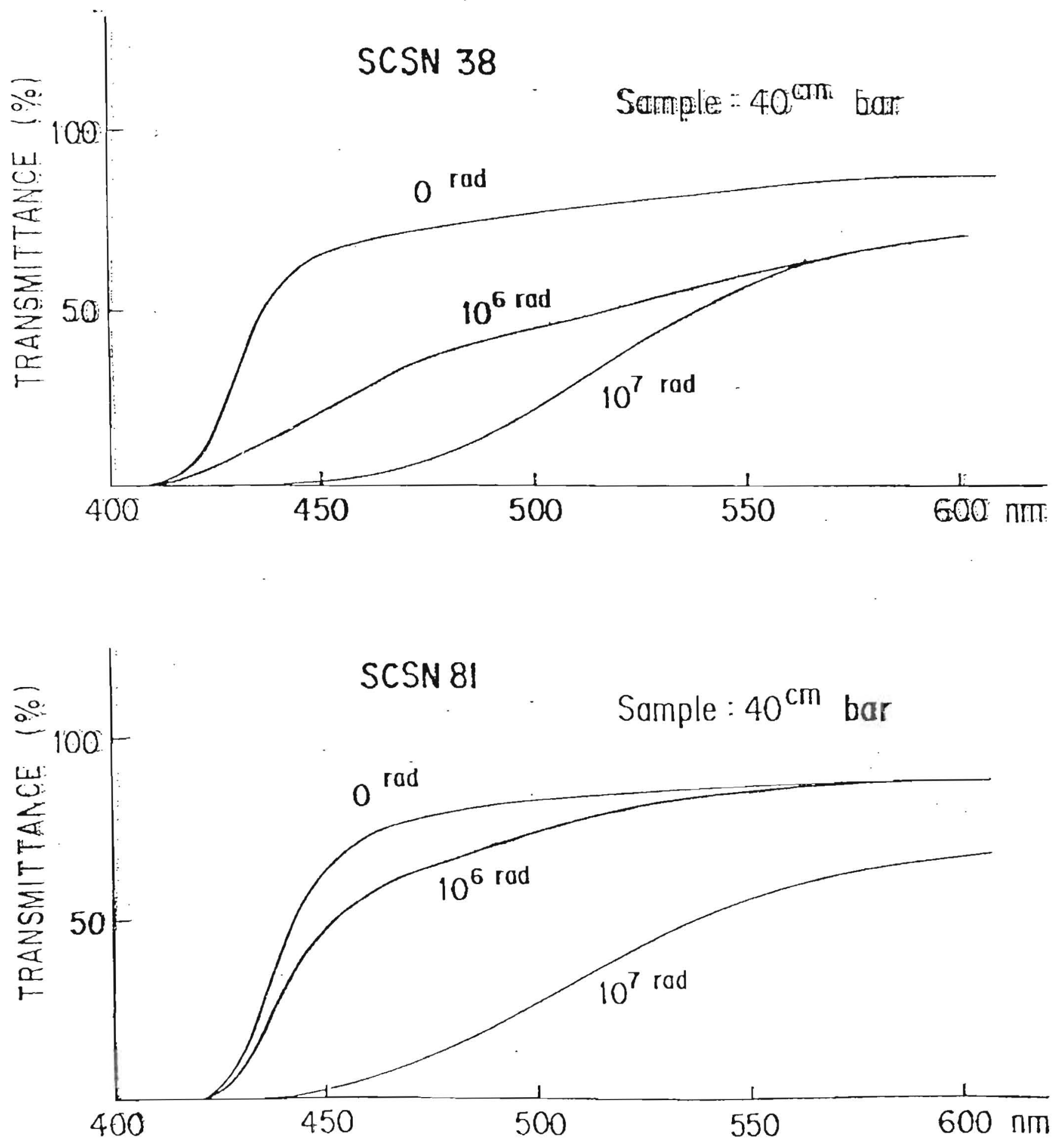

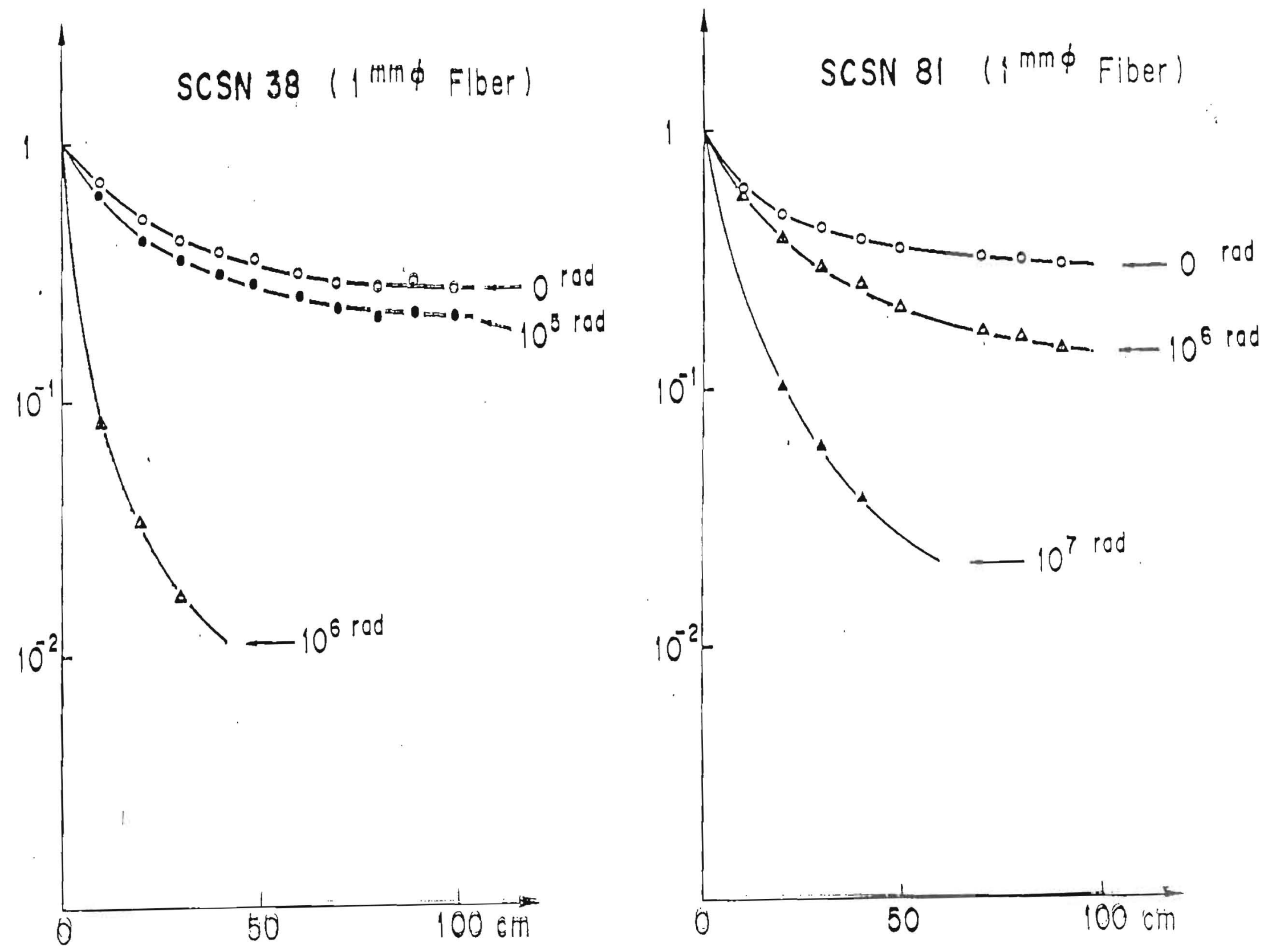
S.M.

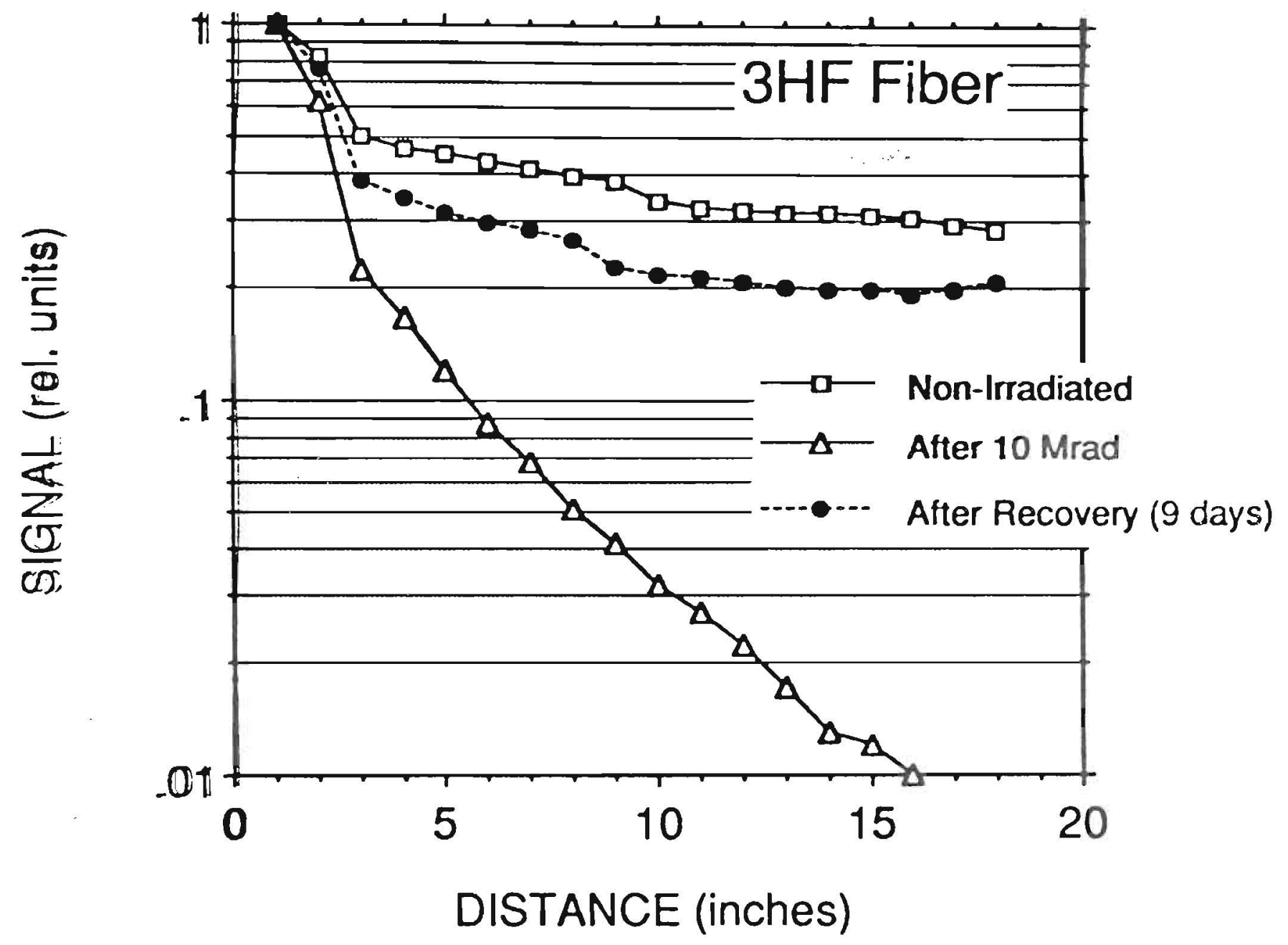

Fig. 13 


\section{CALORIMETRY AND THE SSC EXPERIMENTAL PROGRAM}

M. G. D. GILCHRIESE

Workshop on Calorimetry

Tuscaloosa, March 1989

- Introduction

- The SSC Laboratory

- Detector R\&D

- Generic R\&D

- R\&D on Major Detector Subsystems

- Tentative Schedule for Inititation of the SSC Experimental Program

- Calorimetry 


\section{Introduction}

- Have an excellent site - see photo

- Budget facts

- This year, FY89 - $\$ 100 \mathrm{M}$

- FY90 - budget request is $\$ 250 \mathrm{M}$, of which $\$ 160 \mathrm{M}$ would be construction funds

- Texas contribution - $\approx \$ 1 B+$ purchase of land. \$1B may be used for civil construction, site improvements and research and development on detectors and accelerators

- Thanks to the fantastic work of Central Design Group, DOE, universities, labs..... we have a very strong base from which to build the SSC laboratory in Texas

- But to make this a reality your help is crucial in all aspects of the project 


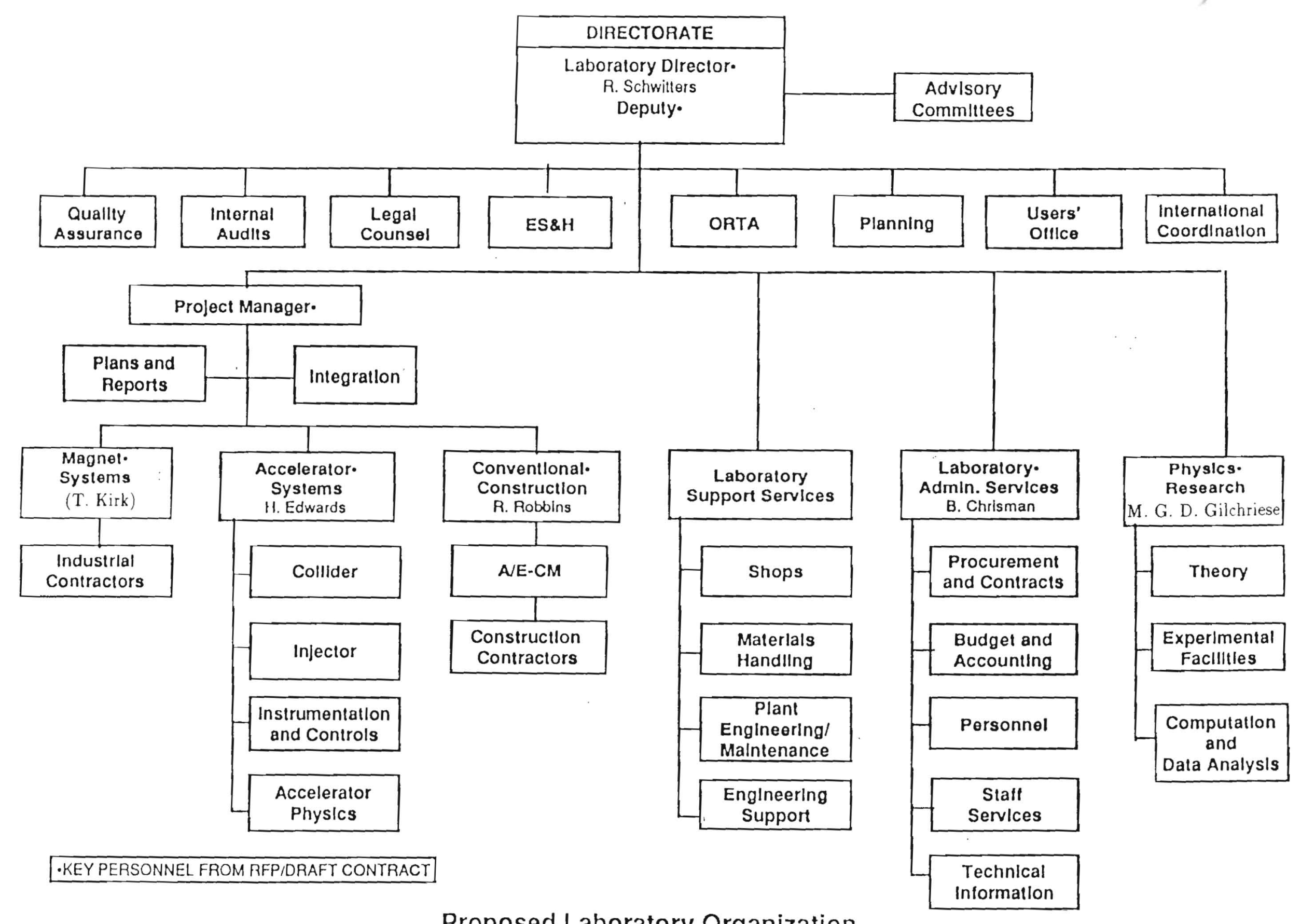

Proposed Laboratory Organization 


\section{Universities}

\section{Who Is Involved in SSC Detector R\&D?}

Boston Univ.
CalTech
Carneglo Mellon
Florida
Florlda State
Harvard
Hawall
IIllnols
Indlana
Mlchlgan
Misslssippl
Northeastern
Notre Dame
Oklahoma
Oregon
Pennsylvanla
PIttsburgh
Princeton
Rockefeller
Stanford(CIS)
Stony Brook
Tennessee
Texas A\&M
UC Berkeley(Space Sclences)
UC Davis
UC San Diego
UC Santa Cruz
UCLA
Yale

\section{Labs}

Argonne

Brookhaven

Formllab

LBL

Oak Ridge

Sandla

BLAC

\section{Industries ${ }^{\dagger}$}

\section{Martin Marletta}

Hughes Alrcraft

United feehnologles Microelectronlas

Harrls semieonductor

Blcron Corp.

HutchInson Teehnology

Micron Semlconduetor

Rockwell

There is also SBIR Involvernent 


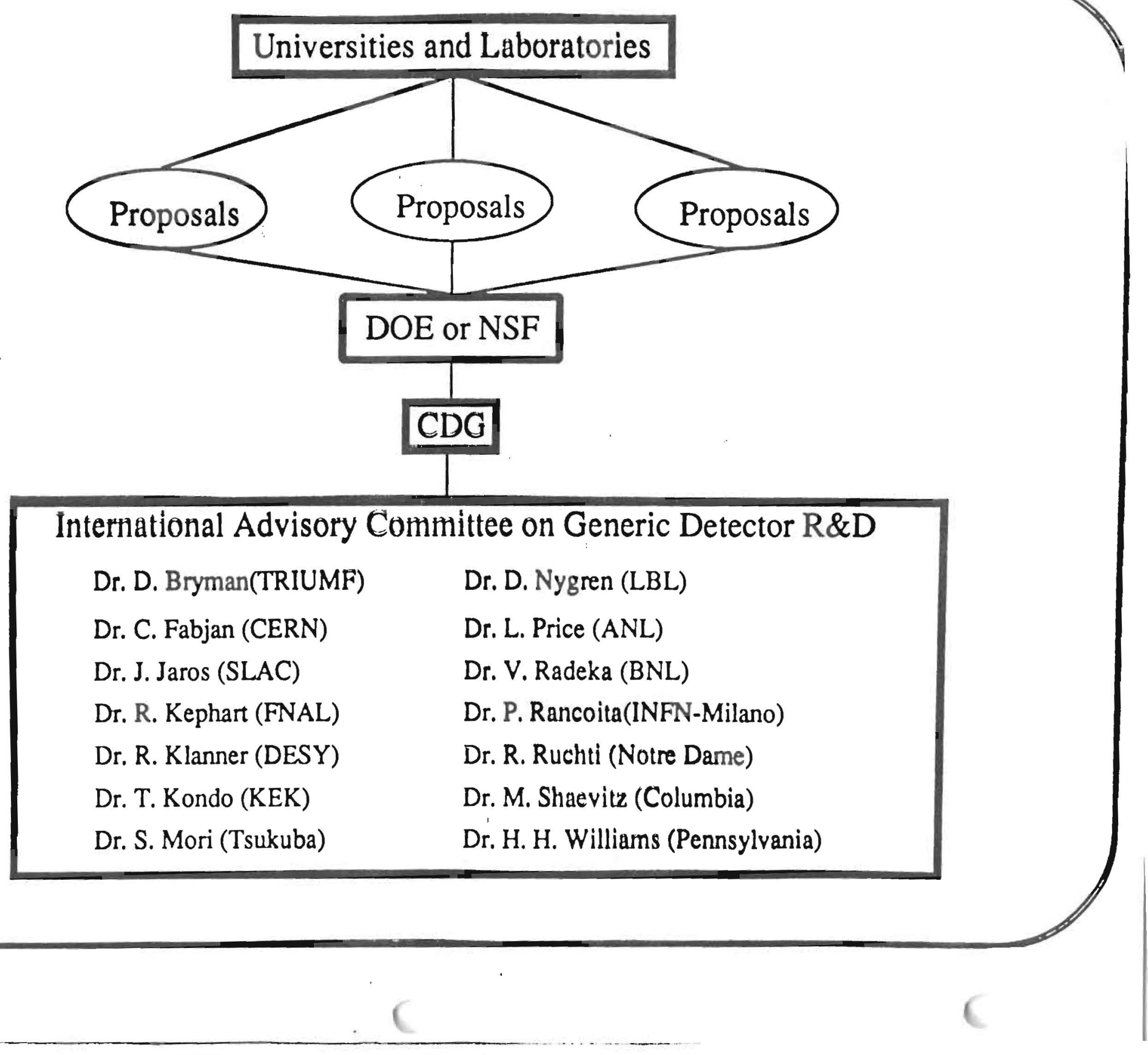




\section{Detector R\&D Cont.}

- In addition to the generic program, we plan to initiate a program of detector R\&D on major detector subsystems for potential SSC experiments.

- Examples of such subsystems include

- calorimetry

- tracking systems

- electronics systems, particularly VLSI and rad hard

- data acquisition and and triggering systems

- particle identification systems

- detector simulation software

- It is anticipated that this R\&D on major subsystems will be carried out by multiinstitutional collaborations

- It is intended to have impact on selection of experimental proposals, tentatively planned for summer of 1991

- Deadline for proposals to the SSC laboratory is October 2, 1989.

- Proposals will be reviewed by Detector R\&D Advisory Committee that also provides advice on generic $R \& D$. 


\section{Meetings and Continuing Activities}

- As part of the R\&D effort, there have been and will be a number of workshops and meetings of interest to SSC experimenters.

- Specific meetings this year

April 5-7 Symposium on Particle Identification at

High Luminosity Hadron Colliders(Fermilab)

July 24 - 28 Workshop on Tracking Detectors for the SSC(Vancouver)

Will be others - to be scheduled

- Continuing activities

- Task Force on Data Acquisition and Triggering Chaired by Andy Lankford(SLAC)

Series of mini-meetings on DAQ and Triggering

Explore industrial potential

Produce written report (with numerous contributed appendices) outlining possible framework by Oct. '89

- Detector Simulation Consortium

Chaired by Larry Price(ANL)

Document, validate and distribute fast simulation extension to GEANT package for SSC detector design by fall.

Assist in validation and distribution of physics packages eg. ISAJET

Test packages with interested industrial vendors ANL-LBL-SSC-BNL(F. Paige) collaboration so far - others welcome - see L. Price. 
Plans for Initiation of the SSC Experimental Program

- Need to understand scope of SSC expt. program - how many IRs, what types of expts.............

- Form Scientific Policy Committee(SPC) starting now. Deliberations until about September of this year

- Input from the community at large

- First general meeting about SSC and experimental program will be in Texas on Oct. 2 - 4, 1989

- Describe scope and nature of program

- Announce precise dates and general guidelines for letters of intent for first round expt. consideration

- Discuss SSC physics and experiments - what can be done and how?

- Site tours, Texas hospitality,...........

- Everyone interested in SSC expts. should attend!

- Form PAC by end of year

- Orientation meeting for PAC in Jan. '90

- Subject to deliberations of SPC, input from the community and others, the tentative plan for letters of intent and proposals is shown on the next page 


\section{Tentative Schedule of Events Leading to the Initiation of the SSC Experimental Program}

\section{9}

Spring

June 5

July

October $2-4$

October 2

November
Form Scientific Policy Committee(SPC)

Deadline for gemeric detector R\&D proposals to DOE

Meeting of detector $R \& D$ advisory committee to consider generic $R \& D$ proposals

Supercollider Ptysics meeting and open house in Texas

Announce scope of experimental program

Announce general guidelines for letters of intent and precise due date

Discuss SSC physics and experiments

Deadline for major detector subsystem R\&D proposals to the SSC Iaboratory

Meeting of detector R\&D advisory committee to consider major detector subsystem $R \& D$ proposals

1990

January

First Program dvisory Committee(PAC) meeting

Comsider interaction between accelerator design and the experimental program

Issue precise guidelines for letters of intent

Deadline for letters of intent for first round of experiments

PAC meeting to consider letters of intent

1991

January

PAC meeting for mid-course review of first round of experiments

May

Deadline for proposals for first round of experiments

July

PAC meeting to consider proposals

Stage I approval 


\section{Calorimetry}

- Where does calorimetry fit into this?

- Big calorimetric systems are likely to be the most important aspect of large SSC detectors.

- We must expand rapidly the effort to develop prototype calorimeter systems and a better understanding of calorimeters for SSC experiments to have intelligent input for proposal selection in 1991

- The time is now to begin to work on both the systems aspects of big calorimeters as well as, where needed, fundamental understanding of performance

- Although some efforts along these lines are more advanced than others, in my opinion all such efforts are undermanned and underfunded.

- We need to work together to solve this problem and prepare properly for SSC experiments.

- Let's get moving!! 
ABACHI, SHAHRIAR;

FERMILAB; P.0. BOX 500, HS 357; BATAUIA, IL 60510

ABE, KDYA ;

PHYSICS DEPT., TOHOKU INIV.; ARAMAKI-AZA-AOBA; JAPAN, 98D

ABOLINS, MARIS;

MICHIEAN STATE LNIUERSITY; 251 PHYSICS \& ASTKONOHY; EAST LANSING, MI 488241116

ABRAMS, GERALD $S$;

LAWRENCE BERKELEY LABORATORY; +1 CYCLOTKON RD 5OA-2160; EERKELEY, CA 94720

ALSHILLER, R.G. ; ENG. PHYSICS \& MATHEMATICS UIV.

DAK RITUE NATIONA LABORATORY; P.0. EOX 2008, WS 6364; OAK RIUGE, TN 378316364

AHAKD, KATSUYA ;

NAT. LAB. FOR HIGH ENERGY PHYS.; CHO1-1, TSUKUEA-SHI; JAPAN,

ATAC, MUZAFFER ;

FERMILAB; P.0. BOX 500; BATAUIA, IL 60510

ALIBERT, BERNARD LUCIEN;

L.A.P.P.; CHEMIN DE BEFFEVIE; FRANCE,

BALER, GERRY ;

BOSTON UNIVERSITY; EP-DIVISION, CEFN; GENEVA-SUITZ, ,

BEDEREDE, DIDIER ;

CEA/IRF; DPHFE-STIPE-STD CEN SACLAY; FRANCE, F91191

BENSINGER, JANES $R$;

LAWRENCE BERKELEY LAB; M.S. 90-4040; BERKELEY, CA 94720

BINTINGER, DAUIII L.;

LAWRENCE BERKELEY LABORATORY; CENTRAL [ESIGN GFCUL, HS 90-4040; BEFKELEY, CA 94720

BLAIR, ROBERT E.;

A.N.L.; 9700 5. CASS AVE,; ARGOANE, IL 60439

BOLTON, TIM A,;

COLUMBIA LNIVERSITY; SLAC, BIN 65; STANFORD, CA 94305

BRANIENBUFG, GEORGE W.;

HAFUARD LNIVERSITY - HEFL; 42 OXFORD STREET; CAMERIEGE, MA O2138

BRITTON, CHARLES L.;

OAK RIIUEE NATIONAL LABOFATOFY; P. 0. EODX 2008; OAK RILGE, TN 378316006

HROMEERG, CARL H.;

MICHIGAN STATE UNIUERSITY; IEFARTMENT OF FHYSICS; EAST LANSIHG, MI 48824 
BUGG, WIULIAM $\mathrm{H}$;

LNIVERSITY OF TENAESSEE; ; KNDXVILLE, TN 379961200

BYLSMA, BEN;

OHIO STATE UNIUERSITY; $174 \mathrm{~W} .18 T H$ AVE,; COLLMBULS, OH 432101106

CALDWELL, ALLEN C;

COLUMBIA LNIUERSITY; NEVIS LAB., P.0 EOX L37; IRUINGTON, NY 10533

CENTRO, SANTRO ;

INST. NAZ'L DI FISICA MUCLEAFE; UIA MARZOLO, g; PADONA, ITALY, I35131

CHASE, ROBERT L.;

LAB DE L'ACCELERATOUR LINEAIRE; BAT 208; ORSAY, FRANCE, 91405

CHRISTOPHOROU, LQUCAS G.;

DAKRIDEE NATIONAL LAB.; P.D. BOX 2008; OAK RIDGE, TN 378316122

CLARK, KENT R.;

LNIVERSITY OF SOUTH ALABAYA; DEPT. OF FHYSICS; MOBILE, AL 36688

CLAVELII, LOUIS J:

THE LNIUERSITY OF ALABAMA; IEPT, OF FHYSICS; TUSCALOOSA, AL 35487

CLELAND, WILFRED EARL;

LNIUERSITY OF PITTSEURCH; IEFT. OF PHYSICS \& ASTRONOWY; FITTSEURGH, FA 15260

COLAS, HACRUES J०;

LAWRENCE BERKELEY LAB.; CYCLOTRON ROAD; REEKELEY, CA 94720

COOPER, HILLIAM E;

FERMILAB M5357; ; BATAVIA, IL 60510

COOPER, WILLIAM $E_{i}$

FEKMILAB MS357; ; BATAUIA, IL 60510

[AUIU, HARC JEAN-LOUIS;

SACLAY-CEA; IFHPE-SEPH; FRAMCE, F-91191

DAWSON, JOHW W;

ARGONAE NATIONAL LABORATORY; ELIG, 362, 9700 CASS AVE; AFGOANE, IL 60439

DAYTON, FODERICK R.;

BICKON CORFORATION; 12345 KINSKAN FOAD; NEWBURYY, OH 44065

DERRICK, MALCOLM ;

ARGONAE NATIONALL LABCLRATORY; ; ARGONAE, IL 60439

DIBITONTO, DARYL IEAN;

TEXAS AEM UNIVERSITY; LEPT, OF FHYSICS; COLL, STATION, TX 77843 
DIGIACONO, NICHOLAS JOSEPH;

MARTIN MARIETTA ASTROANAUTICS; P.0. BOX 179; IEENER, CO 80201

DOMBECK, THOWAS H.;

DPE/5SC; ER-24 GTN; WASHINGTON, DC 20545

DCRENBOSCH, THEROEN P.;

NIKHEF, AMSTERDAY; 1211 GENEVA 23; SHITZERLAND,

DRAPER, PAL A.;

UNIVERSITY OF RDCHESTER; FERHILAB, HS 357; BATAVIA, IL 60510

EIUARDS, WILLIAM R.;

LAWRENCE BERKELY LAEORATORY; 1 CYCLOTRON ROAD; BEKKEIEY, CA 94702

EIIAS, JOAN E;

FERMILAB/CDF; P.0. B0X 500; BATAVIA, IL 60510

FABJAN, CHRISTIAN H.;

CERN; CH 1211, GENEVA; SWITZERLAND,

FAIDAS, HOATER ;

OAK RIDEE NATIONAL LABORATORY; P.O. BOX 2008; OAK RIIGE, TN 378316122

FATYGA, MIREU;

BROOKHAVEN NATIONA LABORATOKY; 510 A; LPTON, NY 11973

FENT, NHERGEN ;

MPI FUER PHYSIK; FOHRINGER RING 6; GERHAWY, [

FESEFELDT, HARM;

FWTH AACHEN; III PHYSIKALISCHES INST,; FRG, GERMANY,

FIEI IS, THOMAS $H$;

ARGOANE NATIONAL LABORATORY; ELIIG.362, 9700 S. CASS AVE.; AFGONANE, IL 60439

FLOYII, DIENNIS ROY;

MANHFACTURING SCIENCES CORF; F.0. BOX 886; OAK RIIGE, TN 3783)

FORDEN, GEOFFKEY E*;

SLNY E STONY EFOOK, FERMILAB; P.0. BOX 500, MS 357; BATAUIU, IL 60510

FKEY, RAYMOND E.;

UNIV. OF MICHIGAN; F.0. EQX 4349; STANFOFD; CA 94301

FRISKEN, BILL R;

YOKK UNIVERSITY/FHYSICS LEFT,; 4700 KEELE STREET; N.YOKF-ONTARIO, M3.J1F3

FLKUI, YASUO ;

FERMILAB/KEK; P.0. BOX 500; BATAUIL, IL 60555 
GAERIEL, TONY A. :

OAK RIDGE NATIDALL LAB,; P.0. BOXX 2008; OAK RIDGE, TN 37831

GEER, STEPHEN $H_{0}$

HARYARD LNIV. HEPL; 42 DXFORD STKEET; CAMERIDGE, MA O2138

GILCHRIESE, HRDOCK G.D.;

SSC CENTRAL IESIGN GROUP; 90-40 LAWRENCE BERKELEY LAB.; BEEKELEY, CA 94720

GIOKARIS, NIKOS; ASST, PROF/THE ROCKEFELLER UWIV.

FERMILAB; KS223 P.0, EOXX 500; BATAVIA, IL 60510

GORDON, HOWARD A.;

BROOKHAVEN NATIONAL LAECRATORY, PHYSICS IEPT,, 510A; LFTON, NI 11973

GREMALDI, LUCIEN;

UNIVERSITY OF MISSISSIPPI; IEPT, OF FHYSICS; UNIUERSITY, HS 38677

GRINDHAMAR, GANTER ;

HPI HUICH AND SLAC; P.0. BOX 4349, SLAC-BIN 61; STANFORI, CA 94309

GROOH, DONALD E.;

SSC CENTRAL IESIGN GROUP; LAWFENCE BERKELEY LAB 90-4040; BEFKELEY, CA 94720

GURYN, WOLEK ;

BROOKHALEN NATIONAL LAB,; FHYSICS ILET,, F10A; UPTON, NY 11973

HADLEY, NICHOLAS J.;

LUNIVERSITY OF MARYLAND; LEPT, OF PHYSICS \& ASTKONGAY; COLLEGE FAFK, MI 20742

HAGSTROM, RAY T;

ARGONAE NATIONAL LABORATORY; ELIG, 362, HIGH ENERGY FHYSICS IIV.; ARGONAE, IL 60439

HANSON, GAIL G.;

SLAC; P.0, BOX 4349, BIN 78; STANFORD, CA 94309

HARTSS, BENJAMIN C;

UNIUERSITY OF ALABAMA; IEEFT, OF FHYSICS \& ASTRDNDOMY; TUSCALOOSA, AL 35487

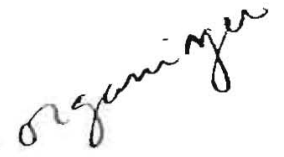

HASELL, DOUGLAS $K$;

YORK LNIVERSITY; 4700 KEELE STREET; TORONTO-ONT., CA M3J 193

HEUSCH, CLEMENS $A_{i}$

LNIUERSITY OF CALIFORNIA-SANTA CFUUZ; ; SANTA CRUZ, CA 95064

HIDED, HIRAYAMA ;

NAT'L LAB, FOR HIGH ENERGY PHYSICS; 1-1 OHO, TSUKUBA-SHI; IFAFAKI, JAFAN, 305

HOFTIEZER, JOHN $\mathrm{H}_{i}$

LECROY CORP.; 700 CHESTNUT RIDGE ROAD; CHESTNUT FID., NY 10977 
HOGOPIAN, VASKEN;

FLORIDA STATE UNIVERSITY; IEPT, OF PHYSICS; TALLAHASSEE, FL 32306

HOLIINGSWORTH, RLSSELL E,;

GLASSTECH SOLAR INC,, (GSI); 12441 W. 49TH AVENE; WHEAT RIIKE, CD 80033

HOLROYD, RICHARD Av;

BROOKHAVEN NATIONAL LAEORATORY; CHEMISTRY DEPT.; LPTON, NY 11973

HOSHI, YOSHIMOTO;

TOHOKUL-GAKUIN LNIVERSITY; CHUO 1-13-1; JAPAN, 985

HUSTON, JOEY W;

MICHIGAN STATE LNIUERSITY; PHYSICS DEPARTMENT; EAST LAHSIMG, HI 48824

JEKINS, MERRILL C.;

LNIVERSITY OF SOUTH ALABANAA; IEEPT. OF PHYSICS; HOBILE, AL 36688

JOB, P.K. ;

ARGDARE NATIOAAL LAB,; $9700 \mathrm{~s}$, CASS AUERLE; ARLOANE, IL 60439

JOWWSON, KLRTIS ;

FLORIDA STATE UNIUERSITY; IEPT, OF PHYSICS; TALLAHASSEE, FL 32306

JOHWSON, MAFVIN;

FEFMILAB; MS 357 FERMILAB; BATAUIA, IL 60510

JONES, STANLEY T;

LNIVERSITY OF ALABAMA; BOX 870324; TUSCALOOSA, AL 35487

KAFLAN, SELIG No;

LAURENCE BETKELFY LABORATORY; \$1 CYCLOTKON ROAD; BEEKKELEY, CA 94720

KILLIAN, KENIRICK ;

MARTIN MARIEITA; P.O, BOX 179; IENYER, CO 802226

KIRSTEN, FREUERICK $A$;

LAWHENCE BERKELEY LAB; BLIG, 50B--6208; BERKELEY, CA 94720

KDNID, TAKAHIKD;

KEK; OHO-MACHI, TSUKUBA-SHI; JAPAN, 305

KROON, FETER J;

BRDOKHAVEN NATIONAL LABORATORY; PHYSICS IEPT 51OC; LFTON, AN 11973

KUESTER, HERTANN;

IESSY, NOTKERL 85; 2000 HAMEULRG 52; WEST GERMANY,

LANKFORD, ANLFEWW $J$;

SLAC; P. D. EOX 4349; STANFORD, CA 94309 
LAU, KWONG $\mathrm{H}$;

UNIVERSITY OF HOUSTON, PHYSICS DEPT,; HOUSTON, TX 772045504

LEROY, CLANDE;

MCGILL LNIVERSITY; DEPT, OF PHYSICS; MONTREAL, QUEEEC, HZA2T8

LEVI, MICHAE ;

LAWRENCE BERKELEY LABORATCRY; ONE CYCLOTRON RUAD; BEKKEIEY, CA 94720

LINDSTROEY, GANAR ;

LNIUERSITY OF HAMBLRG; INST, FOR EXPERIM.PHYSICS; HAHEGRG,FFG, FRG

LING, KUOK ;

TEXAS A \& M LNIUESSITY; DEPT. OF ELECTRICAL ENG,; COL. STATION, TX T78433128

LOBKOWICZ, FREIERICK ;

UNIVERSITY OF ROCHESTER; IEPT, OF PHYSICS \& ASTROWOAY; ROCHESTER, II 14627

LU, ADOLPH;

UNIVERSITY OF CALIFORNIA; SANTA BARBARA; SANTA BARBARA, CA 93106

MAKDISI, YOUSEF I,;

DOE/BAL; 19901 GERHANTOLAN ROAD; GERYANTOWN, MII 20874

MAKOTO, ASAI;

HOROSHIMA INST, OF TECHWOLOGY; 2-1-1 HIYAKE, SAEKI-KU; JAF'AN, 751-51

MARX, MICHAEZ D;

SSC/CD9-STONY BROOK; C/O S5C-CDA ELDG 90/4040; BERKELEY, CA 94720

MASON, LYLE L.;

MARTIN MARIETTA; P.0. BOX 179; DENUER, CO 80201

HILLS, GEOFFREY B.;

UNIVERSITY OF MICHIGAN; CERN EP-DIUISION; GENEVA, SH CH1211

MISHINA, MASANORI ;

KEK/FERMILAB; P.O, BOX 500, MS 223; BATAVIA, IL 60510

MOCKETT, FAUL $H_{1}$;

LAIUERSITY OF WASHINGTON; FH-15, DEPT. OF PHYSICS; SEATTLE, WA 98195

MORGAN, KATE R.; CERN EP DIVISION

BOSTON INIVERSITY; GENEVA 23; SWITZERLANU,

MULOLLAND, GEORGE T.;

FERMI NATIONAL ACCELERATOR LAB,; P. O. EOX 500; BATANIA, IL 60510

MUSGRAVE, BRIAN ;

ARGONAE NATIONAL LABRRATORY; ELDG 362, HEP IIIV; AFIGOANE, IL 60439 
NODULMAN, LALRENCE J.;

ARGONAE NATIONAL LAB.; 9700 CASS AUEME; AREDNAE, IL 60439

OEERG, GARY ;

HUTCHINSON TECHAOLOGY, INC.; 40 W. HIGHLAND PAEK; HUTCHINSDN, 55350

OBERLACK, HORST ;

MPI FNER PHYSIK, MLNICH; MAX-PLAACK-INSTIT F FHYSIK \& AST,; GEFHANY,

OLIUER, JOHN N,;

HAFUARD UNIV. HEPL; 42 OXFORD STREET; CAMBRIDCE, HA O2138

ONG, BEALE $\mathrm{H}_{\text {, ; }}$

UNIV, OF CA/SAN DIEGD; PHYSICS DEPT. BO10, VESD; LA JOLLA, CA 92093

ORTAER, JOE ;

HUTCHINSON TECANOLOGY, INC.; $40 \mathrm{~W}$. HIGNLAND PARK; HUTCHIKSCN, 55350

PAAR, HANS FETER;

UNIU, OF CA/SAN DIEGO; ; LA JOLLA, CA 92093

PAIGE, FRANK E,;

BAL; BUILDING 510; UPTON, NY 11973

PARA, ADAH ;

FERUI NATIONAL ACCELERATOR LAB,; MAIL STATION 318, P.0. EOX 500; GATAUIA, IL 60510

FENN, RICK JAKES;

HUTCHINSON TECHAOLOGY, INC,; $40 \mathrm{~W}$. HIGHLAND PAEK; HUTCHINSDN, HN 55350

PIEKARZ, HENRYK ;

FLORIDA STATE UNIVERSITY; P.0. BOX 500, MS J57; BATAUTA, Il 60510

FOHLEN, JDE $C$;

MARTIN MARIETTA ASTRONAUTICS; F.0. BOX 179 KS IUGOU69; IENEEK, CO 80201

FOL YCHKONAKOS, VENETIOS;

EROOKHAVEN NATIONAL LABORATORY; PHYSICS IIEPT 5IOC; LFTCN, WY 11973

PRICE, LAWRENCE E;

ARGONAE NATIONAL LAB.; BLIKG 362; ARGOANE, IL 60439

FRIPSIEIN, MORRIS ;

LAWRENCE BERKELEY LABORATLRY; 50B-5239; BEFKELEY, CA 94720

FROUDFOOT, JAKES;

ARGONNE NATIONAL LABORATORY; $9700 \mathrm{~S}$. CASS AVENUE; ARGONAE, IL 60439

RAIEKA, VEL HKO;

BROOKHAVEN NATIONAL LAB,; BLLG. 535E; UPTON, NY 11973 
RANCOITA, PIER-GIORGIO;

; INFN; MILANO-ITALY,

REIDY, JAYES $J_{i}$

LWIUERSITY OF MISSISSIPPI; PHYSICS DEPARTRENT; LNIVERSITY, HS 38677

RESCIA, SERGIA;

BROOKHAVEN NAT. LAB,; INSTRLAENTATION DIV BLDG. 535B; LPTON, NY 11973

RITCHIE, JACK L.;

INIV, OF TEXAS AT ALSTIN; DEPARTMENT OF PHYSICS; AUSTIN, TX 787121081

ROBERTS, DAN E;

INTERFET CORPORATION; 322 GORD STREET; GARLAND, TX 75042

RUSS, JAYES S.;

CARNEGIE-KELLON LNIVERSITY; PHYSICS DEFARTKENT; PITTSEURGH, FA 15221

RUTZ, MARK ;

HUTCHINSON TECHWOLOGY, INCE, ; 40 W. HIGHLAND PAFK; HUTCHINSON, MN 55350

SCHINDLER, RAFE $H_{\circ}$;

S.L.A.C.; BIN 65; HENLO PARK, CA

SCHOLLE, ELIZABETHAANN;

UNIVERSITY OF PITTSBURGH; DEPT, OF FHYSICS; PITTSBURGH, FA 15260

SCHREINER, ROBERT SHELTTON;

BICRON CORPORATION; 12345 KINSTAN ROAD; NEWEURY, OH 44065

SHIMIZU, TOHFU ;

KYOMA GAS CHEMICAL INDUSTRY CO.,LTD; SHUWA HIGASHI YAESU, ELIH 9- $L$; TOKYO-JAFAN, 104

SLALGHTER, JEAN;

YALE UNIUERSITY; TTLS KS 219 FEFHILAB; EATAUIA, IL 60510

SMITH, WESLEY H.;

LNIV. OF WISCONSIN, PHYSICS LEPT,; 1150 LNIV. AVE,; MAIISSCN, WI 53706

SPARROW, ROEERT $w_{*}$;

OPTIUAC; EAST BROOKFIELD ROAD; N. BROOKFIELD, MA 01535

STERN, ERIC G;

UNIVERSITY OF PITTSBARGH; 100 ALLEN HALL; PITTSBLRITH, FA 152.13

STKONINK, MAFK WILLIIAM;

UNIV. OF CA., FERMILAB; F.0, BOX 500, MS 357; BATANIA, IL 60510

SUMOFOK, SHAM $C_{\text {, ; }}$

LNS/MIT; ROOH 24-035, 77 MASSACHUSETTS AVE,; CAKBRILGE, MA 02139 
TAKASAKI, FLPIHIKD;

KEK; TSUKUTA-CITY, OHO 1-1; JAPAN,

TAKASHI, OHSUGI ;

HIROSHIKA LNIVERSITY; 1-1-89 HIGASHI-SENDA NAKA-KU; JAPAN,

TATSURASA, TSURULAI ;

HATEARG LNI., II INST, OF FHYSICS; 2000 HAMBLARG 52; HEST GERMANY,

THERIOT, DENIS ;

FERMILAB; P.0, BOX 500, MS 318; BATAVIA, IL 60510

THOMAS, DONALD G;

INIV. CALIFORNIA-SAN DIEGO; FHYSICS DEPT, B019; LANOLLA, CA 92093

THUN, RUDOLF P.;

UNIVERSITY OF MICHIGAN; FHYSICS DEPARTEENT; ANW ARBOR, MI 48109

TITKO, MARK ;

TEXAS ALY LNIVERSITY; 27W240 OAKWOOD STREET; WINFIELD, IL 60190

TRILLING, GEORGE HENRY;

LAWRENCE BERKELEY LAB; ; BERKELEY, CA 94720

TROST, HANS-JOCHEN; IR.

AFGOAE NATIONAL LAB.; AM, HGP IIIV, ELDG 362; AFTONANE, IL 60439

VAAPETEGHEM, PETER M.;

TEXAS ARY UNIVERSITY; LEFT, OF ELECTRICAL ENG,; COULEE STN, TX 778433128

HADSWORTH, BERNARD $F$ *;

LAB, FOR MUCLEAR SCIENCE, MIT; ROOM 26-561, MIT; CAMERIUGE, MA 02139

WAHL, HORST $\mathrm{B}$, ;

FLORILA STATE LNIVERSITY; FHYSICS IEPT,, KEN 512; TALLAHASSEE, FL 32312

WALKER, JAMES K.;

UNIUERSITY OF FLORILA; FHYSICS DEPARTKENT; GAINESUILLE, FL 032611

WANG, EIWUARD Mo;

LAWRENLE BERKELEY LAEORATOFY; LNIVERSITY OF CALIFOFWIA; BEEKELEY, CA 94591

WATT, ROBERT ;

SUPER COLLIDER URA LESIGN CENTER; UCLEA MS 90/4040; EEEKKELEY, CA 94720

WEBER, THOMAS $F_{0}$ :

LAWRENCE BERKELEY LABORATORY; BUILDING 50, ROOH 102; BEEKELEY, CA 94720

WEERTS, HENIRIK J;

MICHIGAN STATE UNIVERSITY; ILEPT, OF FHYSICS \& ASTRONOMY; EAST LANSING, MI 488241046 
WORKSHOP UN CALORIMETRY FOF THE SUFER CORLIDER

03/13/89 FAUL W. EKYANT CONF. CENTER

WEINSTEIN, ROY;

UNIVERSITY OF HOUSTON; IBPD, RDOM 225SR1; HOUSTON, TX 77004

WHITE, ANDREW PALR;

UWIVERSITY OF FLORIDA; 228 C WILLIAATSON HALL; GAINESUILLE, FL 32611

WITE, JANES T.;

TEXAS AEY LNIVERSITY; 2319 TIMBERLOCH PLACE; THE WOOULANLLS, TX TT380

WONCICKI, STAN;

LAWRENCE BERKELEY LABORATORY; ONE CYCLOTRON ROAD; BEFKELEY, CA 94720

WOLGAST, RICHARD;

LAWRENCE BERKEIEY LABCRATORY; \$1 CYCLOTRON ROAD; BEEKELEY, CA 94720

WOMBERSLEY, W.JOHN ;

LNIV. OF FLORIDA, FERTILAB; P.0. BOX 500; BATAVIA, IL 60510

YAES, ROBERT J.;

LNIUERSITY OF KENTUCKY; IEPT, OF RADIATION IED.; LEXINGTON, KY 405360084

ZHN, REN-YUAN;

CALTECH; 256-48 HEP; PASALENA, CA 91125 
BEVILL, TOM ; REPRESENTATIVE

U. 5. HOUSE OF REPRESENTATIVE; ; WASHIMGTON, DC 205150104

COBY, CHASE ; GOUERNOR'S OFFICE

STATE OF TEXAS; ; AUSTIN, TX 78713

COLE, DAUID; ASSOCIATE UICE PRESIIENT FOR ACALERIL AFFAIFS

THE LNIUERSITY OF ALABAMA; BOX 870114; TUSCALOOSA, AL 35487

DYESS, WILLIAM ; RETIRED

U.S. AMBASSADOR; ; WASHINGTON, DC

GLRNICK, JAMES; DIRECTOR OF UNIVERSITY RELATIONS

OAK RIDEE ASSOCIATED LNIVERSITY; ; DAK RILGE, TN

JOLLEY, MARY; DIRECTOR, ECONOMIC AND COMUNITY AFFAIKS

THE LNIUERSITY OF ALABAMA; EOX 870138; TUSCALIOLSA, AL 35487

JOAES, DOUGLAS $E_{0 ;}$ INTERIM UICE PRESIDENT FOR ACALEMIC AFFAIRS

THE UNIVERSITY OF ALAEAMA; 254 ROSE ADMINISTRATION; TUSCALCOSA, AL 35487

KITTRELL, ELIZABETH ; ADMINISTRATIVE OFFICER

OAK RILGE ASSOCIATED UNIVERSITY; ; OAK RIILGE, TN

KNOAKE, HARRY; EXECUTIVE ASSISTANT TO THE FRESILENT

THE LNIUERSITY OF ALABAMA; BOX 870100; TUSEALOOSA, AL 35487

NOLEN, EDD; ASSOCIATE STAFF, ENERGY \& INTERIOR SUACORTITEES

U. S. HOUSE OF REPRESENTATIVES; ; WASHINGTON, DC 205150104

PORTERA, MALCOLM ; UICE FFESIUENT FOR EXTERAAL AFFAIRS

THE LNIVERSITY OF ALABAMA; BOX 870138; TUSCALOOSA, AL 35487

SCHAITTERS, ROY ; PROJECT IIRECTOR

SUFER CONDUCTING SUPER COLLIUER; ; IALLAS, TX 75208 